\title{
Virtual Reality Based Passive and Active Distraction Methods for the Treatment of Chronic Pain
}

\author{
by \\ Jiaheng Wang
}

A thesis

submitted to the Victoria University of Wellington in fulfilment of the requirements for the degree of Master of Science in Computer Science.

Victoria University of Wellington 2020 



\begin{abstract}
Chronic pain is ongoing pain lasting for long periods after the initial injury or disease has healed. Chronic pain is difficult to treat and can affect the daily lives of patients. Distraction therapy is a proven way of relieving pain for patients by taking their attention away from the pain. Virtual reality is a platform for distraction therapy by immersing the user visually, aurally, and even somewhat physically in a virtual world detached from reality. There is little research done regarding the effects virtual reality's physical interactions have on pain management. This project aims to evaluate different types of virtual reality interactions for chronic pain patients to determine which is most effective for pain relief. The results found that physical and mental activities in virtual reality are equally effective as each other at reducing pain while the patients are engaged in the content, while the effects of observing relaxing content persists outside of virtual reality. These results inform the design of future virtual reality games targeted at pain management.
\end{abstract}




\section{Acknowledgments}

I would like to express my gratitude and appreciation to all the people that helped me through this project.

My supervisor, Dr Craig Anslow, for his supervision, insight, and guidance over the course of this project. This entire project would not have even started without Craig.

My co-supervisors, Dr Brian Robinson and Dr Simon McCallum, for their input. Each helped me overcome roadblocks hindering the completion of this project.

Ms Dagmar Hempel and her wonderful team at Wellington Regional Hospital's Pain Management Services for allowing me to recruit participants from their patients and helping to spread the word about this project.

The chronic pain patients who gave their time to participate in the study.

My friends and family for their support in my day-to-day life. 


\section{Contents}

$\begin{array}{lll}1 & \text { Introduction } & 1\end{array}$

2 Background $\quad 5$

2.1 Acute and Chronic Pain . . . . . . . . . . . . 6

2.2 Distraction Therapy . . . . . . . . . . . . . . . . . 7

$2.3 \quad$ Virtual Reality $(\mathrm{VR})$. . . . . . . . . . . . . . . . . 8

2.4 Commercial VR Products for Healthcare . . . . . . . . . . . . 11

2.5 VR for Pain Management . . . . . . . . . . . . . . . . . 12

2.5 .1 First Uses . . . . . . . . . . . . . . . . . 13

2.5 .2 Acute Pain . . . . . . . . . . . . . . . 14

2.5 .3 Chronic Pain . . . . . . . . . . . . . . 14

2.5 .4 Long-term Use . . . . . . . . . . . . . . . . 17

2.5 .5 Lasting Effects Outside of VR . . . . . . . . . . . . . 19

2.5 .6 Optimizing VR for Pain Management . . . . . . . . . 20

2.6 Overview of VR Studies . . . . . . . . . . . . . . . . 24

2.7 Summary . . . . . . . . . . . . . . . 33

3 ChronicVR 35

3.1 Design Requirements . . . . . . . . . . . . . . . . . . . 36

3.2 Game Design . . . . . . . . . . . . . . . . 37

$3.2 .1 \quad$ Virtual Environment . . . . . . . . . . . . . . 37

3.2 .2 Sound . . . . . . . . . . . . . . 38

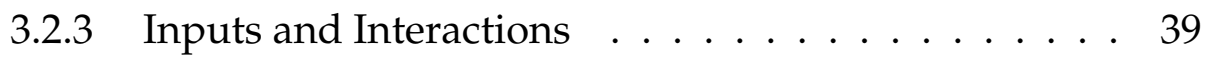


3.2 .4 Physical Level . . . . . . . . . . . . . . . . . . 41

3.2 .5 Mental Level . . . . . . . . . . . . . . . . . . 46

3.2 .6 Passive Level . . . . . . . . . . . . . . . . . 53

3.3 Usability Testing. . . . . . . . . . . . . . . . . . 53

3.4 Summary . . . . . . . . . . . . . . . . . . . 55

$\begin{array}{lll}4 & \text { User Study } & 57\end{array}$

4.1 Study Procedure . . . . . . . . . . . . . . . . . . 58

4.2 Data Collection and Analysis . . . . . . . . . . . . 60

$4.2 .1 \quad$ Pain Rating Scale . . . . . . . . . . . . . . . . 61

4.2 .2 Analysis . . . . . . . . . . . . . . 62

4.3 Study Participants . . . . . . . . . . . . . . . . . . . 64

4.4 Summary . . . . . . . . . . . . . . . . 66

$\begin{array}{lll}5 & \text { Results } & 67\end{array}$

5.1 Participants . . . . . . . . . . . . . . 67

5.2 Quantitative Results . . . . . . . . . . . . . . . . . . 68

5.3 Qualitative Results . . . . . . . . . . . . . . . . . 75

5.4 Discussion . . . . . . . . . . . . . . . 77

$\begin{array}{llr}6 & \text { Conclusion } & 83\end{array}$

\begin{tabular}{|lr|}
\hline A Ethics Approval Documents & 87
\end{tabular}

\begin{tabular}{|l|l|}
\hline B User Study Documents & 91
\end{tabular}

\begin{tabular}{ll}
\hline Glossary & 101
\end{tabular}

\begin{tabular}{ll}
\hline Bibliography & 103
\end{tabular} 


\section{Chapter 1}

\section{Introduction}

Pain is an unpleasant experience that tells us something is wrong with our body [85], where some part of our body is at risk of harm. Pain is commonly divided into two categories: acute and chronic [114]. Acute pain is caused by disease, injury, or some other form of stimulation [114], and serves as a biological alert to prevent further damage [89]. Chronic pain is ongoing pain that lasts well after the initial injury has healed [102]. While drugs are the primary treatment mechanisms for chronic pain, they are not ideal for long-term treatment of chronic pain as all medications have side-effects over long-term use [51]. For example, opioids, a common painkiller, carry the risk of addiction, tolerance, dependency, and withdrawal [108]. An alternative approach is to look to non-pharmacological treatments such as distraction therapy for the long-term management of chronic pain. This thesis investigates using virtual reality $(V R)$ as a distraction tool for chronic pain management.

Distraction therapy works by taking patients' attention away from the pain and onto some other stimuli [83]. As humans have a limited cognitive capacity for focusing on stimuli, distraction therapy seeks to fill that capacity with something other than pain. By the same concept, chronic pain can decrease productivity as the patients are less able to focus on the task at hand. Within distraction therapy, there are two subcategories: 
active attention-diversion, where patients perform a task, and passive distraction, where patients simply observe an engaging stimulus [36].

Virtual reality (VR) is a platform that stimulates users' visual, audio, and tactile senses. By engaging all these senses, VR becomes an effective platform for distraction therapy [81]. VR creates a virtual environment in which users can explore and interact with virtual objects [76]. Commercial headsets from 2010 onwards can track users' head and both hands positions, allowing users to move physically in the real world and have the movement translate into the virtual world [6]. The physical engagement engages users' sense of orientation, which adds another stimulus to disconnect users from their pain. However, the field of pain relief underutilised this feature of VR, with current uses only for the monitoring of specific body parts [82, 86].

By introducing the physical component of VR interactions, the active attention-diversion category above can be divided into two further subcategories: physically active, which requires patients to move around and engage with the virtual world physically; and mentally active, which requires patients to memorise and perform logical thinking. Mentally active distractions can also be achieved by extreme focus or emotional distraction. Physically active distractions cannot be practically used by acute pain patients while undergoing medical procedures because it would be extremely inconvenient for medical staff to have their patients walk around the room while they are trying to perform the procedure on the patient.

This thesis explores what category of content delivered through VR is more effective at managing chronic pain. The two key research questions of this thesis are:

RQ1: Is active attention-diversion VR content more effective at managing chronic pain than passive observation VR content?

RQ2: Within active attention-diversion VR content, is physically active or mentally active more effective at managing chronic pain? 
A game called ChronicVR was developed and evaluated with fourteen chronic pain patients to answer these questions. Staff at Wellington Hospital's Pain Management Services were involved in the system requirements gathering. ChronicVR has three distinct levels of gameplay, and each level emphasises one of the three categories - physical, mental, and passive - to evaluate each in isolation. In addition to the three VR categories, a non-VR distraction category was included as a control group, where patients did what they usually do to distract themselves from the pain such as listening to music, reading, meditation, or watching videos. The control group provides a reference point to determine whether ChronicVR was effective in reducing users' pain. The evaluation of ChronicVR consisted of testing the analgesic effects of the three VR categories and the non-VR control with fourteen chronic pain patients, most of whom are from the Pain Management Service. The results are presented in this thesis. The results and findings from this research can guide and influence the future development of VR content targeting pain to maximise the pain relief experienced by users.

The outline of the rest of this thesis is as follows:

Chapter 2 provides explanations of chronic pain and its treatments, distraction therapy, virtual reality and the extended reality spectrum, and finally covers existing literature on virtual reality as a tool for pain management.

Chapter 3 introduces ChronicVR, the software developed for user testing to answer the research questions. Requirements for the software and design decisions are covered.

Chapter 4 describes the user study design and procedure, participant recruitment, user study tasks, and data collection.

Chapter 5 presents the results of the user study, analysis and interpretation of the results, and limitations of the study. 
Chapter 6 concludes this thesis and identifies areas of future work. 


\section{Chapter 2}

\section{Background}

Pain is something everyone experiences in their lives, whether suffering a broken arm from playing as a child or stumping a toe on some furniture. The International Association for the Study of Pain defined pain [85] as:

\footnotetext{
"An unpleasant sensory and emotional experience associated with actual or potential tissue damage, or described in terms of such damage."
}

We experience acute pain as a self-protection mechanism, a vital warning system to help us reduce the risk of injury [9]. People who suffer from a condition which prevents them from feeling pain will not notice that a hot stove is burning their hand [23]. No warnings are going off in their brain to tell them they are in danger. On the other end of the spectrum, extreme sensitivity to pain causes patients to feel a constant burning sensation that becomes unbearable in a warm environment [84]. The same hot stove would still not register because the burning sensation is no different from the air around them [9]. Pain is an invaluable feature of the human body, designed to keep us safe from harm. Sometimes, the body sends incorrect signals to the brain, causing pain when the danger has long since passed [102]. 


\subsection{Acute and Chronic Pain}

Pain is commonly divided into two categories: acute and chronic [114].

Acute pain is caused by disease, injury, or some other form of stimulation [114], and serves as a biological alert to prevent further damage [89]. Due to injury or some other cause (e.g. tumour, disease, ageing), acute pain can become long term or chronic. Chronic pain is an ongoing pain often defined by the length of time [45]. Definitions vary between pain persisting for an amount of time past the usual time for the sources of acute pain to recover (e.g. pain persisting more than one month after injury), and pain lasting beyond a fixed amount of time (e.g. pain lasting more than three months).

The persistence of chronic pain is associated with a variety of psychosocial outcomes. Constant pain has an impact on a patient's everyday life caused by loss of sleep and function [12]. Pain is an attentiondemanding experience [88]. As pain primarily functions as the body's warning system, it is reasonable that when the warning is fired, the pain, and possible danger, should be the primary focus of the brain. Unfortunately, for chronic pain patients, these warnings are constantly interrupting their daily lives, despite the lack of any actual dangers. The constant disruptions cause patients to lose focus and productivity in their lives [46]. Disruptions to sleep can also lead to increased pain sensitivity [91, 110], and depression [16, 91]. These symptoms compound each other, causing the patient's general health to deteriorate much faster. Chronic pain patients also experience pain avoidance [97]. Patients start thinking that performing certain tasks and activities will cause more pain, so they avoid doing them. This avoidance strips down patients' lives as they withdraw from their hobbies and day-to-day life. Having patients perform physical activities, whether it be simple exercises or therapy, is an excellent way to help them explore their bodies and learn what they are capable of as well as improving general health [2]. 
Chronic pain is more complicated than acute pain to treat as, by definition, the pain did not respond to the treatment which resolved the original cause of acute pain [102]. Current treatment procedures combine medication with rehabilitation and education [49]. Unfortunately, all medication can cause side-effects [53], even over-the-counter painkillers. Non-opioids have recognisable toxicity after long-term use [102]. Weak opioids are considered when the non-opioids are not adequate. Strong opioids are then considered when weak opioids are also not adequate. The opioid-based analgesia carries the risk of respiratory depression, pruritus, nausea, and constipation. There are also concerns over substance dependency, tolerance, withdrawal, and even overdose [108].

Medications are useful for short-term pain management. However, due to the nature of chronic pain, a more long-term solution is required, which medications are not suitable for as there can be more side-effects from long-term use [49]. Non-pharmacological treatments are another method for chronic pain management.

Several non-pharmacological techniques for pain management exist, covering both physical and mental techniques [22]. Examples of physical techniques include physiotherapy, exercise, and manual therapy like massages [52]. Mental, or psychological, techniques include meditation [50, 100], bio-feedback [73], parental participation for paediatric subjects [37], hypnosis [96], and distraction therapy.

\subsection{Distraction Therapy}

Distraction therapy works by directing the attention of the patient to some external stimulus to distract the patient from pain [36]. Pain and cognitive function are closely linked [89, 90]. As pain and cognitive functions are competing for a human's limited attention, distraction therapy seeks to aid a patient's cognition with external, engaging, sensory stimuli so that the patient's main focus is not on the pain. These engaging stimuli can be 
visual, auditory, tactile [118], or a combination of the three [30].

Fernandez's classification of cognitive coping strategies for pain classified this as attention-diversion, with two sub-classifications passive distraction and active attention-diversion [36]. The difference between the two focuses on the medium or object of distraction. Passive distraction requires no input or effort on the part of the patient, such as watching a movie. Whereas active attention-diversion engages the patient more, requiring them to work to complete some task actively. Examples of such tasks include mathematical problems (which ranged from simple addition and subtraction [5, 8] to more complex problems [13]) and pursuit rotor tasks [111].

Virtual reality engages many of the users' senses, thus making it an effective platform for distraction therapy.

\subsection{Virtual Reality (VR)}

Virtual reality (VR) systems create a virtual world (sometimes referred to as a virtual environment) which users "enter" through various devices to experience the sights, sounds, and other sensations of the virtual world [87]. Users can move around the virtual world and interact with their objects and environment through the use of input devices and controllers. This ability to move effectively makes the user feel as if they are physically in the virtual world, otherwise known as presence. The more strongly a user believes that they are actually inside the virtual world, the stronger their sense of presence [104].

VR typically consists of a head-mounted display (HMD) headset inside which there are two displays, one for each eye. The two eyes see two different images, giving the user a sense of depth in the virtual world. The headset's orientation and position are typically tracked so that when the user looks around or moves, the displays are updated accordingly to simulate looking around or moving in the virtual world. Headsets that 
track both orientation and position is categorised as 6 degrees of freedom (6DOF). Headsets that only track orientation are categorised as 3 degrees of freedom (3DOF), users can look around freely but cannot move. Headsets that track neither position nor orientation are categorised as 0 degrees of freedom (ODOF). The majority of headsets blocks out light from the real world, creating a stronger sense of immersion in the virtual world.

VR systems that do not utilise a headset also exist. For example, connecting several ordinary computer screens in such a way that they cover a wide-angle of the virtual world [71]. This angle is defined as the field of view (FoV). Another example is the Cave Automatic Virtual Environment (CAVE), where a projector projects the virtual world onto the walls and floor of a room-sized cube [25].

The first HMD headsets were created in the 1960s [6]. Between then and 2010, various headsets were developed and used, but VR was mostly a niche technology, only seeing use in specialised areas because costs for VR setups were prohibitive beyond specialised interaction and graphics labs. Attempts were made to create headsets for entertainment purposes, but the headsets did not see commercial success. For example, the Sega VR was cancelled before release [34]. Due to technical limitations at the time, the Sega VR headsets were causing a high rate of motion sickness and nausea among reviewers stemming from low resolution and frame rates.

In 2010, the Oculus Rift headset was prototyped and was developed further in the years following. By 2015 other companies such as Razer Inc. ${ }^{1}$ and HTC [32] had taken notice, and were underway in the development of their own VR headsets. The competition marked a turning point of VR in the commercial market as a consumer good and bought VR technology into the mainstream and made VR ubiquitous. VR headset technology also saw a rapid increase in specification and features, as competing companies

1 https://press.razer.com/product-news/industry-leadersannounce-open-platform-for-virtual-reality-gaming/ 


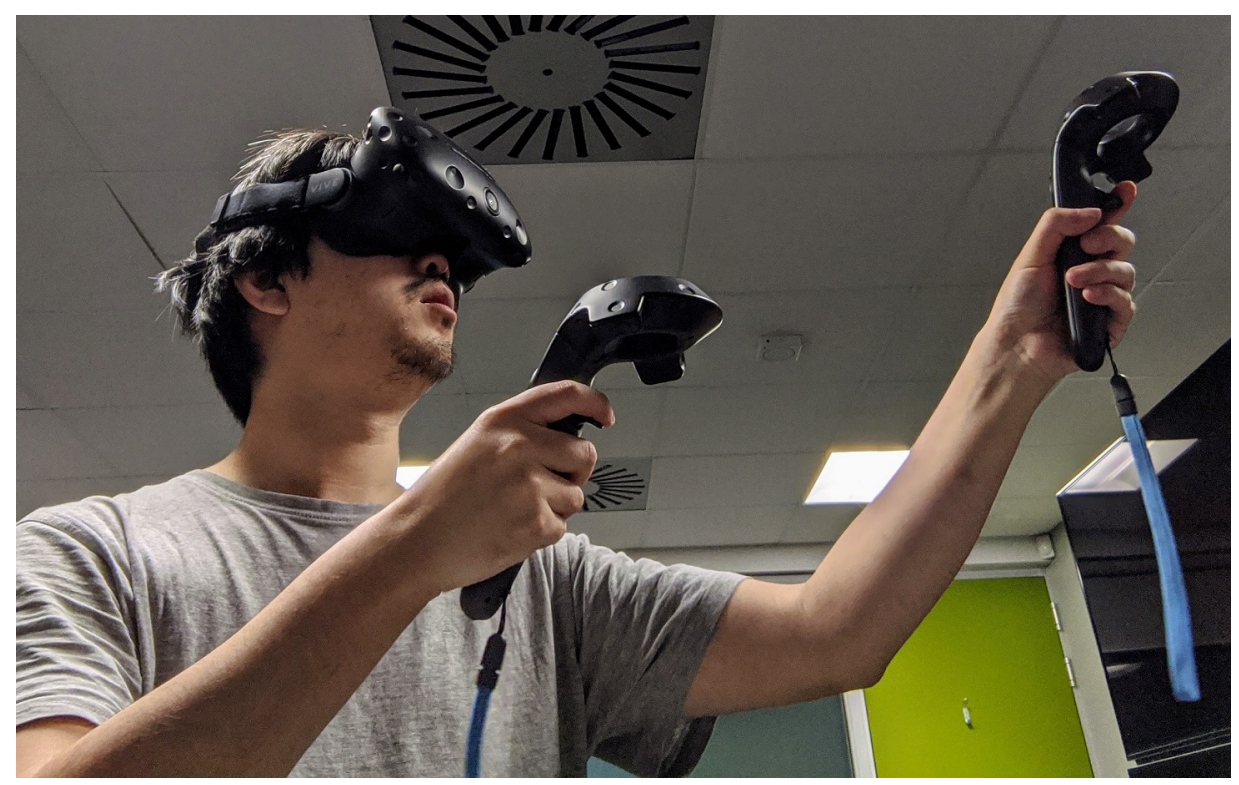

Figure 2.1: An HTC Vive VR headset [32] being used with two tracked handheld controllers.

sought to overtake each other. Frame rate, latency, display resolution, and field of view were all drastically improved in these new devices.

VR has a wide range of uses. Early uses focused on simulation for education and training purposes [19], which continues to the present day [4]. VR simulations are cheaper and faster to deploy than physical mock-ups, as the virtual world can be deployed digitally. VR simulation is also costefficient when compared with training with consumables [80]. As the hardware became widespread, VR saw more use for recreation and entertainment through video games, 360 movies/videos [115], and 3D virtual art ${ }^{2}$. There are also novel productivity uses such as 3D visualisation of data [31] or designs [119], and the focus of this thesis, healthcare.

\footnotetext{
${ }^{2}$ https: / /www.tiltbrush.com/
} 


\section{Extended Reality (XR)}

Extended reality $(\mathrm{XR})$ is a spectrum with VR on one end and the real world on the other [87]. In between these two extremities exists mixed reality (MR), where displays allow you to view both the real world and virtual content simultaneously. It is here that augmented reality (AR) headsets can be found. Where a device sits within MR is determined by the content displayed and how the user views the content. For example, is the primary focus on real objects or virtual objects? Is the real object observed through see-through goggles or transmitted through a display? VR headsets can, therefore, sit on the MR spectrum if video captured through a camera on the headset is then transmitted through to the user.

With the rise of VR headsets, AR headsets have also seen commercial releases like the Microsoft HoloLens [54] and Magic Leap [24]. Although AR for distraction therapy is an area that is still unexplored [33], this thesis focuses on VR. By completely removing the user from the real world, and placing them entirely in a virtual environment, a higher sense of presence would be achieved and thus becoming more effective at pain relief $(\S 2.5 .6)$.

\subsection{Commercial VR Products for Healthcare}

Several companies have created commercial products using VR in the healthcare space. Four of them will be given as examples here. Two are targeted at medical staff for training and education purposes, and the other two are targeted at patients for pain management.

Osso VR is a company building VR tools for training surgeons and hospital staff $f^{3}$ The aim of the tool is for surgeons to practice performing operations. By doing so in a virtual space, surgeons can practice for longer due to the lowered operation costs and can do so in a risk-free environment.

$\sqrt[3]{\text { https: //ossovr.com/ }}$ 
Virtual Medical Coaching is a company focusing on medical simulation 4 . The company is focused on the education of students by providing realistic environments for learning. Their VR tool provides interactive environments from real-time 3D data sets. Students can interact with patients and devices in the virtual environment. In addition to VR, Virtual Medical Coaching also specialises in Big Data and artificial intelligence.

AppliedVR is a company focusing on therapeutic VR ${ }^{5}$. Their tool helps users relax to aid pain and anxiety. Their software has a range of content available. There are relaxing videos, guided meditations, and games for users to play. The software utilises a hands-free, gaze-based control so that it is accessible for users with limited mobility.

Karuna Labs is a company focusing on treating chronic pain with $\mathrm{VR}^{6}$ They achieve this by teaching patients about chronic pain, provide physical training based on patients' range of motion, games to help patients increase their range of motion, teaching patients to decrease anxiety by placing them in calm environments, and Virtual Embodiment Training. Virtual Embodiment Training shows a model of patient's body in VR, and by differing the model's movement from the patient's actual movement, it presents patients an image that those movements which were once pain, are non-threatening.

These companies demonstrate that VR for healthcare is not bound to academic research, but have already emerged into real-world applications.

\subsection{VR for Pain Management}

Since 1996, many researchers conducted studies looking into VR for pain relief with a wide variety of factors. The factors are the type of pain, cause

\footnotetext{
$4_{\text {https: / / virtualmedicalcoaching.com/ }}$

5 https://appliedvr.io/

6 https://karunalabs.com/
} 
of pain, patient demographic, choice of headsets, input device, the content presented, type of distraction, and repeated/long term use. These studies conclusively showed that VR was capable of pain management in a wide range of types of acute pain. Only in the past decade has research explored chronic pain [81]. This section examines the feasibility and effectiveness of VR as a tool for chronic pain and summarises existing literature. This section also examines the suitability of VR as a long-term solution, and continuing the pain relief outside of VR.

In addition to pain management, VR was also used for exposure therapy to treat patients with anxiety. Exposure therapy was one of the few application areas which was not dependent on the fidelity of the equipment and therefore was applied continuously throughout from the 1990's to today [17, 101] ]

\subsubsection{First Uses}

A study in 1996 utilised three screens to achieve a 100-degree field of view (FoV) for acute pain management [72]. A driving simulator and a flying simulator were displayed while thermal pain was induced. Participants were measured on both physiological and subjective ratings. Participants were observed to have increased in respiration rate, exhibited higher pain thresholds, and were subjectively more positive, suggesting that the VR aided stress reduction and relaxation. One out of the ten participants experienced motion sickness. The 1996 study was a pilot investigation for a 1997 study into the use of VR as a tool to aid relaxation and to provide mental stimulation for cancer patients who are subject to long-term hospitalisation [94]. Although in the 1997 study, the use of VR was more focused on relaxation and mental health through education and counselling rather than distracting patients from pain.

A study published in 1997 investigated the use of VR headset as a dis-

7 https://www.virtuallybetter.com/ 
traction technique in a routine gastric laboratory procedure [75]. Out of 50 patients participating in the study, 41 found the VR headset improved tolerance and would use it again.

Before these two studies, VR was used in the medical field [105] but for other purposes. Use cases targeting medical staff were for training, education, and visualization/analysis/diagnosis purposes [74, 94]. Patient uses were for education and visualisation of upcoming medical procedures, and therapy [17] purposes.

\subsubsection{Acute Pain}

Early research only focused on acute pain. VR for pain relief was studied in a wide range of medical procedures, therapy sessions, and induced/simulated pain, conclusively showing that VR was an effective relief for acute pain. Common procedures in which VR was used include burn patients [20, 29, [55, 57, 58], labour [39], surgery [21], cancer [3], port access [43], and dentistry [56, 121].

With the use of custom VR headsets, VR was even able to be used in situations typically unsuitable for electronics like water for hydrotherapy [60] and was even successfully used during MRI scans with a custom non-ferromagnetic headset [61, 62, 63].

\subsubsection{Chronic Pain}

In recent years, more research was conducted into using VR as a distraction tool for chronic pain.

Wiederhold et al. [120] conducted a study with 40 chronic pain patients where participants were placed in a relaxing virtual environment for 15 minutes. Although some participants called this a "game", the virtual environments were not interactive. The virtual environments consisted of natural areas such as forests, beaches, and mountains. Relaxing music was also played. Plants and trees swayed to guide breathing. Patients 


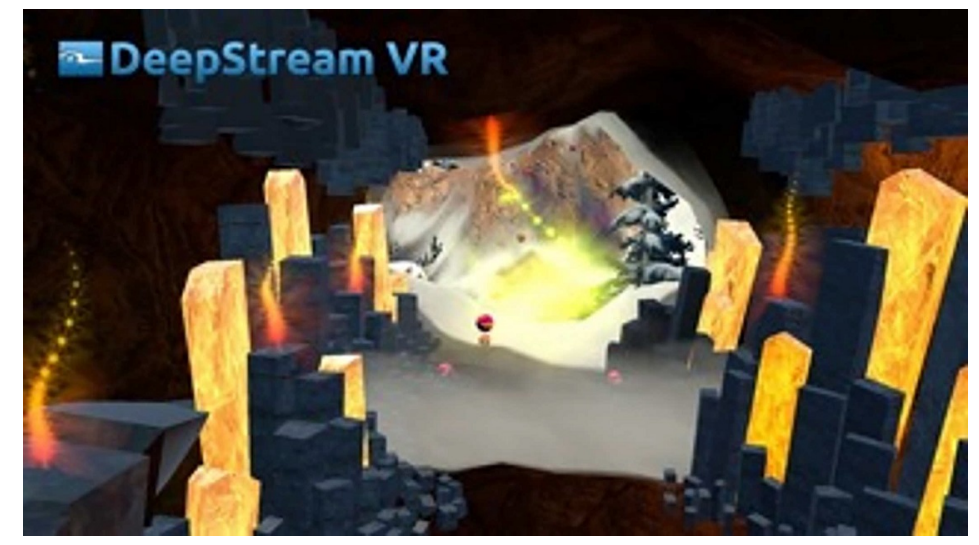

Figure 2.2: The COOL! virtual environment used by Jones et al. [69]

had an average pain rating of $\geq 4$ (on a 0 to 10 scale, 0 being no pain and 10 being worst possible pain) for a period longer than three months. The results showed that VR was effective at reducing pain. Participants subjectively reported a $75.8 \%$ decrease in pain ratings while exploring the environment. Objective measures in the form of skin temperature and heart rate also indicated greater relaxation. A post-study questionnaire also addresses the issue of simulator sickness. Participants were asked to rank general discomfort, fatigue, headache, eye strain, and nausea on a scale from 0 to 3, where 0 is "absent", and 3 is "severe". The average for all five issues was below 1.5 in the rating which the authors considered to be very low. Feedback from participants was also positive. Participants were quoted to say "I was so busy playing the game, I forgot about my pain," and "even though the procedure was finished, I wanted to keep playing." This study investigated the general feasibility and effectiveness of using VR to treat chronic pain. The study did not investigate any correlations between the content presented through VR with the effectiveness of pain management.

Jones et al. [69] conducted a study in 2016 with 30 chronic pain patients. They used an application called COOL! (Figure 2.2) which saw users move through a fantasy landscape along a set path. Users could 
control the speed at which they move and have the option to interact with elements of the environment if they wished. Jones et al. reported that pain ratings dropped by an average of $60 \%$ during the session and 33\% post-session when compared with the initial pre-session ratings. All participants reported a decrease in pain during the study, with a third of participants reported no pain felt during the session. Three participants reported no change in pain ratings after the study when compared to initial pain ratings taken before the study. Only one participant (out of 30) reported nausea. This participant had a history of nausea with video games. However, Jones et al.'s study used a short VR session of only 5 minutes, which may not have been sufficient time to develop motion sickness. Participants had the option of one of two VR headsets. The default option was an Oculus Rift DK2, and the alternative is a DeepStream 3D Viewer. The DeepStream 3D Viewer was available for anyone uncomfortable with the Oculus Rift for any reason including head/neck/face injuries or claustrophobia. However, all participants chose to use the Oculus Rift despite several participants having pain originating in the head or neck. No participant reported any problems in using the headset.

Garrett et al. [42] conducted a study with eight chronic pain patients. The patients used VR in their own homes for 30 minutes every other day for a month, with pain ratings taken before and after the 30-minute sessions. Participants played a commercially available game, Subnautica VR, where players explore an underwater world. The game was played with a keyboard, which was difficult for participants while wearing the VR headset. There were no significant changes between before and after pain ratings. 5 out of 8 participants anecdotally reported decreases in pain while using VR, but no pain ratings were taken during the session. Garrett et al. had a relatively high percentage $(60 \%)$ of participants reporting motion sickness, which could be due to the elongated session time (30 minutes) spent in VR. One participant, not included in the 8, even dropped out partway through the study citing motion sickness as the reason. 
Jin et al. [68] conducted a study in 2016 with 20 chronic pain patients using their own VR game called Cryoslide. The game was specifically designed to distract players from pain. Players moved through an icy world throwing snowballs at agitated creatures to calm them down. The creatures were a representation of the pain, and calming them down was symbolic of pain subsiding. The game was played with an Oculus Rift headset and a mouse. The game reduced pain intensity by $36.7 \%$ during the session and was significantly better than the control group. However, the analgesic effects did not last beyond the VR session. Subjective feedback was also positive, with patients losing track of time while playing the game.

These four studies have all shown that VR distraction therapy is both usable and useful for managing chronic pain. The VR sessions not only reduced pain but was a positive experience for patients. However, a common trend found in three of the four studies is that reductions in pain did not last past the VR session 8 . None of the VR content used in these four studies allowed patients to walk around to interact with the virtual environment physically. The relaxing environment used by Wiederhold et al. was a passive observation distraction which required no input, and the other studies utilised a mouse or keyboard for interactions. The game presented in this thesis, ChronicVR, utilised the 6DOF and hand-tracking capabilities of modern headsets and investigates whether these features assist in pain management uses.

\subsubsection{Long-term Use}

Due to the nature of chronic pain, a repeated and long-term use of VR is needed to provide pain relief into the future. Current research do not conclusively show the effects of long-term VR use. Hoffman et al. showed early on that repeated use of VR over multiple visits did not diminish the

\footnotetext{
${ }^{8}$ Wiederhold et al. [120] did not report pain ratings after the session, only during.
} 
magnitude of pain reduction [58, 59].

Hoffman et al. conducted a study on a burn patient during physical therapy sessions [58]. The patient used VR on five different days, spending half of the therapy session in VR, and the other half with no VR as a control condition. The analgesic effects did not diminish across all five sessions.

Hoffman et al. conducted a further study on seven burn patients during physical therapy sessions [59]. Patients participated in as many sessions as possible before they were released from the hospital or underwent surgery. All seven patients participated in at least three sessions. There were no differences in the drop in pain between during VR and no VR across all three sessions.

Steele et al. also conducted a study with one post-surgery patient over six physiotherapy sessions [113], with half of each session (10 minutes) in VR and the other half without VR. The order of VR and non-VR were randomised, and usual pharmacological analgesia was used. Pain ratings were lower with VR in all but one session, and the drops in pain ratings did not decrease. The most massive difference in pain ratings between non-VR and VR was observed in the last session.

Rutter et al. conducted a study with 28 healthy adults undergoing coldpressor pain over eight weekly exposures [103]. The headset used in this 2009 study did not include any head tracking features, nor does the gam $9^{9}$ place the player in a 360-degrees virtual environment. The setup was a 3D display inside a headset. However, wearing the headset achieved similar results and consistently resulted in higher pain tolerance than the baseline.

Garrett et al. conducted a study with 20 chronic pain patients and 12 sessions throughout a month [42]. Although pain ratings were not taken during the VR session but instead post-session, meaning the change in pain was not significant. The change in pain fluctuated over the 12 sessions but mostly stayed in the same range, meaning the effects of VR on pain did not improve nor deteriorate.

\footnotetext{
9“Finding Nemo" (PlayStation 2)
} 
These studies showed that repeated use of VR does not diminish the analgesic effects. However, the long-term effects of using VR for pain relief lack research. Current literature is not conclusive due to several limitations: the studies had small sample sizes of patients or sessions, the studies only report pain once the VR session was over and not while participants were actively using VR, or the studies did not use modern headsets.

\subsubsection{Lasting Effects Outside of VR}

Although the research discussed earlier has shown that the analgesic effects of VR faded once the session had finished. VR can also be used for training and education to help patients learn to self-manage in ways that exist past the VR session.

VR can be used as a tool to teach patients techniques like meditation for pain management, which they can later apply without a VR headset. Gromala et al. designed a system to guide and teach users through a form of meditation called Mindfulness-Based Stress Reduction (MBSR) [47]. MBSR is a technique that requires users (of the meditation technique) to focus on their internal state rather than their surroundings. The purpose of VR, in this case, is to replace the user's surroundings with a non-distracting environment for the users to enter their meditative state.

Similarly, Botella et al. used a virtual environment as an adjunct to cognitive-behavioural therapies (CBT) in the treatment of fibromyalgia, a form of chronic pain [11]. The virtual environment used in this study consisted of six categories of content: CBT, relaxation, educational interventions, behavioural treatments, mindfulness-based programs, and other treatments. Patients were exposed to 10 group sessions of CBT supported by VR. Measurements of variables were taken at pretreatment, posttreatment, and 6 months after. The variables measured were functional status related to pain, depression, a negative and positive effect, and coping skills. While the use of VR was adjunct to CBT, results showed that pa- 
tients were satisfied with the virtual environment and showed improvements in the 6 months following treatment.

Physical activity, however simple, is an excellent way to help improve the general health of chronic pain patients and help reduce pain avoidance. VR can be used here to motivate patients to perform physical activities and provide feedback on performance with factors like posture and range of motion [107].

Both education of techniques and encouraging physical activity can be designed into engaging games, combining them with distraction therapy.

\subsubsection{Optimizing VR for Pain Management}

The previous sections covered the feasibility of VR for pain management, answering the question of "does it work?" with "yes, it does". This section covers research that seeks to optimise the amount of pain relief experienced by patients by looking at what kind of VR to use for pain relief, covering both the hardware and content. Hardware considerations include the types of headsets used, the specification of headsets, or even to use headsets at all. Content considerations cover what the users are seeing and doing in VR, whether it be a game or a movie.

\section{Presence and Hardware}

One concept of virtual reality research is the illusion of presence [104]. Presence is the sense of being inside the virtual environment rather than the real world. In more practical terms, although the user understands that what they are seeing are merely outputs of a screen and is not real, they respond and behave as if what they are seeing is real. How much presence a user experience is based on several immersion factors: display framerate, latency between movement and display update (essentially input and output), head-tracking, depth-perception, field-of-view, sound, haptic feedback, virtual body representation, and body engagement. These im- 
mersion factors may or may not lead to increased presence [106]. Many of these factors also relate to hardware specifications.

Hoffman et al. (2004) established early on that the effect of presence has on pain relief [65]. Hoffman et al. conducted a study with two groups of subjects undergoing thermal pain. One group had regular VR headsets and were considered the High-Tech group. The other group had the same headset but with tape covering a + shape in the middle of the headset and were considered the Low-Tech group. The High Tech group reported a stronger sense of presence as well as more pain reduction. The pain reduction was significantly correlated with presence $(\mathrm{r}=0.48)$.

Hoffman et al. (2006) [64] later compared two different headsets (HighTech and Low-Tech) for thermal pain. The Low-Tech headset was less immersive than the High-tech as well as any of today's VR headsets. The Low-Tech system did not block out the real world (see-through glasses), did not provide sound, had a narrower field-of-view, lower resolution, no interaction with the virtual world, and finally no head tracking. The results were consistent with Hoffman et al.'s 2004 study [65]. The High-Tech group reported more substantial pain reductions and more participants showed a significant reduction in pain. Hoffman et al.'s studies show the importance of using the correct hardware to optimise pain relief. Although today's headsets are more powerful and more affordable than the headsets from 2004-2006, some headsets still omit head-tracking capabilities to reduce costs so that it can reach a wider audience. Therefore studies carried out today still need to consider the correct headset for the situation in which the study is carried out.

Dahlquist et al. (2008) compared a VR headset to a desktop PC for 41 children experiencing cold pressor pain [27]. Their results showed that the younger children (age 6 - 10) did not experience additional benefits from VR, whereas the older children (age 11 - 14) did. They attributed this to the headset not fitting the younger children properly as it was designed for adults. The novelty of the VR headset meant the younger children were 
more focused on the headset than the game, whereas the older children could redirect their attention back to the game itself [109]. The display on the headset was less vivid than the desktop PC monitor as the headset available within their budget was of a low specification for the time. On this point, Hoffman et al.'s comparison of High-Tech and Low-Tech headsets [64] was cited. Dahlquist et al. conducted a further study targeting only the younger children the following year [28], but both the headset and game used in the study had several limitations. The headset was a 3D stereoscopic head-mounted display, with no head position or orientation tracking, and the game was a third-person game with a fixed camera. While the children playing the game saw improvements in pain tolerance when compared to no distractions, playing the game on the computer and headset yielded similar results. This result can be expected as the headset used was simply a display that did not react to user movements.

Tong et al. [116] conducted a study on seven chronic pain patients. The study had patients play games on both VR and PC in random order. Participants were asked to rate, on an 11-point Likert scale, their interest to play each game after they play all the games. Both quantitative and qualitative results suggest participants prefer VR to PC. Six out of seven participants expressed a preference for VR over PC due to its immersive factor. The one participant who preferred PC over VR was due to the VR headset causing pain in their neck. However, a similar problem was reported with PC where a participant had pain located in their hands and wrist and had trouble using a mouse and keyboard for extended periods.

Both Dahlquist et al. [27, 28] and Tong et al. [116] compared VR and PC, and both found participants preferred VR over PC for pain distraction (except for young children under the age of 10). Their results showed that although both VR and PC video games can be used for distraction, the added layer of immersion and thus presence available through VR allowed for better pain relief. This result motivated the study presented in this thesis to only focus on immersive VR environments as opposed 
to a comparison between VR and desktop or AR systems. The headset used for this project is HTC Vive, a 6DOF headset with tracked handheld controllers which allow for users to physically move around the room to interact with the virtual world.

\section{Active Distraction vs Passive Observation}

Inside the headset, users can be either actively working to complete some task (active distraction) or simple observing the virtual environment around them (passive observation).

Dahlquist et al. (2007) [26] compared active distraction and passive observation for 40 children experiencing cold pressor pain. The active distraction group played a video game in VR with a joystick. The passive observation children watched, in VR, a pre-recorded footage of someone else playing the game. Some children were also not given any distractions and acted as the control group. It was found that while both active and passive forms were effective compared to no distraction, active distraction was significantly superior to passive observation. In this study, the VR headset used did not have head-tracking, as the game itself was a 2D game projected into a $3 \mathrm{D}$ view in the headset.

\section{Game Genre}

In addition to comparing VR and PC, Tong et al. also compared the genre of games on both PC and VR [116]. Two games were played for each system, one game was a puzzle game (Carpe Lucem for VR and The Witness for $\mathrm{PC}$ ), and the other was an exploration game (Call for the Starseed for VR and Obduction for PC) (Figure 2.3). Participant preference for the game genre appeared to be dependent on the platform on which the game was played. One participant preferred the puzzle game on PC but preferred the exploration game on VR. Participants rated the puzzle game higher overall, but each game appealed to different participants. However, participants in- 
dicated that the hardware platform (PC vs VR) was more important than the content. This preference is possibly due to the novelty of VR to the participant sample.
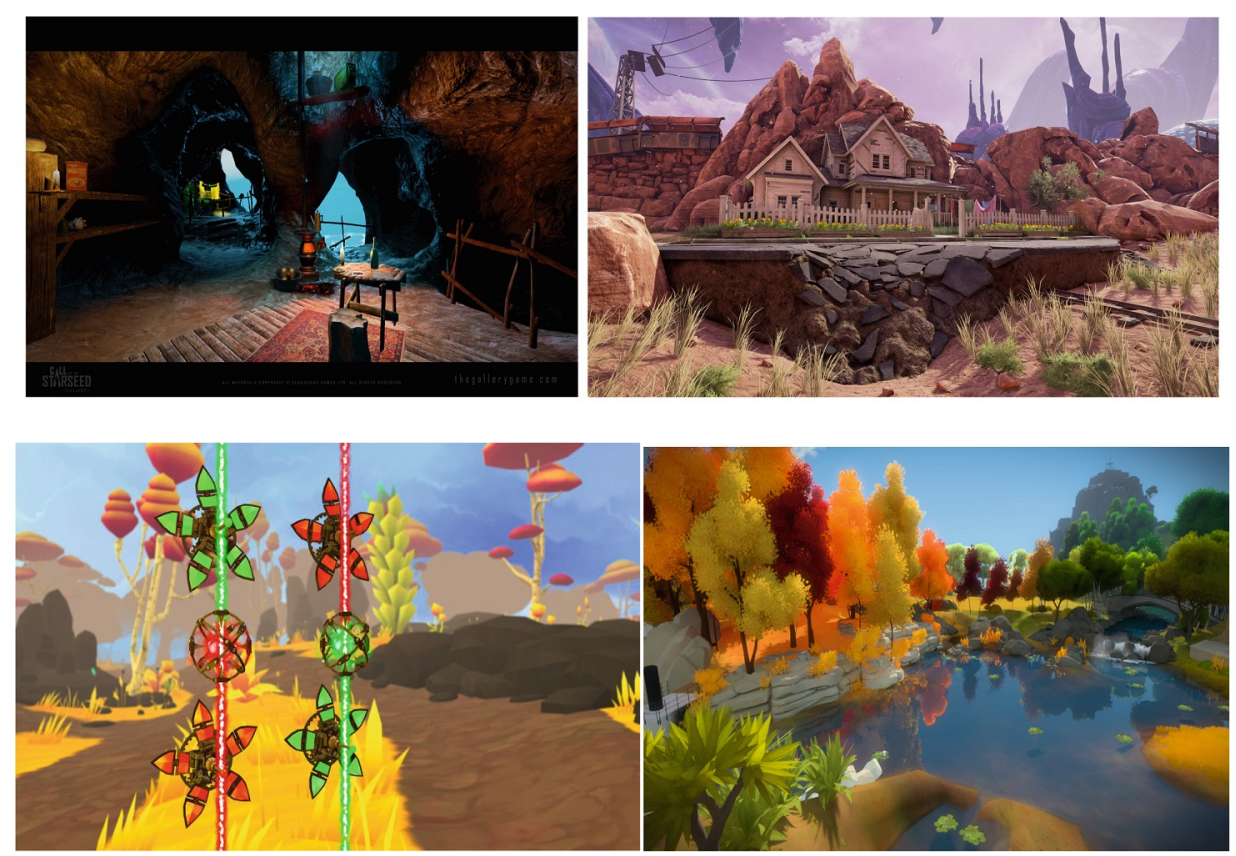

Figure 2.3: Screenshots of games used by Tong et al. [116]. From top to bottom: Call for the Starseed (VR game); Obduction (PC game); Carpe Lucem (VR game); The Witness (PC game).

\subsection{Overview of VR Studies}

The following table presents a summary overview of the studies referenced in this chapter. These studies all provide novel insight into some factor of VR for pain and how it affects the amount of pain relief experienced by the patients. The factors are the type of pain, cause of pain, patient demographic, choice of headsets, input device, the content presented, type of distraction, and repeated/long term use. 
From this overview, it can be seen that only one study out of these 25 utilises physically active distraction. However, the study in question did not record pain ratings, only participant preference for games [116]. Other studies since 2010 using modern headsets did not use tracked controller but rather mouse and keyboard. This shows that physically active distraction, which encourages patients to move and explore what they are capable of, is an area still lacking research. The study presented in this thesis distinctly splits physically active distraction, mentally active distraction, and passive observation and compares them against one another.

Three types of pain measures frequently appear: Visual Analogue Scale (VAS) [18], Numerical Rating Scale (NRS) [10], and the Wong-Baker FACES Pain Rating Scale (FACES scale) [41]. VAS, NRS, and the FACES scale share many core elements. One end of the scale is no pain, and the other end is the worst pain. How these scales differ is in their presentation to the patient. VAS appears as a continuous line, usually around $100 \mathrm{~mm}$ long, where the patient is asked to mark along the line how bad their pain is. The distance along the line where the patient marks are recorded as the pain rating $(0-100 \mathrm{~mm})$. NRS is also a line, often continuous, marked from 0 to 10 in 1 unit intervals. Discrete 0 to 10 numbers are also used, with numbers placed in individual boxes as opposed to a number line. The FACES scale presents the patient with images of faces, with the first face showing a smiling face and subsequent faces showing more and more unhappy faces. Faces are associated with a number from 0 to 10 , which is recorded as the pain rating.

Three games, Spider World, SnowWorld, and Ocean Rift, appear repeatedly, so they are detailed here and referred to by name in the table. Spider World is a VR experience initially used to overcome spider phobias [17]. Users are placed in a kitchen which contains two spiders in which they can interact (pick up) various virtual objects. Tactile augmentation was initially part of this virtual experience, where users can feel the material and texture of virtual objects. This physical feeling was an essential part of 


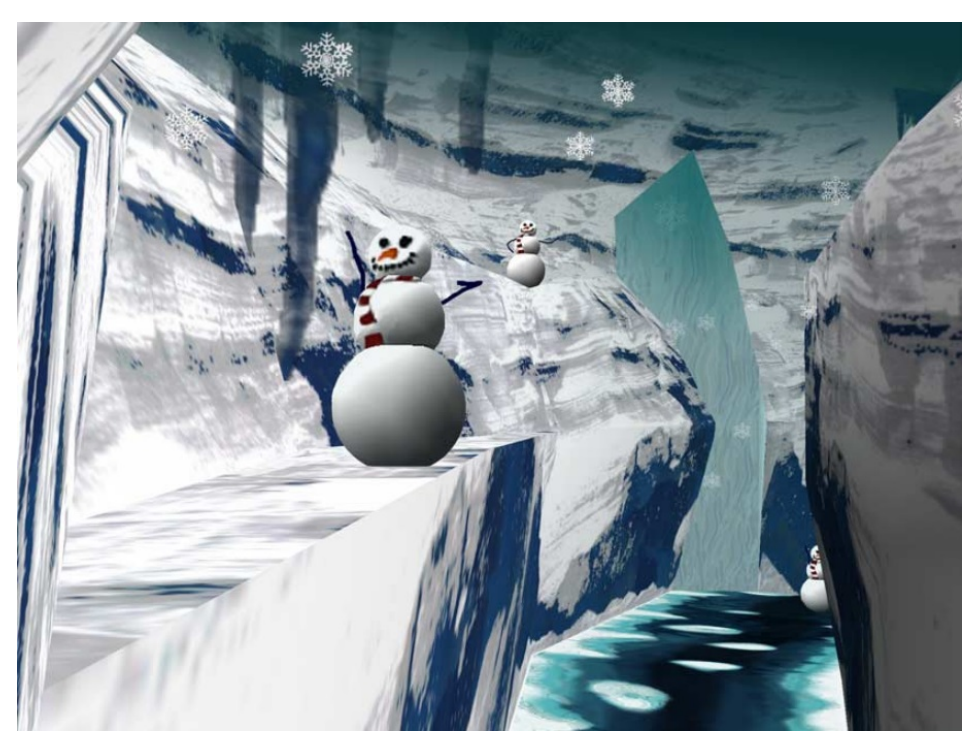

Figure 2.4: The SnowWorld virtual environment often used by Hoffman et al. 65

the spider phobia treatment, in which users would feel the furriness of the virtual spider. SnowWorld (Figure 2.4) was initially used to reduce pain in burn patients, where the burn patients flew through an icy world shooting snowballs at snowmen and igloos. The snow and ice theme were design to take the patient's thoughts away from fire and burning, which were the causes of the injury. Ocean Rift is a commercially available VR game in which players explore underwater worlds where they can see and learn about different marine life.

The number of participants in the studies differs significantly. Two are case studies with only one participant each, while the highest is 80 participants.

\section{Table Columns}

The first column contains the authors and the year of publication. The table is ordered alphabetically by the author's name, followed by the year of publication. 
The second column contains the type of pain participants were experiencing, number of participants, how the pain was measured, and the control or baseline against which pain was measured.

The third column contains the type of VR headset, the category of distraction (physically active distraction, mentally active distraction, passive observation), and the game used in the study. The headset is referenced by the degrees of freedom (DOF) the headset has. ODOF means there is no head tracking, and the headset is merely a display. 3DOF means the headset tracks the orientation; the user can look around freely but cannot move. 6DOF means both the head's position and orientation are tracked, and users can move and look around freely. The game used describes the type of game participants played during the study.

The fourth and last column of the table contains the results of the studies. 


\begin{tabular}{|c|c|c|c|}
\hline Author & $\begin{array}{l}\text { Pain type, Participants, Pain Measure, Con- } \\
\text { trol Group }\end{array}$ & Headset, distraction type, and game used & Results \\
\hline $\begin{array}{l}\text { Bani Moham- } \\
\text { mad \& Ahmad } \\
(2019)[3\end{array}$ & $\begin{array}{l}\text { Chronic - cancer pain. } 80 \text { female cancer pa- } \\
\text { tients. VAS. Standard care }\end{array}$ & $\begin{array}{l}\text { Unspecified headset, assumed no input. } \\
\text { Passive observation, Ocean Rift or "sitting } \\
\text { on the beach" }\end{array}$ & $\begin{array}{l}\text { Significant reduction in pain with VR. Sig- } \\
\text { nificant reduction in anxiety with VR }\end{array}$ \\
\hline $\begin{array}{l}\text { Chan et al. } \\
(2007) \text { [20] }\end{array}$ & $\begin{array}{l}\text { Acute - burn dressing. } 8 \text { children. Faces } \\
\text { scale. No distraction, baseline analgesics } \\
\text { applied to both }\end{array}$ & $\begin{array}{l}\text { 3DOF with mouse input. Mentally active } \\
\text { distraction with first-person rail shooter. } \\
\text { Scary away foxes in an ice-cream factory by } \\
\text { shooting them with ice-cream. Ice-cream } \\
\text { factory removes thoughts of burning }\end{array}$ & $\begin{array}{l}\text { Not statistically significant less pain with } \\
\text { VR compared to without VR. Nurses ob- } \\
\text { served improvement in behaviour and anx- } \\
\text { iety levels of the children. }\end{array}$ \\
\hline $\begin{array}{l}\text { Chan et al. } \\
(2017)[21]\end{array}$ & $\begin{array}{l}\text { Acute - surgery. } 19 \text { ( } 9 \text { in VR, } 10 \text { in con- } \\
\text { ventional care). Amount of medication use } \\
\text { (Propofol, fentanyl, midazolam). Conven- } \\
\text { tional care }\end{array}$ & $\begin{array}{l}\text { 6DOF (Oculus Rift) with no input. Passive } \\
\text { observation, Iceland, based on SnowWorld }\end{array}$ & $\begin{array}{l}\text { No significant reduction in medication use } \\
\text { but trend suggested less use }\end{array}$ \\
\hline $\begin{array}{l}\text { Dahlquist et al. } \\
\text { (2007) [26] }\end{array}$ & $\begin{array}{l}\text { Acute - induced cold pressor. } 40 \text { children } \\
\text { aged } 5-13 \text {. Time spent with hand in cold } \\
\text { water. No distraction, same game on nor- } \\
\text { mal computer screen }\end{array}$ & $\begin{array}{l}\text { 3DOF (VFX3D) with PlayStation } 2 \text { con- } \\
\text { troller. Mentally active distraction and } \\
\text { passive observation with the PlayStation } 2 \\
\text { game Finding Nemo }\end{array}$ & $\begin{array}{l}\text { Both active distraction and passive observa- } \\
\text { tion demonstrated better results than no dis- } \\
\text { traction. Active distraction was superior to } \\
\text { passive distraction }\end{array}$ \\
\hline $\begin{array}{l}\text { Dahlquist et al. } \\
\text { (2008) [27] }\end{array}$ & $\begin{array}{l}\text { Acute - induced cold pressor. } 41 \text { children } \\
\text { aged 6-14. 26-item parent report, 37-item } \\
\text { self-report measure for children, VAS, pain } \\
\text { tolerance. No distraction, same game on } \\
\text { normal computer screen }\end{array}$ & $\begin{array}{l}\text { 3DOF (VFX3D) with a joystick. Mentally } \\
\text { active distraction in } 360 \text { underwater en- } \\
\text { vironment scuba diving with marine life } \\
\text { while searching for treasure }\end{array}$ & $\begin{array}{l}\text { Distraction demonstrated significantly } \\
\text { higher pain thresholds. Adding VR im- } \\
\text { proved performance for children over the } \\
\text { age of } 10 \text { but not under } 10 \text {. }\end{array}$ \\
\hline $\begin{array}{l}\text { Dahlquist et al. } \\
\text { (2009) [28] }\end{array}$ & $\begin{array}{l}\text { Acute - induced cold pressor. } 50 \text { children } \\
\text { aged } 6-10 . \text { Time spent with hand in cold } \\
\text { water. No distraction, same game on nor- } \\
\text { mal computer screen }\end{array}$ & $\begin{array}{l}\text { ODOF (5DT HMD 800) with a joystick. } \\
\text { Mentally active distraction in a third- } \\
\text { person game controlling a character sliding } \\
\text { down a path collecting items and avoiding } \\
\text { obstacles }\end{array}$ & $\begin{array}{l}\text { Significant improved with distraction, no } \\
\text { differences between computer and VR. }\end{array}$ \\
\hline
\end{tabular}




\begin{tabular}{|c|c|c|c|}
\hline Author & $\begin{array}{l}\text { Pain type, Participants, Pain Measure, Con- } \\
\text { trol Group }\end{array}$ & Headset, distraction type, and game used & Results \\
\hline $\begin{array}{lrl}\text { Das et } & \text { al. } \\
(2005) & {[29]}\end{array}$ & $\begin{array}{l}\text { Acute - burn dressing. } 9 \text { children, } 7 \text { in- } \\
\text { cluded for analysis. Faces scale. No distrac- } \\
\text { tion, baseline analgesics applied to both }\end{array}$ & $\begin{array}{l}\text { 6DOF with mouse input. Mentally active } \\
\text { distraction with first-person rail shooter. } \\
\text { Designed to be played with the small- } \\
\text { est possible movement during the dressing } \\
\text { change procedure }\end{array}$ & $\begin{array}{l}\text { Statistically significant less pain in VR. Par- } \\
\text { ents and nurses observed improvement in } \\
\text { behaviour and anxiety levels of the children. }\end{array}$ \\
\hline $\begin{array}{lrl}\text { Frey et } & \text { al. } \\
(2018) & {[39]}\end{array}$ & $\begin{array}{l}\text { Acute - labour. } 27 \text { women in labour. NRS. } \\
\text { No distraction }\end{array}$ & $\begin{array}{l}\text { 3DOF (Samsung GearVR) with a hand con- } \\
\text { troller. Passive observation - patients had a } \\
\text { controller but did not interact with (merely } \\
\text { looked around) the virtual environment or } \\
\text { complete any set task. Ocean Rift }\end{array}$ & $\begin{array}{l}\text { Pain significantly lower in VR. } 82 \% \text { very } \\
\text { much/completely enjoyed using VR during } \\
\text { labour }\end{array}$ \\
\hline $\begin{array}{l}\text { Garrett et al. } \\
(2017) \text { 42 }\end{array}$ & Chronic. 10 patients. NRS. Desktop PC & $\begin{array}{l}\text { 6DOF (Oculus Rift) with a keyboard. Pas- } \\
\text { sive observation and mentally active dis- } \\
\text { traction through various VR games }\end{array}$ & $\begin{array}{l}\text { No significant difference between before } \\
\text { and after VR. Pain levels not recorded dur- } \\
\text { ing VR but } 5 \text { participants reported positive } \\
\text { benefits from VR. High level of motion sick- } \\
\text { ness }(60 \%) \text {. The magnitude of pain reduc- } \\
\text { tion did not change with repeated use of VR } \\
\text { over } 12 \text { sessions. }\end{array}$ \\
\hline $\begin{array}{l}\text { Gershon et al. } \\
(2004) \text { 43] }\end{array}$ & $\begin{array}{l}\text { Acute - port access. } 59 \text { children. } 22 \text { had VR } \\
\text { distraction, } 15 \text { had a non-VR distraction, } \\
22 \text { had no distraction. VAS (patient, par- } \\
\text { ent, nurse), pulse rate, CHEOPS pain scale. } \\
\text { Non-VR distraction (the same game but on } \\
\text { monitor) and no distraction }\end{array}$ & $\begin{array}{l}\text { Not specified (assumed to be 3DOF) with } \\
\text { a joystick. Mentally active distraction with } \\
\text { a roleplaying game. Users play as a young } \\
\text { gorilla learning how gorillas communicate } \\
\text { and interact [1] }\end{array}$ & $\begin{array}{l}\text { No significant different before and after port } \\
\text { access procedure. VR and NonVR signifi- } \\
\text { cantly less pain during procedure }\end{array}$ \\
\hline
\end{tabular}




\begin{tabular}{|c|c|c|c|}
\hline Author & $\begin{array}{l}\text { Pain type, Participants, Pain Measure, Con- } \\
\text { trol Group }\end{array}$ & Headset, distraction type, and game used & Results \\
\hline $\begin{array}{l}\text { Gromala et al. } \\
\text { (2015) 447 }\end{array}$ & $\begin{array}{l}\text { Chronic. } 13 \text { patients. NRS. Mindfulness- } \\
\text { based meditation audio track without VR }\end{array}$ & $\begin{array}{l}\text { 3DOF (DeepStream viewer) with no in- } \\
\text { put. Passive observation/mentally active } \\
\text { distraction. Patients followed along with a } \\
\text { guided mindfulness-based meditation au- } \\
\text { dio track in an immersive virtual environ- } \\
\text { ment }\end{array}$ & $\begin{array}{l}\text { Pain reduced in VR. Patients learned } \\
\text { mindfulness-based stress reduction tech- } \\
\text { nique. }\end{array}$ \\
\hline $\begin{array}{l}\text { Hoffman et al. } \\
\text { (2000) [55] }\end{array}$ & $\begin{array}{l}\text { Acute - burn dressing. } 2 \text { male, } 16 \text { and } 17 \\
\text { years old. VAS. Nintendo } 64 \text { game }\end{array}$ & $\begin{array}{l}\text { 6DOF (Division Provision } 100 \text { headset with } \\
\text { an external tracker) with hand tracking. } \\
\text { Mentally active distraction, Spider World }\end{array}$ & $\begin{array}{l}\text { Considerable pain reductions in VR. The pa- } \\
\text { tient looked at wounds several times in the } \\
\text { control group, which was not possible in VR }\end{array}$ \\
\hline $\begin{array}{l}\text { Hoffman et al. } \\
\text { (2001) [56] }\end{array}$ & $\begin{array}{l}\text { Acute - dental procedure. } 2 \text { patients. NRS. } \\
\text { Non-VR distraction (movie) and no distrac- } \\
\text { tion }\end{array}$ & $\begin{array}{l}\text { 0DOF headset (Virtual Research Systems } \\
\text { V8 Head Mount Display) with a mouse. } \\
\text { Mentally active distraction, SnowWorld }\end{array}$ & Considerable reduction in pain for VR. \\
\hline $\begin{array}{l}\text { Hoffman et al. } \\
\text { (2001) [58] }\end{array}$ & Acute - burn dressing. 1 patient & $\begin{array}{l}\text { 6DOF headset (Virtual Research Systems } \\
\text { V8 Head Mount Display with an external } \\
\text { tracker) with hand tracking. Mentally ac- } \\
\text { tive distraction, Spider World }\end{array}$ & $\begin{array}{l}\text { Considerable reduction in pain for VR. The } \\
\text { magnitude of pain reduction did not dimin- } \\
\text { ish with repeated use of VR over } 5 \text { visits }\end{array}$ \\
\hline $\begin{array}{l}\text { Hoffman et al. } \\
\text { (2001) [59] }\end{array}$ & $\begin{array}{l}\text { Acute - physiotherapy. } 7 \text { patients. VAS. No } \\
\text { distraction, baseline analgesics applied to } \\
\text { both }\end{array}$ & $\begin{array}{l}\text { 6DOF (Virtual Research Systems V8 Head } \\
\text { Mount Display with an external tracker) } \\
\text { with hand tracking and keyboard. Men- } \\
\text { tally active distraction with Spider World } \\
\text { (1 participant) and SnowWorld (6 partici- } \\
\text { pants) }\end{array}$ & $\begin{array}{l}\text { Statistically significant less pain in VR. The } \\
\text { magnitude of pain reduction did not dimin- } \\
\text { ish with repeated use of VR over } 7 \text { days }\end{array}$ \\
\hline
\end{tabular}




\begin{tabular}{|c|c|c|c|}
\hline Author & $\begin{array}{l}\text { Pain type, Participants, Pain Measure, Con- } \\
\text { trol Group }\end{array}$ & Headset, distraction type, and game used & Results \\
\hline $\begin{array}{l}\text { Hoffman et al. } \\
\text { (2004) [60 }\end{array}$ & $\begin{array}{l}\text { Acute - burn hydrotherapy. } 1 \text { patient. NRS. } \\
\text { No distraction }\end{array}$ & $\begin{array}{l}\text { ODOF, Custom water-friendly headset with } \\
\text { a joystick. Mentally active distraction, } \\
\text { SnowWorld }\end{array}$ & Considerable reduction in pain for VR. \\
\hline $\begin{array}{l}\text { Hoffman et al. } \\
\text { (2006) 64 }\end{array}$ & $\begin{array}{l}\text { Acute - induced thermal. } 77 \text { healthy sub- } \\
\text { jects. } 26 \text { in high tech VR, } 28 \text { in low tech VR, } \\
23 \text { with no distraction. NRS. No distraction }\end{array}$ & $\begin{array}{l}\text { 6DOF ( } 2 \text { different headsets with an external } \\
\text { tracker) with a keyboard. Mentally active } \\
\text { distraction in SnowWorld }\end{array}$ & $\begin{array}{l}\text { Pain reduced more in high tech VR than low } \\
\text { tech VR, which reduced more than no dis- } \\
\text { traction control group. }\end{array}$ \\
\hline $\begin{array}{l}\text { Hoffman et al. } \\
\text { (2006) 65] }\end{array}$ & $\begin{array}{l}\text { Acute - induced thermal pain. } 39 \text { healthy } \\
\text { subjects. NRS. Low Tech VR, ODOF, no } \\
\text { interaction, non-immersive, see-through, } \\
\text { smalled FoV, lower image resolution }\end{array}$ & $\begin{array}{l}\text { 6DOF (Kaiser XL-50 with an external } \\
\text { tracker) with keyboard input. Mentally ac- } \\
\text { tive distraction in SnowWorld }\end{array}$ & $\begin{array}{l}\text { Considerable reduction in pain with high } \\
\text { tech VR. High tech VR gave more sense of } \\
\text { immersion }\end{array}$ \\
\hline $\begin{array}{l}\text { Hoffman et al. } \\
\text { (2007) 63 }\end{array}$ & $\begin{array}{l}\text { Acute - induced thermal. } 9 \text { healthy sub- } \\
\text { jects. NRS. No analgesia, opioids }\end{array}$ & $\begin{array}{l}\text { Custom nonferromagnetic headset with } \\
\text { trackball and button. Mentally active dis- } \\
\text { traction, SnowWorld }\end{array}$ & $\begin{array}{l}\text { VR and VR+opioid resulted in significantly } \\
\text { lower pain ratings. VR+opioid resulted in } \\
\text { significantly lower pain ratings than opioid } \\
\text { along }\end{array}$ \\
\hline $\begin{array}{lcc}\text { Jin } & \text { et } & \text { al. } \\
(2016) & {[68]}\end{array}$ & $\begin{array}{l}\text { Chronic. } 20 \text { patients. VAS. Daily distrac- } \\
\text { tion activity (meditating, reading, listening } \\
\text { to music etc.) }\end{array}$ & $\begin{array}{l}\text { 6DOF (Oculus Rift) with mouse input. } \\
\text { Mentally active distraction with first- } \\
\text { person rail shooter }\end{array}$ & $\begin{array}{l}\text { Significantly less pain during VR but not af- } \\
\text { ter. }\end{array}$ \\
\hline $\begin{array}{lrr}\text { Jones } & \text { et } & \text { al. } \\
(2016) & 69]\end{array}$ & Chronic. 30 patients. NRS. None & $\begin{array}{l}\text { 6DOF (Oculus Rift) with mouse input. } \\
\text { Mentally active distraction, first-person rail } \\
\text { shooter }\end{array}$ & $\begin{array}{l}\text { Reduced by } 60 \% \text { during VR session, re- } \\
\text { duced by } 33 \% \text { post-VR session }\end{array}$ \\
\hline $\begin{array}{l}\text { Rutter et } \quad \text { al. } \\
(2009) \text { [103] }\end{array}$ & $\begin{array}{l}\text { Acute - induced cold pressor. } 28 \text { healthy } \\
\text { subjects. Time endured in cold pressor. No } \\
\text { distraction }\end{array}$ & $\begin{array}{l}\text { ODOF (5DT } 800 \text { HMD Virtual Reality Hel- } \\
\text { met) with PlayStation } 2 \text { controller. Men- } \\
\text { tally active distraction with the PlayStation } \\
2 \text { game Finding Nemo }\end{array}$ & $\begin{array}{l}\text { Increased pain threshold and tolerance in } \\
\text { VR. The magnitude of pain reduction did } \\
\text { not diminish with repeated use of VR over } \\
8 \text { weeks }\end{array}$ \\
\hline $\begin{array}{l}\text { Steele et al. } \\
(2003) \text { [113] }\end{array}$ & $\begin{array}{l}\text { Acute - post-surgery. } 1 \text { patient. Faces scale. } \\
\text { No distraction, baseline analgesics applied } \\
\text { to both }\end{array}$ & $\begin{array}{l}\text { 6DOF ( } 2 \text { different headsets with an exter- } \\
\text { nal tracker) with a joystick. Mentally active } \\
\text { distraction with a rail shooter. Designed to } \\
\text { be played with the smallest possible move- } \\
\text { ment }\end{array}$ & $\begin{array}{l}\text { Less pain in VR. The magnitude of pain re- } \\
\text { duction did not diminish with repeated use } \\
\text { of VR over } 6 \text { sessions. Reduction in anxiety } \\
\text { levels }\end{array}$ \\
\hline
\end{tabular}




\begin{tabular}{|l|l|l|l|}
\hline Author & $\begin{array}{l}\text { Pain type, Participants, Pain Measure, Con- } \\
\text { trol Group }\end{array}$ & Headset, distraction type, and game used & Results \\
\hline \hline $\begin{array}{l}\text { Tong et al. } \\
(2018) \text { [116] }\end{array}$ & $\begin{array}{l}\text { Chronic. 7 patients. No pain measurements } \\
\text { were taken. 0-10 Likert scale used for game } \\
\text { preference. Desktop PC }\end{array}$ & $\begin{array}{l}\text { 6DOF (HTC Vive) with hand controllers. } \\
\text { Physically active distraction and mentally } \\
\text { active distraction with 4 commercially } \\
\text { available games (Call for the Starseed, Ob- } \\
\text { duction, Carpe Lucem, The Witness) }\end{array}$ & $\begin{array}{l}\text { 6 participants prefered VR games. } \\
\text { neck. }\end{array}$ \\
\hline $\begin{array}{l}\text { Wiederhold et } \\
\text { al. (2014) [120] }\end{array}$ & $\begin{array}{l}\text { Chronic. 40 patients. 1-7 scale, tempera- } \\
\text { ture, heart rate. No distraction }\end{array}$ & $\begin{array}{l}\text { Unspecified headset with mouse input. } \\
\text { Passive observation in a relaxing environ- } \\
\text { ment }\end{array}$ & $\begin{array}{l}\text { Significant reduction in pain with VR. Skin } \\
\text { temperature and heart rate indicated greater } \\
\text { relaxation }\end{array}$ \\
\hline
\end{tabular}




\subsection{Summary}

This chapter introduced the background to pain, distraction therapy, and $\mathrm{VR}$, as well as covering previous research on VR for pain relief. VR has been conclusively shown to be effective against acute pain, but less research has been done into chronic pain. Research has also evaluated VR against other computer systems, as well as different types of content within VR, to optimise the amount of pain relief experienced by patients. The common consensus in the literature covered in this chapter is that VR headsets with a higher level of immersion are more effective than desktop PCs and other VR headsets that do not offer as much immersion. However, there is less research on the content delivered through VR and their effectiveness at reducing pain. An overview of the literature examined in this chapter has shown that physically active distraction is underutilised.

The focus of this thesis is on the content delivered through VR and its effectiveness against chronic pain, an area currently lacking in research. In the next chapter, ChronicVR is presented, a game for managing chronic pain with three distinct levels of gameplay, each focusing on one of physically active distraction, mentally active distraction, and passive observation. 


\section{Chapter 3}

\section{ChronicVR}

This chapter discusses the design of an interactive game called ChronicVR. A game is, by nature, designed to draw in the player and provides them with an engaging activity. Gameplay elements, such as having an objective to accomplish within the session, provides participants with an incentive to do well within the game, further drawing in the players' focus and attention.

Within ChronicVR there are three categories of gameplay, each focusing on one type of distraction: physically active distraction, mentally active distraction, and passive observation. ChronicVR is designed to isolate each category as much as possible so that the categories can be studied. Inside ChronicVR, the player plays the role of a magician, using a magic wand (handheld controller) to cast various magic to interact with the world. Players solve puzzles with these interactions and progress through the game.

ChronicVR was developed using Unity3D version 2019.1.17 for the HTC Vive [92] VR headset. ChronicVR was developed to answer the two research questions: "is active attention-diversion or passive observation more effective at managing chronic pain in VR?" and "is physically active distraction or mentally active distraction more effective at managing chronic

${ }^{1}$ https://unity.com/ 
pain?"

This chapter discusses the design of ChronicVR, starting with the requirements gathered from the staff at the Pain Management Service, and followed by what was implemented and used in user studies.

\subsection{Design Requirements}

The design of ChronicVR was created with consultation from Wellington Regional Hospital's Pain Management Services. The Pain Management Service advised on what chronic pain patients were capable of, what would be beneficial for the patients, and what kinds of environment patients would enjoy. Around 6 members of staff from the Pain Management Services were consulted. Their roles consisted of psychologists, therapists, physiotherapists, and nurses.

Due to the pain in patients' bodies, there are limits on the amount or extent of physical interactions they can perform. For example, a patient with pain in their arm would not be able to perform broad, sweeping arm movements. However, some patients underestimate their limits, leading to pain avoidance. Pain avoidance is the situation where patients start to think that performing tasks that they are capable of would cause more pain, leading to them to stop performing said tasks. This avoidance strips down their life as they avoid many activities and lose sources of excitement in life. Patients should connect with their body in a better way rather than disconnect from their body. Patients should also seek to regain their previous excitement in life.

Education is an essential part of pain management. There is a wrong public perception that pain is just a signal that something is wrong and needs to be fixed, that pain is something that cannot be easily removed in chronic pain patients, and that forceful attempts can cause further damage to the body. Patients need to accept the pain and learn tools that help them live with and manage the pain. Education is vital in this aspect to help 
patients manage pain on their own.

Staff at the Pain Management Services also mentioned that patients tend to enjoy nature, bush, or underwater settings.

In summary, key design requirements gathered from the Pain Management Services are:

Req1 Encourage movement without being excessive, allowing patients to explore their capabilities.

Req2 Bring excitement to the patient, helping them understand that they can still enjoy activities.

Req3 Teaching pain management through techniques rather than relying on pharmacological painkillers.

After the initial meeting with the Pain Management Services, a prototype was developed with basic interactions in an open environment. This prototype was demonstrated to the Pain Management Services, and further feedback was received on the kinds of interactions that would be feasible and beneficial for chronic pain patients. This prototype was then iterated upon following feedback from the Pain Management Services.

\subsection{Game Design}

This section explains the design of ChronicVR. Aspects common across multiple levels are explained first, followed by details specific to each particular level.

\subsubsection{Virtual Environment}

The game has a magical theme, where the player takes on the role of a magician. The player is in a magician training facility, where they must 


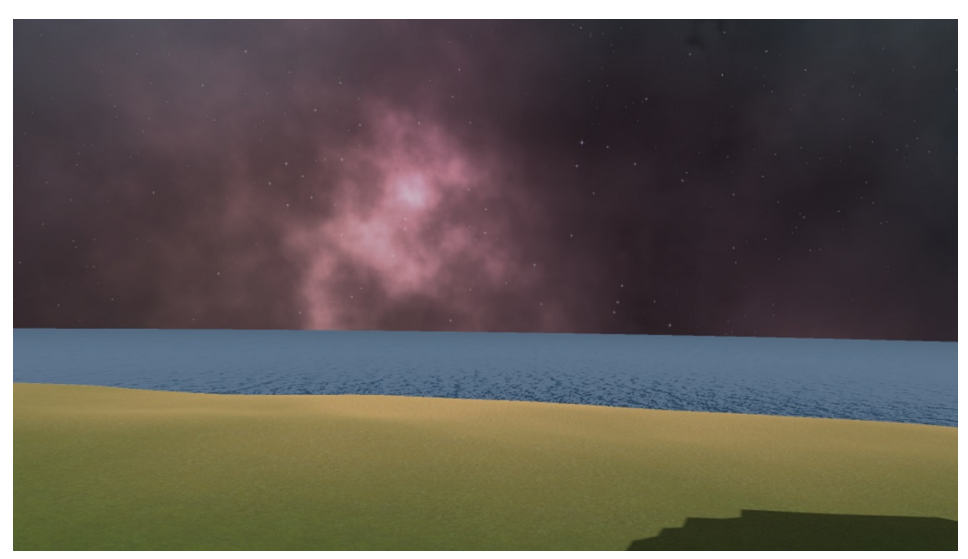

Figure 3.1: The beach that greets players when they complete every puzzle in the level. The sky is a starry night sky.

complete a series of challenges to measure their magical skill. As the magical energy comes from nature, players are surrounded by green under an open sky. A bright blue sky is used for the physical level, while a starry night sky is used for the mental level. Players exit into a beach with calming waves overlooking an expansive ocean at the end of the challenge (Figure 3.1). This setting conforms with the Pain Management Services' advice that the patients enjoy nature and the bush.

\subsubsection{Sound}

The same background music is used across all three levels. The music used is "Weightless" by Marconi Union. Weightless is said to be the most relaxing music in the world [95] and has been used as music medicine to reduce anxiety in patients [44].

Instructions were provided to the players via a voice-over inside the game. An online text-to-speech engine generated the voice-over. The voice-over was delivered at a slow pace to both allow players sufficient time to understand instructions and not to induce any sense of urgency in the players. Voice-overs were used at the beginning of each level to in- 
troduce players to the level. The voice-over was also used to ask players to rate their current pain level at the start and middle of the 10-minute session. Asking the players to rate their pain is part of the user study conducted with ChronicVR, in which the player's pain rating is the primary dependent variable.

Deep breathes help aid relaxation. Remembering to take deep breathes is part of the set of tools for chronic pain patients to self manage the pain. The voice-over reminded players to breathe at regular intervals. The reminders happened at the beginning of the level in the introduction and 3-minute and 7-minute marks. The voice-over asks players to take deep breathes to fill up their magic wand with magical energy. The 3-minute and 7-minute voice-over told players their wands have run out of energy and needed to be recharged. The breathing reminders is the result of Requirement 3 of the design requirements, assisting patients with selfmanagement techniques.

\subsubsection{Inputs and Interactions}

Players interact with the virtual environment through a handheld controller. The VR system tracks the position and orientation of the controller. The player's gaze was not used as an input. While two controllers are available, only one controller was used. Using only one simplifies inputs for players unfamiliar with video games by limiting the number of possible buttons. Only requiring one controller also provides accessibility for players unable to use both hands. Players could hold the single controller in whichever hand they preferred.

The system governing player interactions with virtual objects was built by modifying the SteamVR library such that it is customised for ChronicVR. 


\section{Moving in the Virtual World}

Players can physically walk around as much as space constraints in the real world allow before walking into a wall or furniture. However, each level is laid out so that the tasks / challenges were laid out consecutively in a straight line, resulting in the virtual world being over 100 meters long. This linear layout prevents players from losing their sense of direction as well as allowing them to see how much they have progressed at a quick glance backwards. At over 100 meters long, the virtual world is many times larger than the space available in the real world. From this arises the problem of how players would move through the virtual world without moving the equivalent distance in the real world.

One solution that was heavily investigated is a walking-in-place algorithm, where players can walk up and down on the spot. The head movements from such a motion would be detected by an algorithm to recognise that the player is walking-in-place and thus move the player forward in the virtual world. Walking-in-place would be the next ideal solution, as it encourages physical movement from the players. Teleportation would remain available as an accessibility option to players who had trouble walking or standing.

However, implementation of the step-detection algorithm proved difficult. Several libraries and plugins for such a task were investigated, but all were not fit for purpose. Problems included needing to touch the touchpad on the controller to tell the system that the player wishes to walk, needing to point the controller in that particular direction to dictate the direction of travel, no code or algorithm available to integrate into ChronicVR, or walking is done by the swinging of arms (hand tracking) rather than moving legs up and down.

A jog-in-place algorithm presented by Lee et al. [79] was implemented in ChronicVR. The step detection in the algorithm required large and rapid steps. This movement cannot be reasonably expected of chronic pain patients to maintain for up to 10-minutes and would violate Requirement 1 
of the design requirements. An attempt was made to convert this algorithm from jog-in-place into waddle-in-place. The side-to-side motion of the head was used rather than the up and down motion. The side-to-side displacement was calculated by a dot product calculation of the head's position vector on the head's right axis so that "side-to-side" could be calculated regardless of the direction the player was facing. However, this caused problems should the player look in a different direction while waddling, as the head's right axis would change and thus change the "side-toside" displacement value. The step detection for the waddle-in-place algorithm was also unreliable, reporting both false positives and false negatives.

In the end, the walking-in-place functionality was unreliable and inaccurate and was therefore discarded. Players simply teleported from place to place in the final implementation used in the user study. Teleporting is not a preferred solution as the ability to teleport discourages players from physically walking around ${ }^{2}$, Due to the instantaneous timing of teleporting, players would naturally opt to teleport and reach the desired destination immediately, rather than spend a few seconds walking. Slowing down or putting time constraints on the teleporting is also undesirable, as the players should be focusing on solving the puzzles rather than spend time moving around.

\subsubsection{Physical Level}

Physically active distraction content focuses on requiring the player to perform physical activities within virtual reality. Excessive or large movements may cause increased pain for patients. ChronicVR is designed such that it rewards players who perform the large movements, but still doable with small movements only. Larger or faster movements reward players

\footnotetext{
${ }^{2}$ Movement in the real world still translated directly into the virtual world. The problem arises when players need to move vast distances that would exceed the physical space available.
} 


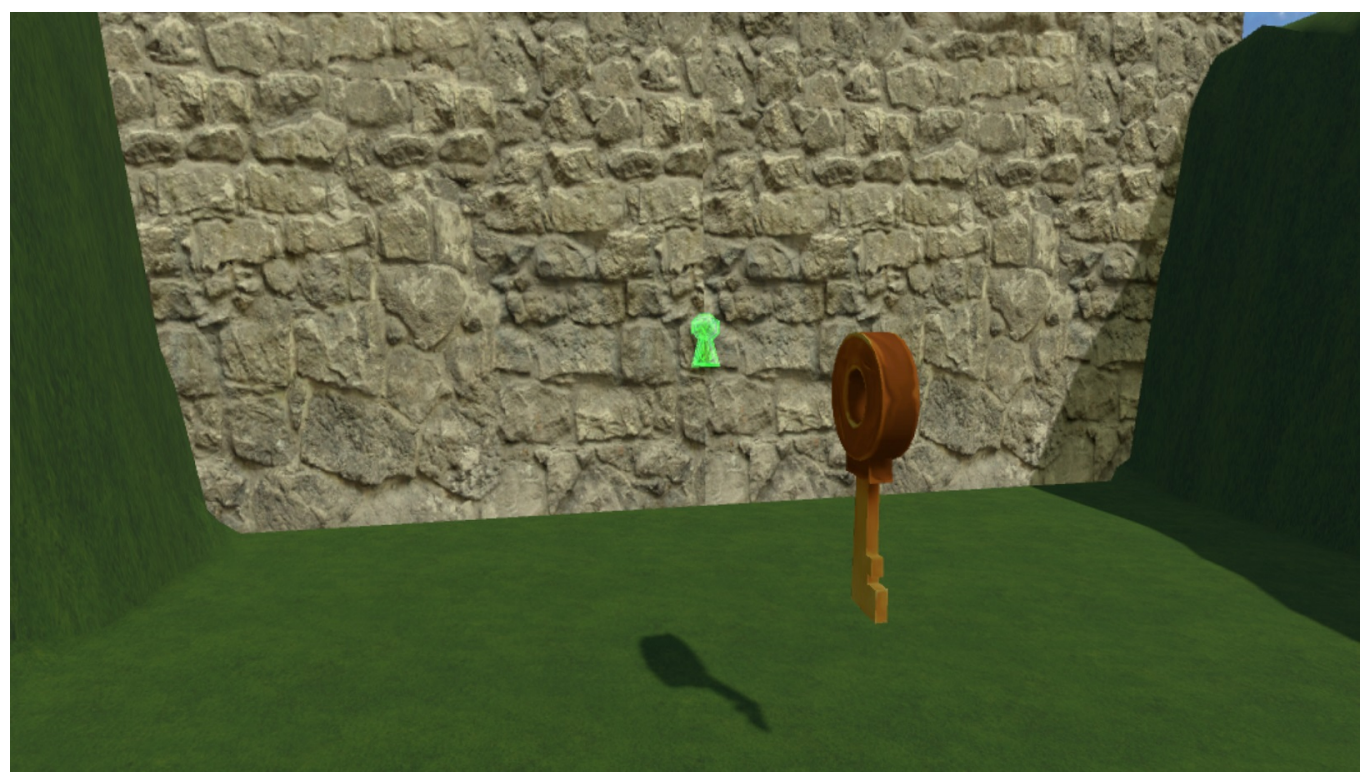

Figure 3.2: A key and the keyhole. Players must move the key near the keyhole to open the gates.

with more distance in throwing objects which leads to faster completion times. Smaller movements mean players will take longer to complete each task, but not so long that they are stuck on the same task for the entire 10minute session. This level conforms to Requirements 1 and 2 of the design requirements, allowing patients to explore their capabilities at their own speed as well as providing them a sense of achievement as they progress through the puzzles.

In the physical level, players progress by gaining access to a key somewhere in the level then moving the key into the vicinity of the keyhole on the gate (Figure 3.2). The key only needs to be within a certain distance of the keyhole and does not need to be inserted into the keyhole correctly. The key can be simply thrown at the keyhole to activate. The player achieves this using magic.

In addition to the teleportation magic described above, players have access to three other types of magic: telekinesis, fireball, and lightning 


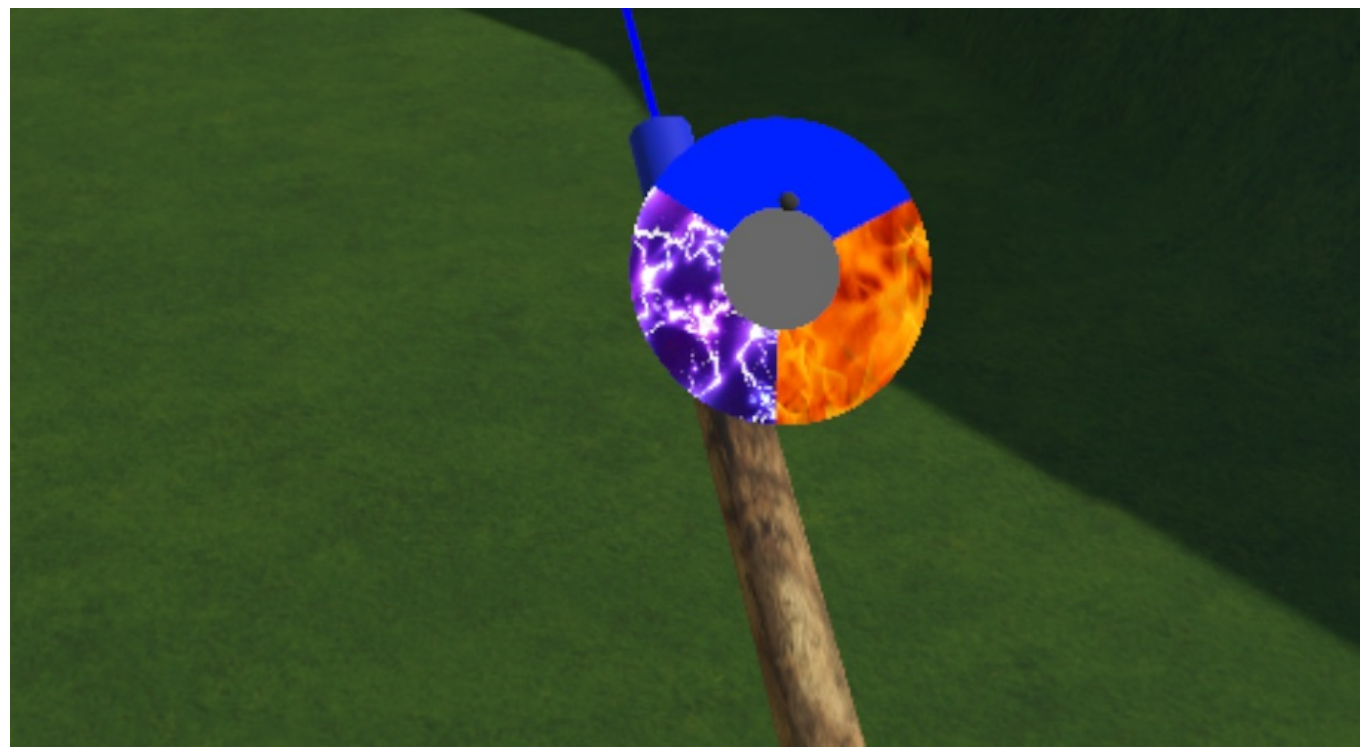

Figure 3.3: The pop-up display indication which part of the circular touch pad corresponds to which magic. The blue section is telekinesis, the red section is fireball, the purple section is lightning arrow, and the centre is teleportation. A black sphere can be seen in the blue section, indicating where the player is currently touching.

arrow. These three types of magic are gradually introduced to the player, individually demonstrating the mechanic to the player in the earlier parts of the level. In the later parts of the level players must use a combination of the magic to progress.

Players can freely swap between the three types of magic with the touchpad on the controller. The circular touchpad is divided into three equal arcs, one for each magic. By touching the arc on the outer edge of the circular touchpad, the currently active magic is changed to the magic in the corresponding arc. The centre of the circular touchpad is teleportation. The circular touchpad is entirely mapped out inside VR with a pop-up display above the wand when the player touches the touchpad, with a black sphere indicating where the player is currently touching (Figure 3.3.) 


\section{Telekinesis Magic}

The telekinesis magic allows players to pick up objects from any distance away (Figure 3.4). The telekinesis is the magic players use to pick up the key and put it in the keyhole. While the telekinesis magic is the currently active magic, a guidance pointer is projected from the tip of the wand. The pointer is blue, turning green when the player is aiming at something that can be picked up. The targeted object also glows with a yellow outline. The pointer turns yellow when the object is picked up. Players can aim at the object they wish to pick up with this pointer before activating the magic by pulling the trigger.

The object remains in the player's "grasp" as long as the trigger is held down, dropping when the player releases the trigger. Upon release, the held object maintains the velocity it had immediately before release. Players are therefore able to throw objects around with this system by releasing the trigger while moving their hand. The concept is the same as throwing an object in the real world. Telekinesis magic, therefore, encourages players to move their arm and wrists. However, as the object is not held directly inside the player's palm but at some distance away with magic, the velocity of the object becomes higher than the velocity at which the player's hand is moving. This increase in velocity allows for players to throw objects a considerable distance without requiring significant movements in their hand or arm.

\section{Fireball Magic}

The fireball magic allows players to create a fireball in their hand (Figure 3.5). Once created, the fireball behaves the same as an object held with telekinesis magic. The fireball is held in the player's hand as long as they are holding down the trigger. Releasing the trigger releases the fireball. The fireball can be thrown just like any other object.

When the fireball comes into contact with wooden logs, the logs burn 


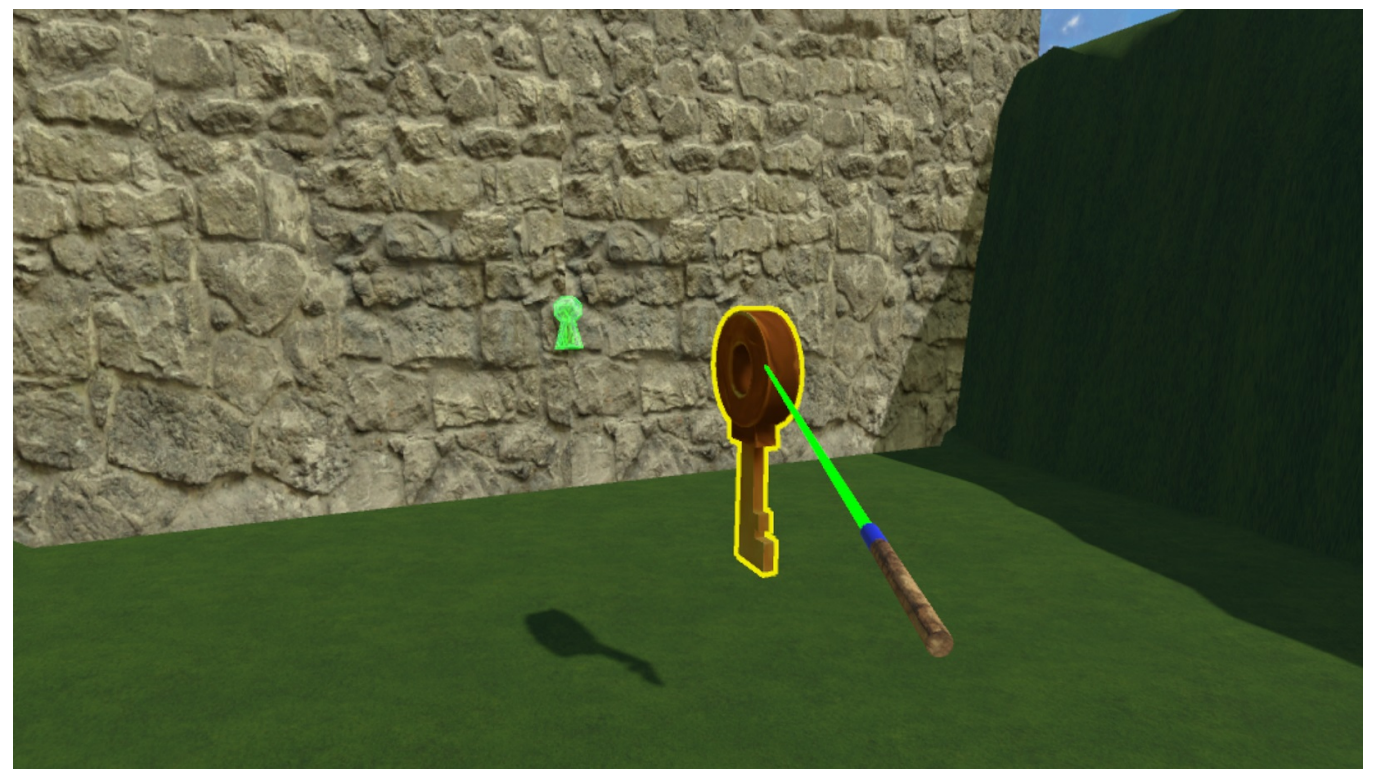

(a) Aiming at an object with telekinesis magic.

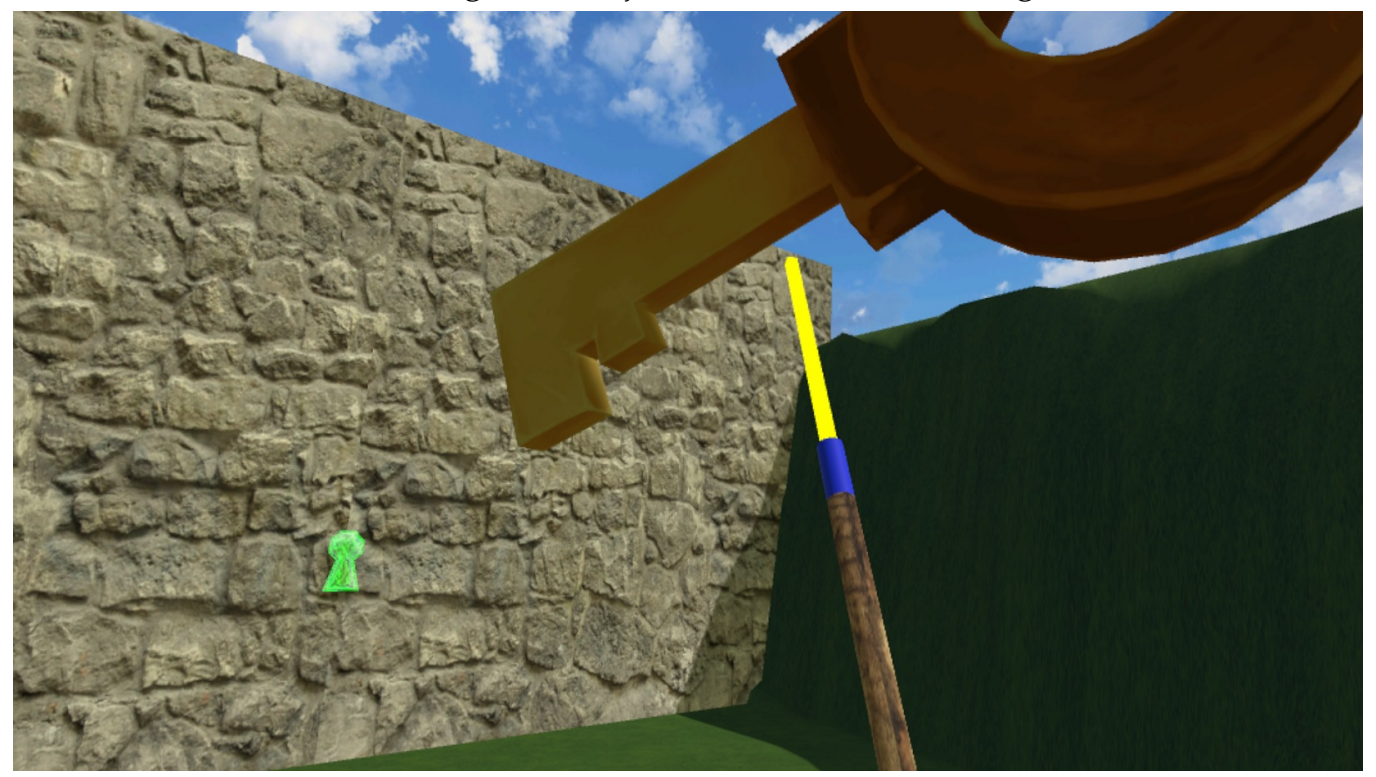

(b) Picking up and holding an object with telekinesis magic.

Figure 3.4: Telekinesis magic 
away to reveal the key hidden behind it. In later parts of the level, the wooden logs grow back once burned, so the player must retrieve the key hidden behind the log within a certain amount of time before the log grows back. If players do not retrieve the key in time, they must burn the log again.

\section{Lightning Magic}

The lightning arrow magic allows players to create and shoot an arrow (as in, bow and arrow) made of lightning (Figure 3.6). When players pull and hold the trigger, the tip of the arrow is set where the wand is. The feather end of the arrow following the player's hand while the player holds down the trigger. Players "draw" the arrow like this, and the arrow shoots off in the direction it is facing once the trigger is released. The further back the player "draws" the arrow, the faster the arrow moves once released.

Players use the lightning arrow to hit lightning targets in the level. All but one target is stationary, the moving target flies across the sky and players must time the arrow correctly to hit it. Lightning targets open a particular door when hit. These could be the big gate to progress to the next part of the level or a side door behind which the key is hidden. In the later parts of the level, the side doors close after a certain amount of time, so the player must retrieve the key hidden behind the door within a certain amount of time before the door closes. If players do not retrieve the key in time, they must hit the lightning target again.

\subsubsection{Mental Level}

Mentally active distraction content focuses on requiring the player to think and memorise elements to solve puzzles. In the mental level, players progress by solving a series of puzzles. There are four types of puzzles to- 


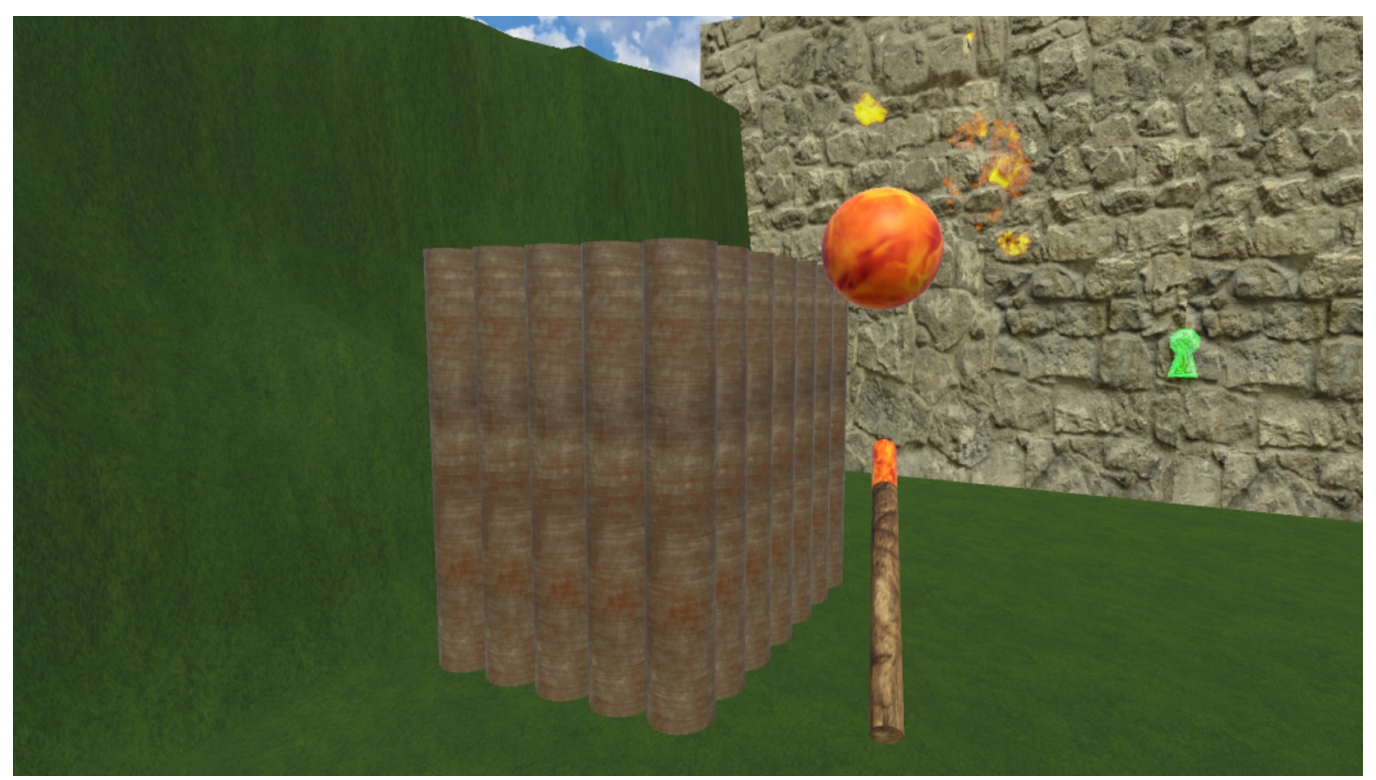

(a) Holding the fireball created with fireball magic.

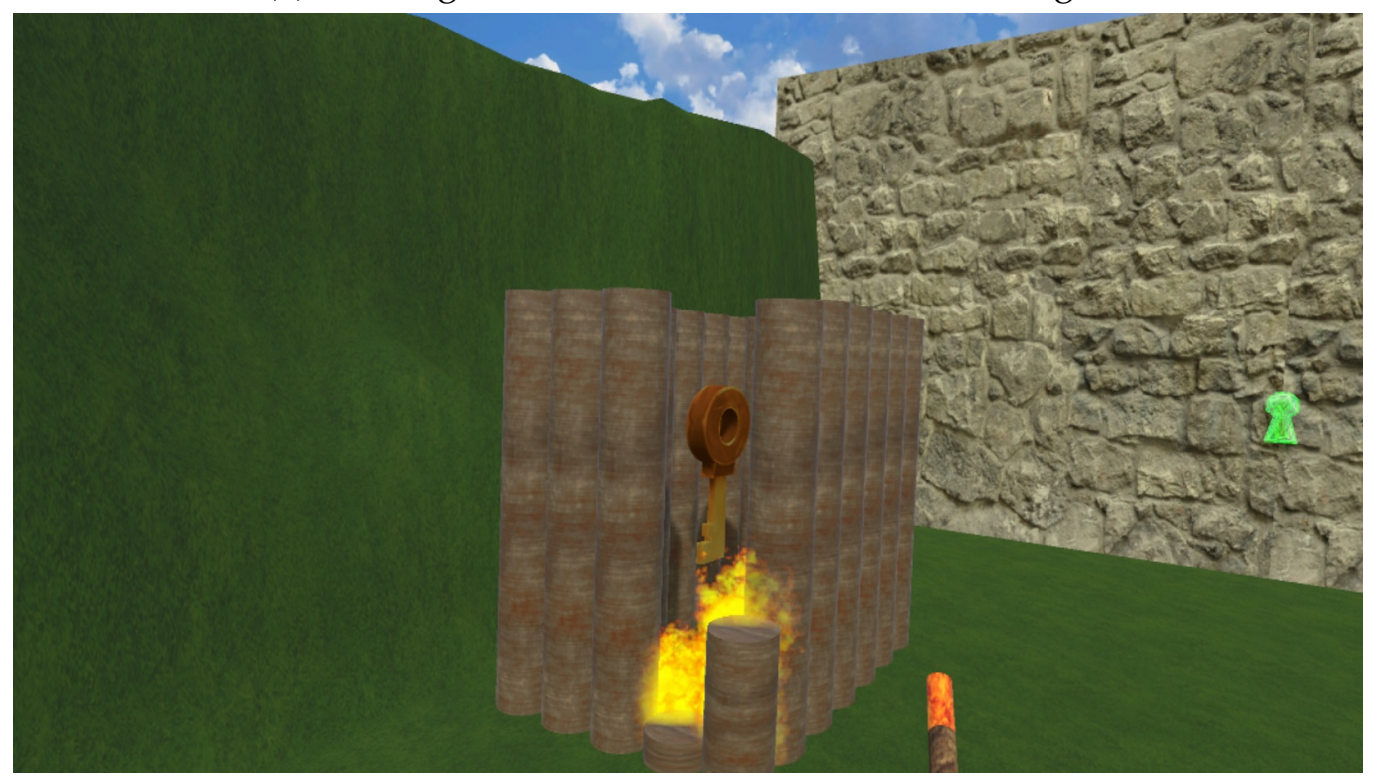

(b) Wooden logs burning away after being hit with fireball magic, revealing the key hidden behind it.

Figure 3.5: Fireball magic 


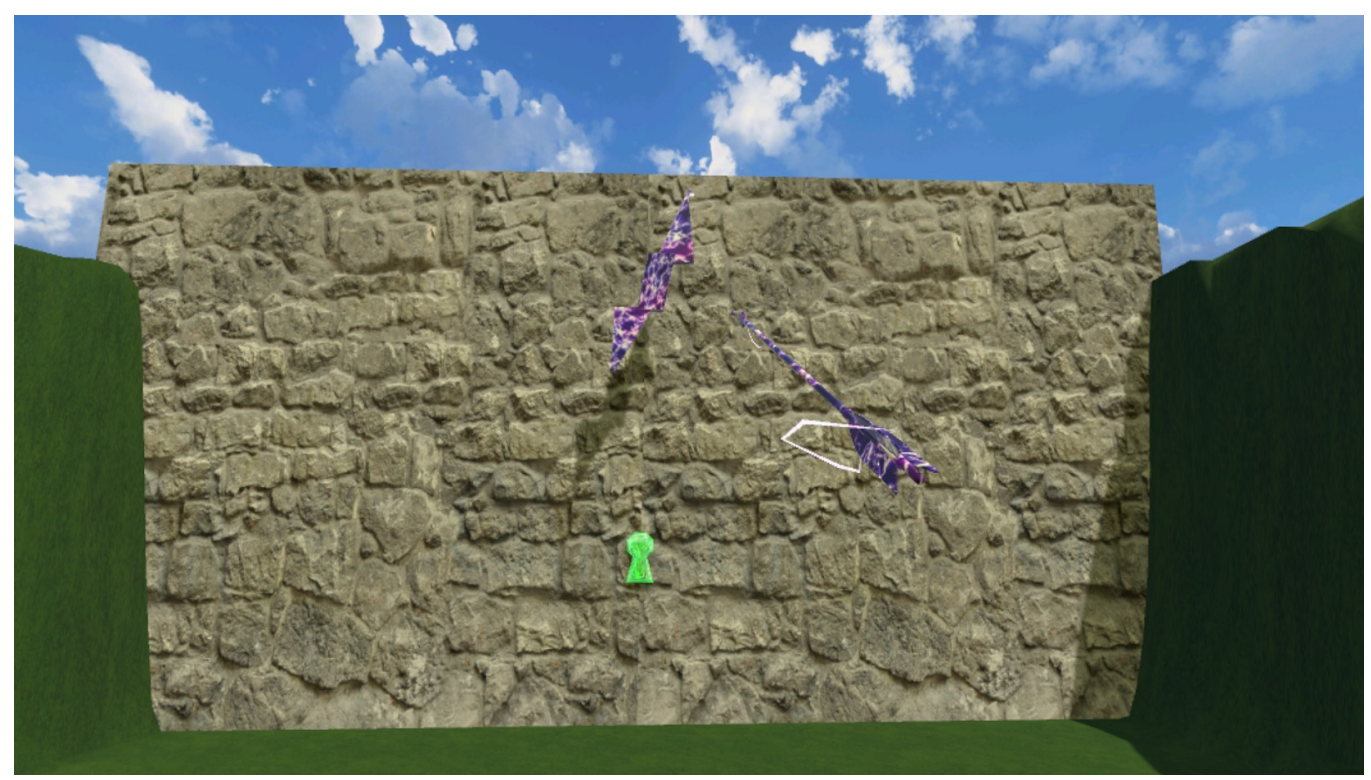

Figure 3.6: Lightning arrow magic. The target is above the keyhole and the arrow is to the right of the target.

tal: concentration ${ }^{3}$ jigsaw puzzle, flipping puzzle, and Rush Hour $!^{4}$. Concentration is a memory game, while the other three require logical thinking.

These four puzzles were selected based on several criteria:

Literacy agnostic Players may not be fluent in English, so word or spelling puzzles were excluded

Simple rules and goal The puzzle must have simple rules and goals that can be understood by looking at or playing with the puzzle board without prior instructions

No complex strategy needed The puzzle must be completable without formulating a complex strategy

\footnotetext{
$\sqrt[3]{\text { https://en.wikipedia.org/wiki/Concentration_(game) }}$

${ }^{4}$ https://en.wikipedia.org/wiki/Rush_Hour_(puzzle)
} 
Concentration presents players with several cards floating in the air (Figure 3.7). Players flip the cards around in twos and match the pairs. Once the player matches a pair, the pair disappears. Players can progress in the level once all the pairs are matched. To be effective at solving the puzzle, players must remember the position of previously flipped cards so that they can match it when the corresponding pair appears. As players progress through the level, more and more pairs are added, increasing the difficulty of the puzzle. Players are not able to look behind the cards even if they move, as the cards automatically turn to face the player with what they should be seeing.

The second puzzle, the jigsaw puzzle, presents players with a rectangular grid puzzle board with Tetris-lik $\mathrm{e}^{5}$ puzzle pieces (Figure 3.8). Players need to fit the puzzle pieces into the board such that all the pieces fit onto the board. The board will be filled by up the pieces. A reset button is next to the board should the player make a mistake in solving the puzzle. The reset button removes all the pieces from the board and places them back in their original position.

The third puzzle is based on the Folding Blocks game by POPCORE⿱ The puzzle presents players with a rectangular grid puzzle board with some grids filled with pieces already (Figure 3.9). The piece doubles and flips in the dragged direction when players drag on a piece. If the puzzle board has space in the flipped direction, the flipped piece double in size. If another piece obstructs the flipping, the flipped piece simply flips back as if nothing had happened. The goal of the puzzle is to cover the entire board with pieces.

The fourth and last puzzle, Rush Hour, presents players with a rectangular grid puzzle board occupied by $1 \times n$ or $n \times 1$ pieces (Figure 3.10). One piece is marked with arrows to indicate that piece as the key piece. Similar arrows are marked on a position on the board also to indicate the

5 https://en.wikipedia.org/wiki/Tetris

6 https://popcore.com/index.html 


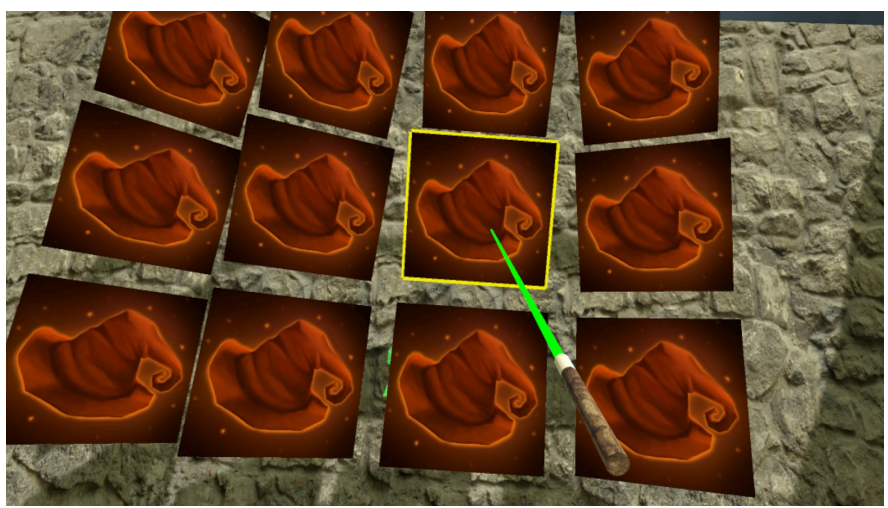

(a) Concentration puzzle with 6 pairs. The cards are turned to face the player.

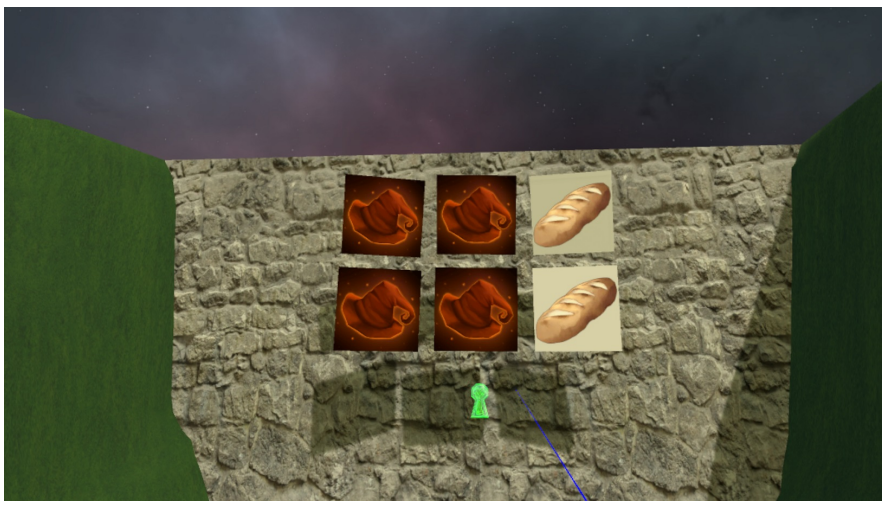

(b) Matching the pairs.

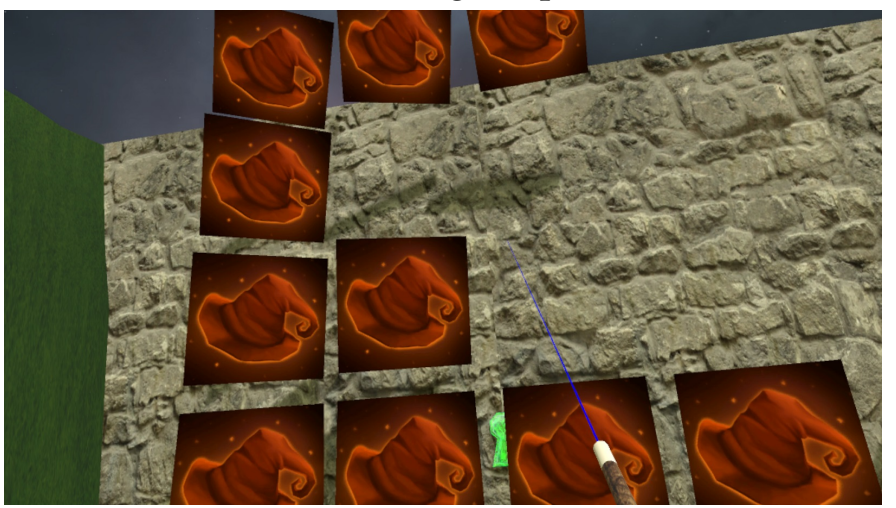

(c) A partially solved puzzle with already matched pairs having disappeared.

Figure 3.7: Concentration puzzle 


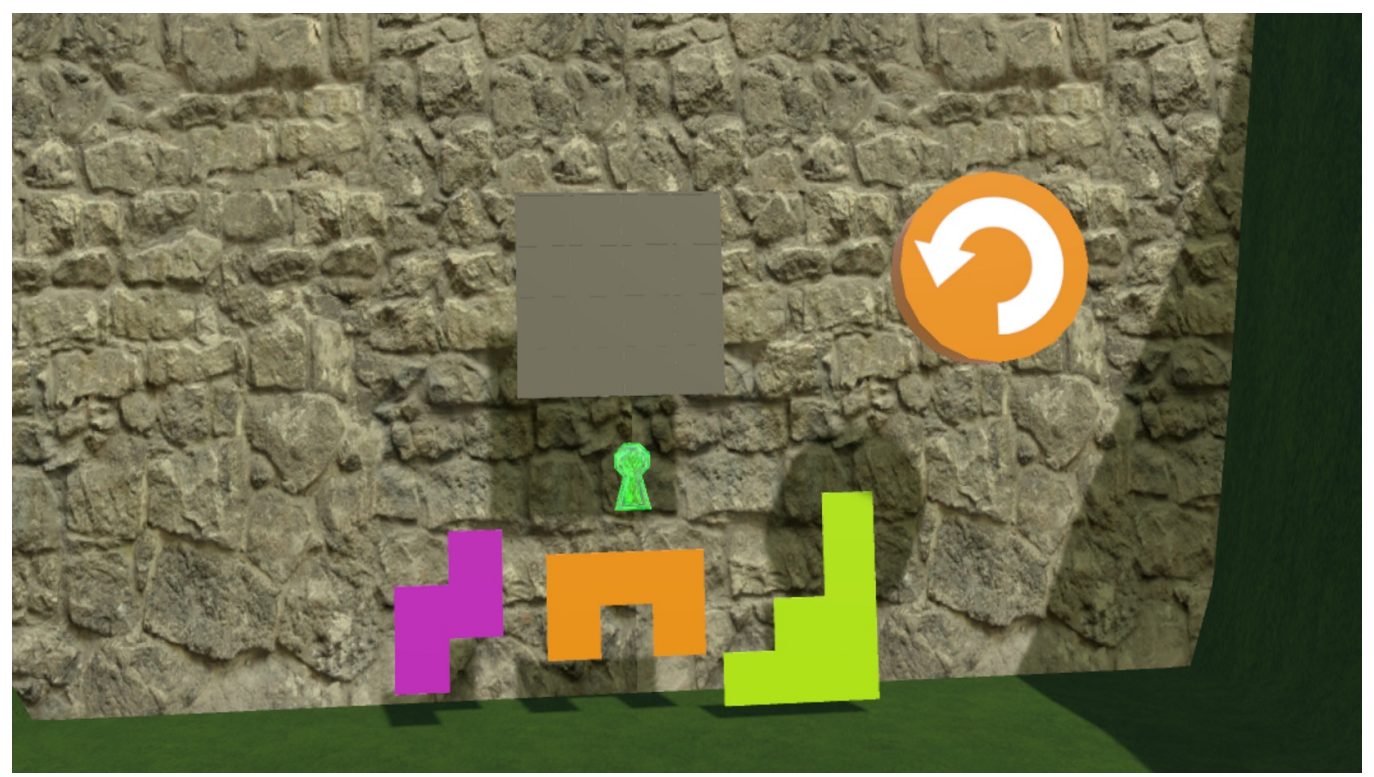

(a) A jigsaw puzzle in its initial state with a $4 \times 4$ grid and 3 pieces. The reset button can be seen on the right.

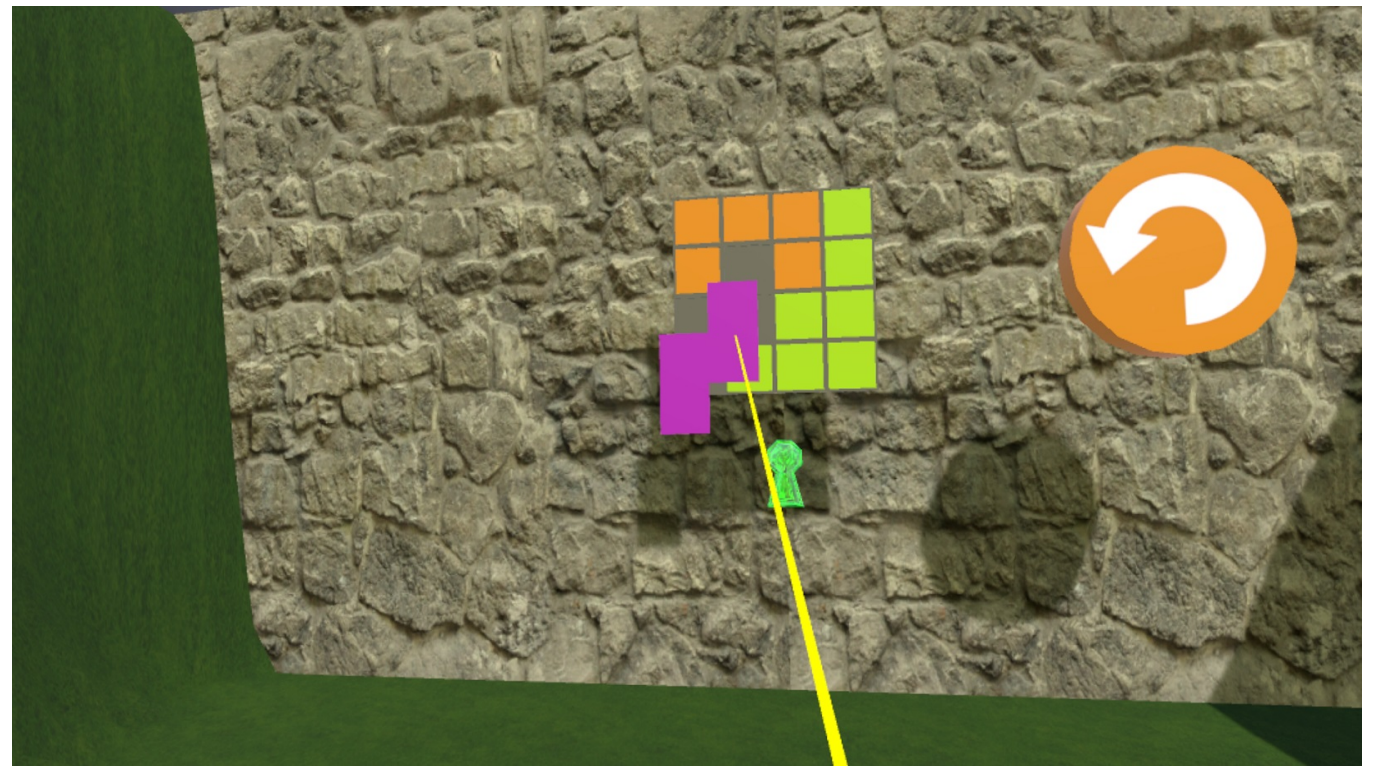

(b) An almost solved puzzle. The player is 1 piece away from completing the puzzle.

Figure 3.8: Jigsaw puzzle 


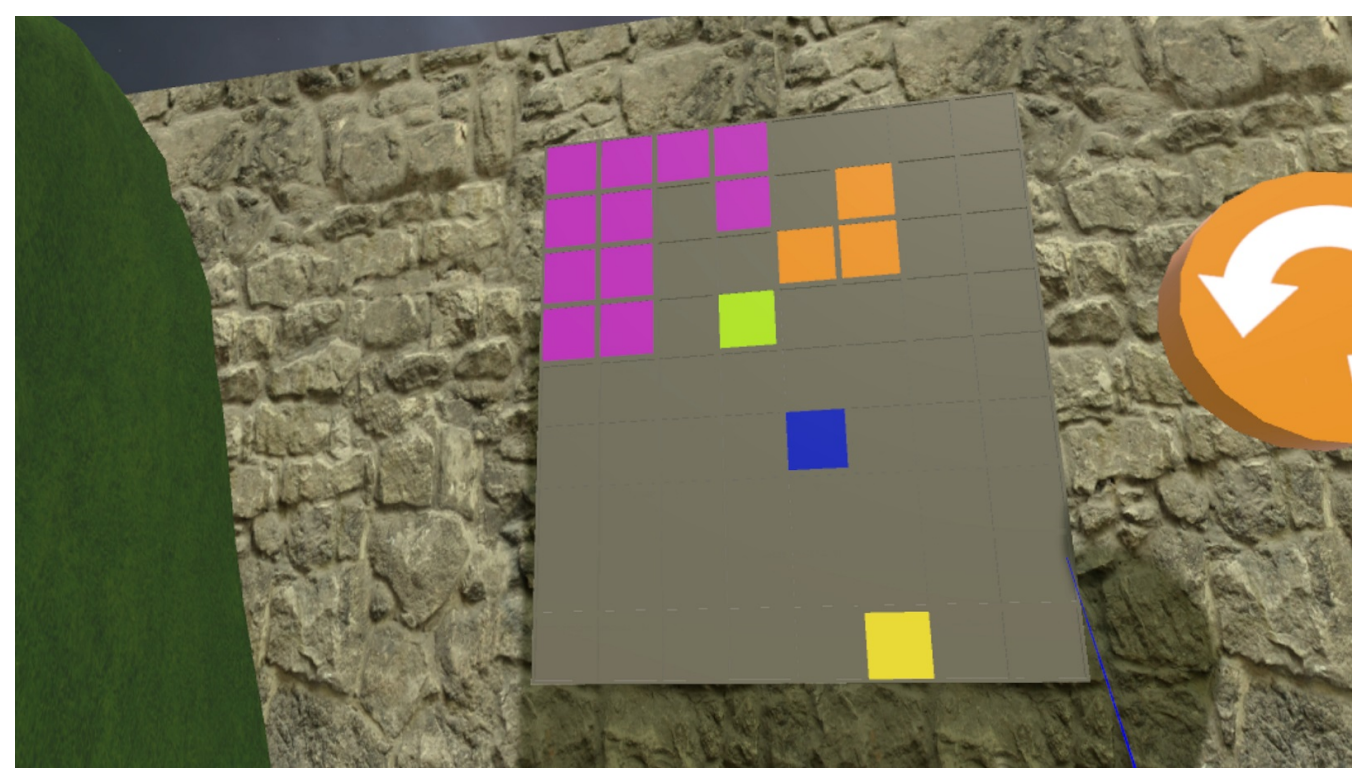

(a) A flip puzzle in its initial state with a $8 \times 9$ grid and 5 pieces. The reset button can be seen on the right.

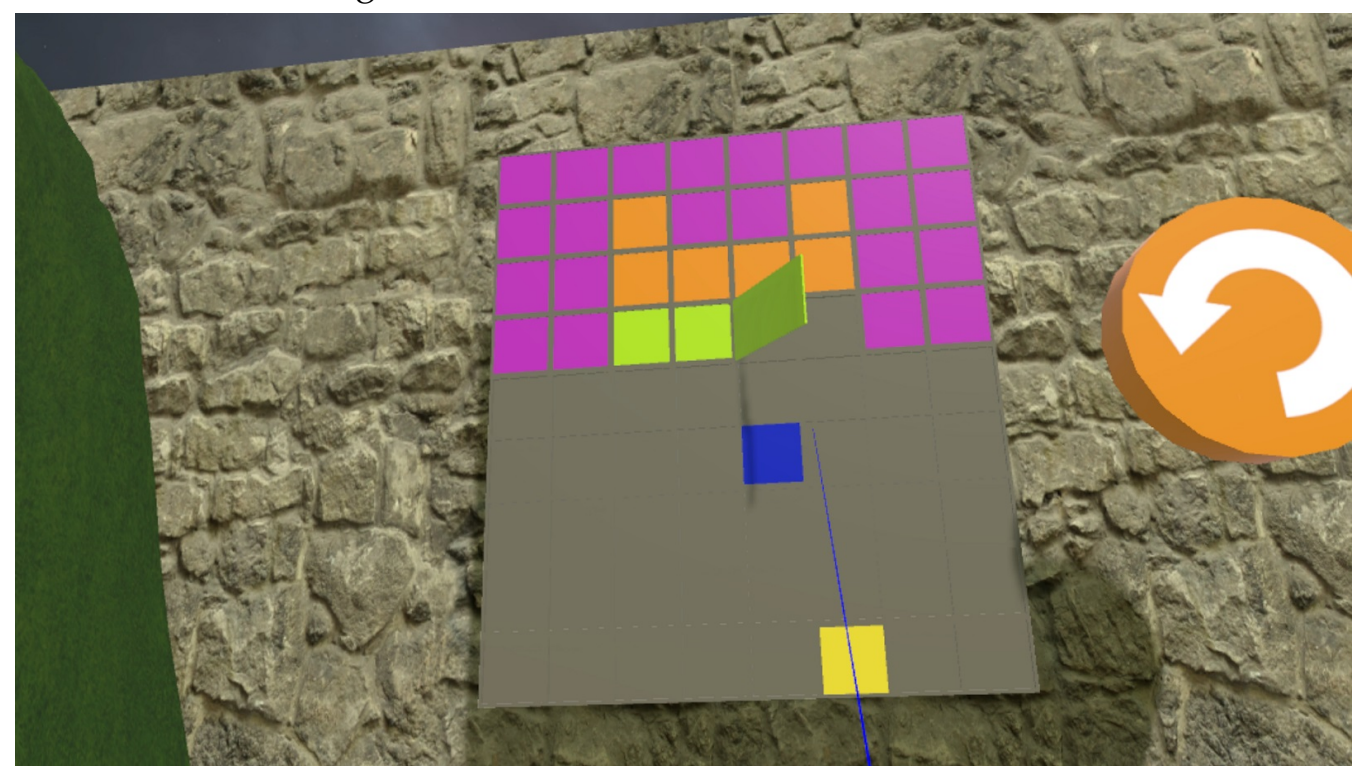

(b) A piece in the middle of a flip. The lime-green piece is flipping towards the right. The purple piece has flipped right, the orange piece has flipped left, and the lime-green piece has flipped left since the previous image.

Figure 3.9: Flipping puzzle 
target position. The goal of the puzzle is to move the key piece to the target position. Pieces can only slide around the board along its long side, and can only move when there is no other piece blocking it. The difficulty of this game arises from the non-key pieces on the board. The non-key pieces must be moved out of the way to allow for the key piece to reach the target position.

Players interact with the puzzles with the controller similar to the telekinesis magic from the physical level. A guidance pointer helps players aim at the puzzle piece they wish to move, and pull the trigger to grab it. Players cannot change magic as there is only one magic in the mental level, but players are still able to teleport.

\subsubsection{Passive Level}

The passive observation level consists of players watching relaxing 360degree videos of natural scenery in VR. The videos are real footage recorded with a 360-degrees camera. Players are unable to interact with any of the virtual environment. There are seven videos total evenly divided across 10 minutes. Players are encouraged to look around and take in as much of the scenery as possible.

\subsection{Usability Testing}

ChronicVR was demonstrated at a virtual reality conference. Conference attendees had the opportunity to play with ChronicVR in an informal setting with no constraints on level choice or time spent. This demonstration helped provide feedback on the usability of the system and helped identify bugs. Around twenty conference attendees played ChronicVR. The attendees enjoyed playing the game and had fun with the tasks and puzzles. As most of the attendees were from a computer science background, they especially enjoyed solving the logic puzzles in the mental level. No 


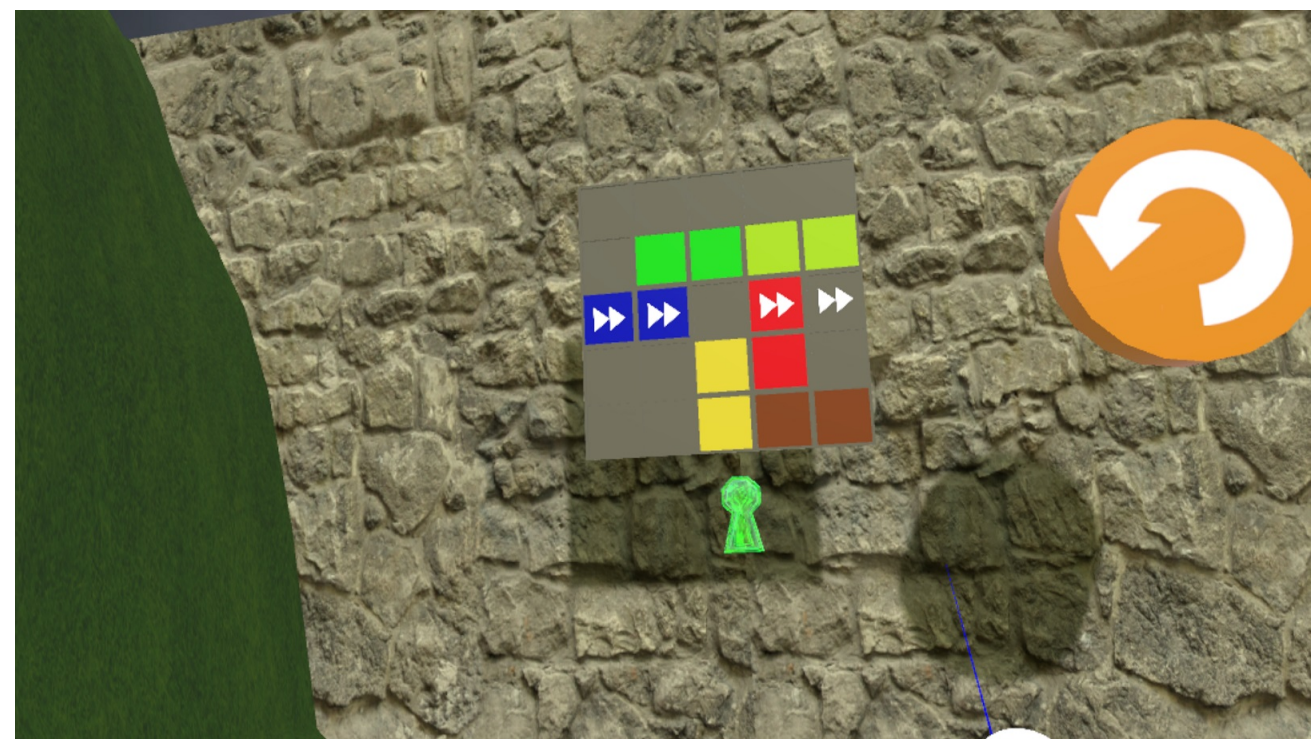

(a) A Rush Hour puzzle in its initial state with a $5 \times 5$ grid and 6 pieces. The reset button can be seen on the right. The blue piece on the left is marked with the arrows indicating that it is the key piece.

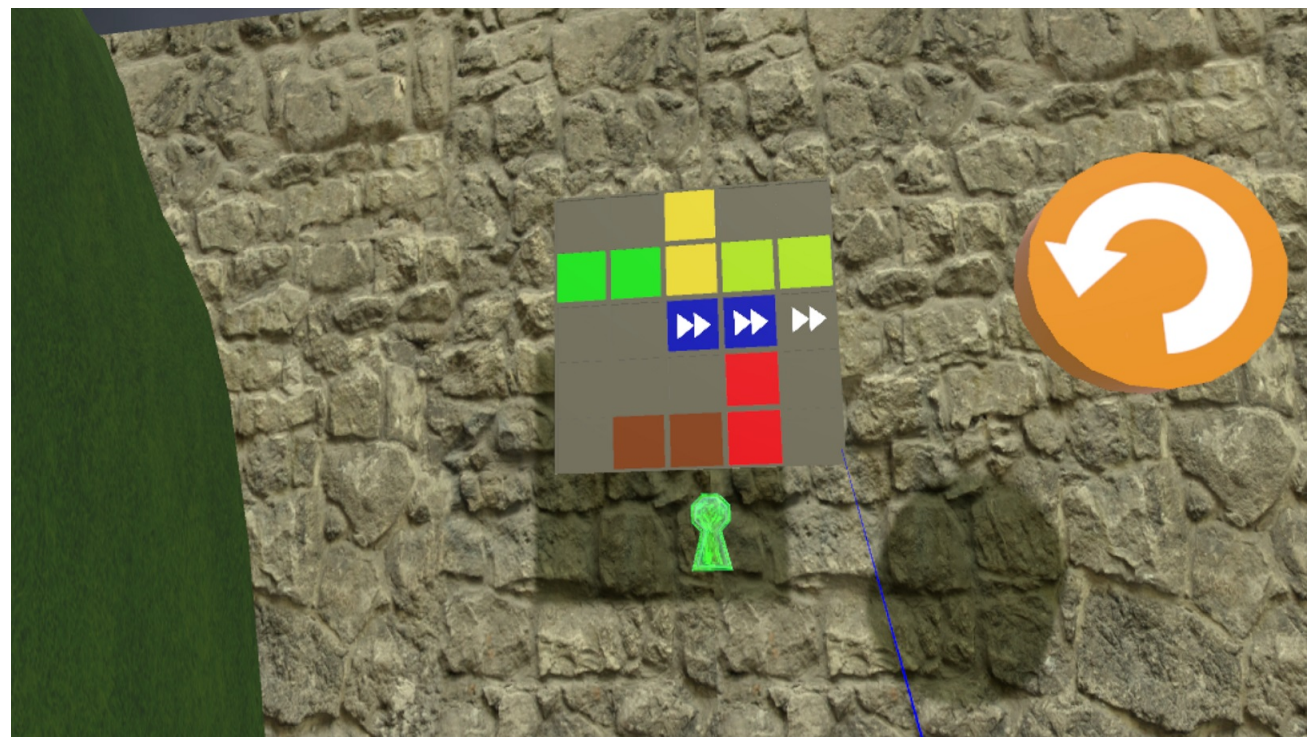

(b) A Rush Hour puzzle about to be solved. The blue key piece is one move away from the target position. The other pieces have been moved out of the way to allow for the blue piece to reach this position.

Figure 3.10: Rush Hour 
changes to the design were made to ChronicVR following the feedback received here, but the bugs identified during this conference were fixed prior to commencing the user study with chronic pain patients. The bugs identified were related to physics and user interactions with the virtual environment.

\subsection{Summary}

ChronicVR is a game designed to distract players from chronic pain. The game is divided into three levels: physical, mental, and passive. Each level focuses distinctly on one type of distraction. The goal for each level is to be engaging for the player such that they do not think about the pain. Considerations are given to accessibility issues for players who are unable to move about freely.

The next chapter discusses a user study conducted using ChronicVR. The participants of the study play all three levels of ChronicVR, and the effectiveness of each level for pain relief is measured. 


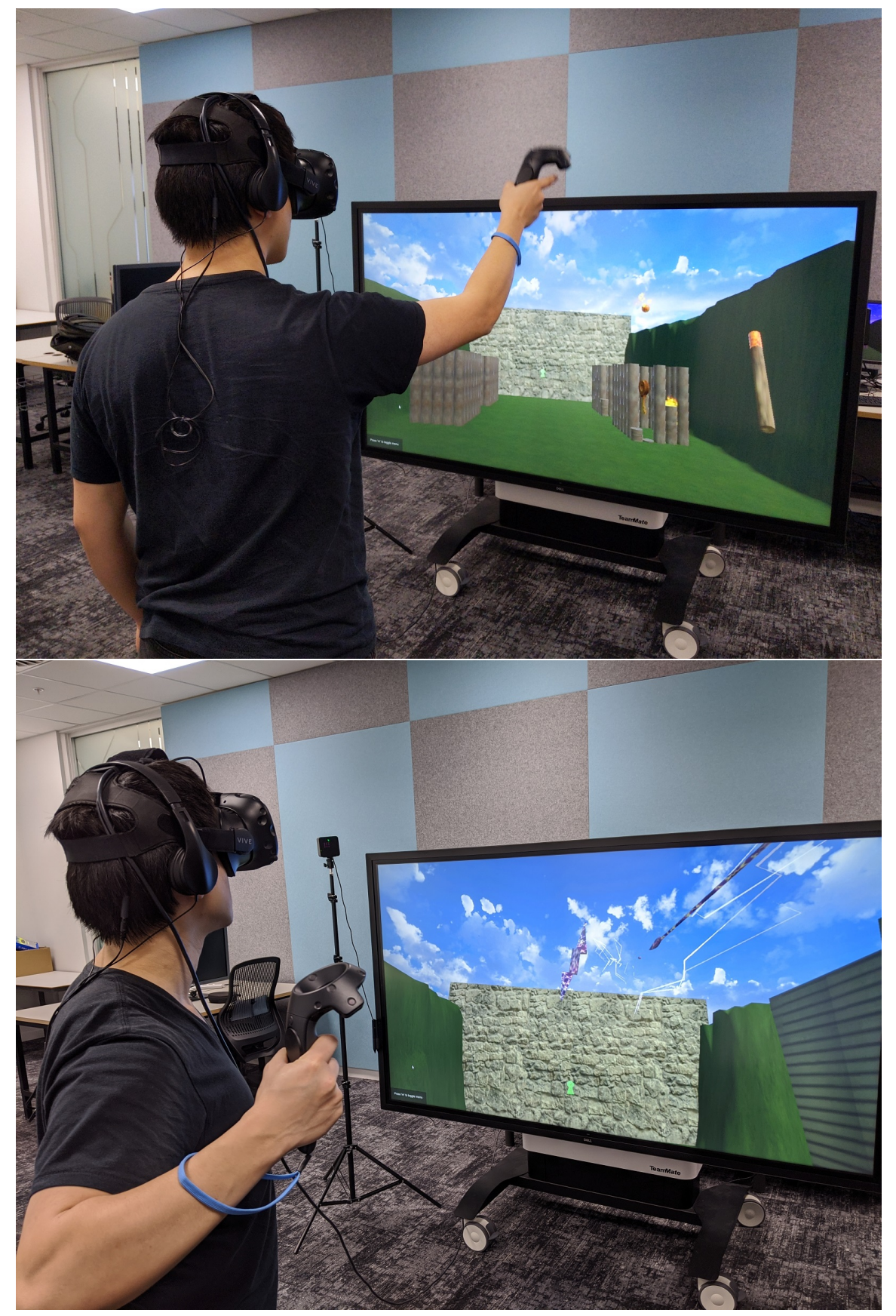

Figure 3.11: A player playing ChronicVR. The top picture shows the player throwing a fireball. The bottom picture shows the player readying a lightning arrow. 


\section{Chapter 4}

\section{User Study}

A study was conducted to understand the effectiveness of the ChronicVR to support people with chronic pain. The purpose of the study is to answer the research questions: "is active attention-diversion or passive observation more effective at managing chronic pain in VR?" and "is physically active distraction or mentally active distraction more effective at managing chronic pain?". This chapter explains the design of the user study and the details of its execution. The user study evaluated differences in pain relief between physically active distractions, mentally active distractions, and passive observations using ChronicVR, which distinctly separates the three conditions. The results from this study answer this thesis's research questions by isolating the three categories of distraction and evaluating the analgesic effects of each.

Two healthy people were recruited to perform a pilot study. The pilot study consisted of performing the main study in its entirety to examine the logistics and time constraints of the study. The pilot study participants were not in any pain, so no pain results were gathered.

The user study was approved by the Ministry of Health's Health and Disability Ethics Committees and Māori Partnership Board's Research Advisory Group Māori (RAG-M). Supporting documentation can be found in Appendix A 
The VR distraction therapy in this study was not applied against no treatment. Participants were not withheld from their usual day-to-day pain management techniques. This study was applied in addition to their usual pain management techniques. Several participants scheduled their study session immediately after their appointment with Wellington Hospital's Pain Management Services out of convenience as the study was held at the same location.

\subsection{Study Procedure}

The user study started with an introduction to the study and asking the participant to read the information sheet and sign the consent form, followed by filling out the pre-study questionnaire. The study tasks were then performed. After the study tasks were complete, the study finished with the post-study questionnaire and wrap-up. The information sheet, consent form, and questionnaires can be found in Appendix B.

An timeline of the entire study is as follows:

- Introduction and Pre-study questionnaire

- 10 minutes in task $\mathrm{A}$ - rate pain at 0 -minute, 5-minute, and 10-minute marks

- 5 minutes cooldown/rest period

- 10 minutes in task B - rate pain at 0-minute, 5-minute, and 10-minute marks

- 5 minutes cooldown/rest period

- 10 minutes in task $\mathrm{C}$ - rate pain at 0 -minute, 5-minute, and 10-minute marks

- 5 minutes cooldown/rest period 
- 10 minutes in task $\mathrm{D}$ - rate pain at 0 -minute, 5-minute, and 10-minute marks

- Post-study questionnaire and wrap-up

The entire study took up to 90 minutes, depending on how fast participants answered the questions.

\section{Introduction and Pre-study Questionnaire}

At the start, an explanation was given on the basic overview of the study and what was required of the participants. Participants were asked to read the information sheet and sign the consent form. Participants then filled in the pre-study questionnaire which gathered participant's background information consisting of gender, age, ethnicity, average daily pain, where the pain is located, what they did to self manage the pain usually, and how familiar they were with VR.

Once participants were briefed on the study and had filled out the consent form and pre-study questionnaires, a training session was given before participants started performing the study tasks.

Before the first VR task, participants were given a tutorial on wearing the headset and were informed again that they were allowed to take off the headset at any time should they feel motion sickness.

Before the physically active and mentally active tasks, participants were given a tutorial on the controls and how to play the game. This tutorial was not necessary for the passive observation level of ChronicVR as the passive observation level required no input or interaction from the participant.

\section{Study Tasks}

The study tasks consisted of using ChronicVR and a non-VR activity. There were four tasks in total: physically active distraction, mentally active distraction, passive observation, and non-VR distraction. The first three were 
completed in ChronicVR, and the non-VR distraction was an activity that the participant likes to do regularly, such as reading or listening to music. The four tasks were completed by a within-subjects randomised crossover study [14]. Every participant completed every task in a randomised order.

Each task lasted 10 minutes, regardless of how much of the task was completed. A 5-minute cooldown period was given between each task. This time was given so that participants do not spend an extended period using VR, allowing them to rest their eyes as well as recover from any onset of motion sickness. Participants were asked to subjectively rate their pain at the beginning, middle, and end of each of the four tasks, resulting in 12 pain ratings per participant. The mid-session pain rating was asked at the 5-minute mark.

\section{Wrap-up}

At the end of the study, participants were asked about their experience using virtual reality and playing the game through the post-study questionnaire. The post-study questionnaire consisted of four questions:

- Did you enjoy the VR experience?

- Would you use VR for pain relief in your daily life?

- Would you recommend others to use VR?

- Any other feedback/comments?

Participants were given a supermarket voucher worth NZ $\$ 10$ as an honorarium.

\subsection{Data Collection and Analysis}

Participant background information was collected in the pre-study questionnaire. During the study, participants performed four tasks and were 
asked to verbally rate their pain at the beginning, middle, and end of each task, resulting in 12 pain ratings per participant. After the study, participants filled in a post-study questionnaire about what they thought of the experience. All questionnaires were on paper, with the pain ratings wrote down for the participant once they expressed their pain rating verbally. The questionnaires used in the study can be found in Appendix B

As the participants were allowed to stop using the VR headset at any onset of discomfort from motion sickness, measurements of the severity of motion sickness such as the Kennedy and Lane's Simulator Sickness Questionnaire were not used [70].

\subsubsection{Pain Rating Scale}

Russo and Brose [102] stated that "Nociceptive pain and suffering are all internal to the organism and cannot be measured directly." Meaning that pain is subjective to each individual, and cannot be measured objectively. Therefore, a self-report measure was used where participants were asked to rate their pain on a scale from 0-10 [117]. This measure gave a value for that person's pain perception [81]. Participants were asked to rate their pain ratings on a descriptive 0-10 scale before, during and after each task. These ratings were the main results of the user study.

There have been arguments that using a number scale to represent pain can be misleading [35]. Since pain is subjective, a pain rating of 7 could mean different things for different people. Patients also do not like to distil down their experience down to a number or a frowny face. For this study, for each number to have different meanings for different people is not a significant concern, as this project is more focused on the changes in pain ratings. So an 8 reducing down to 6 is no different from a 6 down to 4 . Although there are also arguments against the use of Likert-like scales in empirical research due the the assumption of equidistant data points [78].

Regardless, Kaiser Permanente's 2008 "0-10 scale of pain severity" is 
used $^{1}$. In this scale, a description was provided for each number so that that meaning would be associated with each number rather than a vague scale. The descriptions that were given concerns the impact of the pain on the day-to-day lives of the participant and were given in a more objectively measurable way. This description provides a better reference point for participants which also helps them decide on the rating. Table 4.1 shows the descriptions that were given.

The NASA Task Load Index (NASA-TLX), while a widely used tool for assessing cognitive load [48], was not used in this study. The NASA-TLX is useful for assessing how difficult it was for one to complete a given task. It would be unsuitable for this study as both the physical and mental levels of ChronicVR increase in difficulty as the participant progresses through the game, the passive observation level requires no input or interaction from the participant, and the non-VR task is an ordinary recreational activity for the participant.

\subsubsection{Analysis}

The participant pain ratings were preprocessed in preparation for statistical analysis. The three pain ratings for each task (start, middle, and end) were subtracted from each other to give three new numbers: Middle-Start, End-Start, End-Middle. These values show the changes in pain while performing the task. A positive number indicates a drop in pain, which is the desired result.

The decreases were tested for normality with a Shapiro-Wilk test [99]. As the decreases were not normally distributed, a Friedman test was used to determine if decreases in pain between the four tasks were significantly different [40]. The Friedman test is used as the comparison is between more than two matched groups (physical, mental, passive, non-VR) and the data is not normally distributed. The Friedman test is backed up

$\sqrt[1]{\text { https: //healthy.kaiserpermanente.org/ }}$ 
$0 \quad$ No Pain - I have no pain.

1 Minimal - My pain is hardly noticeable.

2 Mild - I have a low level of pain. I am aware of my pain only when I pay attention to it.

3 Uncomfortable - My pain bothers me but I can ignore it most of the time.

4 Moderate - I am constantly aware of my pain but I can continue most activities.

5 Distracting - I think about my pain most of the time. I cannot do some of the activities I need to do each day because of the pain.

6 Distressing - I think about my pain all of the time. I give up many activities because of my pain.

7 Unmanageable - I am in pain all the time. It keeps me from doing most activities.

8 Intense - My pain is so severe that it is hard to think of anything else. Talking and listening is difficult.

9 Severe - My pain is all that I can think about. I can barely talk or move because of the pain.

10 Unable to Move - I am in bed and can't move due to my pain. I need someone to take me to the emergency room to get help for my pain.

Table 4.1: Descriptive Pain Scale. The description associated with each pain rating. 
by a Wilcoxon signed-rank test [122] with p-values adjusted using the Holm-Bonferroni method [66]. The Wilcoxon signed-rank test is a pairwise comparison of significant difference. As there are four groups in the study, six pairwise comparisons are required to test every group against another. Therefore p-values must be adjusted to mitigate the multiple comparisons problem.

A linear mixed-effects model was also created to examine if different aspects of participants (gender, age, etc.) had significant influences on pain ratings.

\subsection{Study Participants}

Participants were recruited from chronic pain patients who were not requiring medical assistance (i.e. on a typical day), having had a daily average pain intensity score of 4 or more on the $0-10$ scale (Section 4.2.1) for the past three months or more.

As ChronicVR is an audio-visual experience, blind or hard of hearing patients would be unable to utilise the VR headset properly and were therefore excluded from the study. No patients fell under this category. Participants with glasses were not excluded.

Participants were required to be physically present for the study. The study could not be conducted remotely. This in-person requirement was an issue with six would-be participants who were unable to attend the study during their scheduled time. None of the six came back at a later date.

\section{Participant Recruitment}

Recruitment was difficult due to the nature of the target group. Many people were busy, cannot easily physically attend at the hospital, or were having a bad day on the day of the appointment. Pain differs day by day, 
pain ratings fluctuate. This problem is not limited to this study, but the pain clinic as a whole. Patients often do not show up for their appointment as on the day the pain is too bad.

Recruitment was done via flyers, social media, word of mouth from the staff at the pain clinic, and meeting patients face-to-face either in the waiting room of the pain clinic as they came in for their appointment with the clinic or as part of a group programme on pain management run by the pain clinic. Flyers were posted in the pain clinic, outpatient department of Wellington Hospital, and outside the university's student health centre on campus. Flyers were also emailed to eleven physios and two pain management services around Wellington, but few replied so it is unknown how many were put up.

At least 120 people were spoken to face-to-face during the recruitment period. An unknown number (minimum 30, judging from the number of contact information slips taken from the flyers) of other patients were made aware of the study through the other means listed above, only two established contact but was unable to find time to participate.

Out of the 120 people spoken to face-to-face, around 50 people declined to participate in the study. Almost all reasons for declining to participate were one of the following: uninterested in the technology, their schedule was too busy to fit in the study, concerns regarding motion sickness, and not being able to be physically present to participate in the study. As Pain Management Services is a regional service, many patients were from the wider region coming into the city specifically to receive the service. It would have been very inconvenient for them to come back again to participate in the study. Around 50 others expressed interest and willingness to participate in the study, and contact details were exchanged to arrange a time for the study. However, very few participants established contact to schedule a time. As further contact was not established with the rest, reasons for not participating are unknown.

Eleven people scheduled a time to participate during the first face to 
face meeting. Five attended the study at their scheduled time. Six withdrew on the day of the study. One withdrew due to external factors (called into work), the rest were not willing or not able to go to the hospital due to personal reasons. Five withdraws declined to reschedule, one kept contact but was unable to find a suitable time.

Four people agreed to participate on the day of the initial meeting after their appointment with the pain clinic.

In summary, eight participants attended a scheduled time. Four participated on the day of the first meeting after their appointment. Two participated on the day of an appointment on the second meeting.

\subsection{Summary}

This chapter discussed the user study that was conducted to answer the research questions. The user study consisted of evaluating ChronicVR with fourteen chronic pain patients. Participants played all three levels of ChronicVR as well as a non-VR control task in a randomised order. Each session lasted 10 minutes, with a 5-minute break in between. Participants were asked to rate their pain at the start, middle, and end of each task. These pain ratings form the primary results of this study. The next chapter presents the results of this user study. 


\section{Chapter 5}

\section{Results}

This chapter presents the results of the user study from Chapter 4 Participants completed each of the four tasks in a random order, rating their pain levels at the beginning, middle, and end of each task. These pain ratings are presented in $\S 5.2$ as the main results of this study. Results from the post-study questionnaire as well as observations and verbal feedback from participants are presented in $\S 5.3$.

\subsection{Participants}

Fourteen participants completed the study. Fourteen was considered adequate as it is greater than the most common sample size of twelve in $\mathrm{CHI}$ publications [15]. Gender, age, average daily pain, pain regions, and familiarity with virtual reality of participants are shown in Table 5.1. Average daily pain is rated on a scale from 0 to 10 (\$4.2.1). Pain regions are divided into the head $(\mathrm{H})$, neck $(\mathrm{N})$, torso $(\mathrm{T})$, upper limbs or arms and hands $(\mathrm{U})$, lower limbs or legs and feet (L).

Seven participants were female, five were male, and two were nonbinary. Twelve out of fourteen participants were under the age of 40 . Eleven out of fourteen participants daily pain rating average between 4 and 6 . The other three participants had average daily pain ratings of 7 , 
9, and 9.5. Five participants had pain in the head, seven participants had pain in the neck, every participant had pain in the torso, seven participants had pain in the upper limbs, and ten participants had pain in the lower limbs. Three participants were not at all familiar with VR, eight participants were a little familiar with VR, and three participants were somewhat familiar with VR. No participant reported that they were very or extremely familiar with VR.

The frequency of participants' self-management techniques is shown in Table 5.2. Nine out of fourteen participants regularly use medication or drugs to self manage the pain. The second highest is listening to music or spoken media with five participants. All other techniques have three or fewer participants utilising it.

\subsection{Quantitative Results}

This section presents the results of the pain ratings presented by the participants at the start, middle, and end of each task: the four tasks being physical, mental, passive observation, and non-VR.

Table 5.3 shows the mean and standard deviation of pain ratings for each task, measured at the start, middle, and end of the task. Figure 5.1 presents the Pain Rating column of Table 5.3 graphically, with the first, second, and third data point representing the average pain rating at the start, middle, and end of each task respectively. Error bars show one standard deviation above and below the mean. Although the pain was rated on a 0-10 scale, $y$-axis has been adjusted to a more suitable range to display this data better.

The data was processed, and the decrease in pain ratings was calculated for each task. The three calculations were Middle-Start, End-Start, and End-Middle. A larger value is better as it indicates a larger decrease in pain. These results are the focus of the statistical analysis later in this section. The values are provided in the last two columns of Table 5.3. Fig- 


\begin{tabular}{|c|c|c|c|c|c|}
\hline PID & Gender & Age & $\begin{array}{c}\text { Average } \\
\text { Daily Pain }\end{array}$ & $\begin{array}{c}\text { Pain } \\
\text { Regions }\end{array}$ & $\begin{array}{c}\text { Familiarity } \\
\text { with VR }\end{array}$ \\
\hline \hline 01 & Female & $30-39$ & 5.5 & HNT - L & A little \\
\hline 02 & Male & $30-39$ & 5.5 & HNTUL & A little \\
\hline 03 & Female & $20-29$ & 5 & - - TUL & A little \\
\hline 04 & Female & $40-49$ & 5 & - - T- - & A little \\
\hline 05 & Male & $40-49$ & 6 & - - T - L & Somewhat \\
\hline 06 & Male & $50+$ & 5.5 & - - T- - & Not at all \\
\hline 07 & Male & $50+$ & 6 & HNTUL & Somewhat \\
\hline 08 & Female & $20-29$ & 4 & - - TUL & Somewhat \\
\hline 09 & Female & $20-29$ & 4 & - - T - - & Not at all \\
\hline 10 & Female & $30-39$ & 4 & HNTUL & Not at all \\
\hline 11 & Female & $20-29$ & 9 & - NT - L & A little \\
\hline 12 & Male & $20-29$ & 9.5 & - NT - - & A little \\
\hline 13 & Non-binary & $20-29$ & 7 & - - TUL & A little \\
\hline 14 & Non-binary & $20-29$ & 6 & HNTUL & A little \\
\hline
\end{tabular}

Table 5.1: Participant background information. Average daily pain is on a scale from 0 to 10 (\$4.2.1). Pain regions are divided into the head $(\mathrm{H})$, neck $(\mathrm{N})$, torso $(\mathrm{T})$, upper limbs or arms and hands $(\mathrm{U})$, lower limbs or legs and feet (L). 


\begin{tabular}{|c|c|}
\hline Technique & Frequency \\
\hline \hline Medication/drugs & 9 \\
\hline Listening to music/spoken media & 5 \\
\hline Physical exercise & 3 \\
\hline Watching visual media & 3 \\
\hline Meditation/ quietness & 2 \\
\hline Rest/sleep & 2 \\
\hline Talking/socializing & 1 \\
\hline Reading & 1 \\
\hline Heat & 1 \\
\hline Eat healthy & 1 \\
\hline Mobility tools (wheelchair) & 1 \\
\hline Mental puzzles & 1 \\
\hline
\end{tabular}

Table 5.2: Participant self management techniques

ure 5.2 presents this data graphically.

Physical, mental, and passive observation tasks all saw a drop in pain ratings in the middle of the task. The mean pain rating dropped by 0.750 , 0.643 , and 0.393, respectively. At the end of the physical and mental tasks, the mean pain rating went back up by 0.214 for physical and 0.036 for mental. However, in the passive observation task, the mean pain rating decreased even further by 0.107 . In the non-VR task, mean pain ratings increase both in the middle of the task and at the end.

For the three VR tasks (physical, mental, and passive), pain rating is lower at both the middle and end of the task when compared to the start. Whereas for non-VR tasks, pain ratings went up at each step. This result was affected by less than half of the participants, as 10 participants saw no change in pain ratings between the start and middle of the non-VR task, 7 of whom saw no change between the start and end either. This result is illustrated in Figure 5.3, where the median (and for two of them, 


\begin{tabular}{|c|c|ccc|}
\hline \multirow{4}{*}{ Task } & Time & $\begin{array}{c}\text { Mean (SD) } \\
\text { Pain Rating }\end{array}$ & $\begin{array}{c}\text { Mean (SD) } \\
\text { Decrease from Start }\end{array}$ & $\begin{array}{c}\text { Mean (SD) } \\
\text { Decrease from Mid }\end{array}$ \\
\hline \multirow{4}{*}{ Physical } & Start & $4.250(0.872)$ & & \\
& Mid & $3.500(1.271)$ & $0.750(0.915)$ & \\
& End & $3.714(1.528)$ & $0.536(1.184)$ & $-0.214(1.139)$ \\
\hline \multirow{4}{*}{ Mental } & Start & $3.857(1.393)$ & & \\
& Mid & $3.214(1.369)$ & $0.643(0.663)$ & $-0.036(0.909)$ \\
& End & $3.250(1.590)$ & $0.607(1.243)$ & \\
& Start & $4.321(1.203)$ & & $0.107(0.626)$ \\
\hline \multirow{3}{*}{ Nonvive } & Mid & $3.929(1.269)$ & $0.393(0.944)$ & \\
& End & $3.821(1.381)$ & $0.500(1.109)$ & $-0.179(0.504)$ \\
\hline & Start & $3.679(1.137)$ & & \\
& Mid & $3.714(0.848)$ & $-0.036(0.634)$ & \\
& End & $3.893(1.147)$ & $-0.214(0.995)$ & \\
\hline
\end{tabular}

Table 5.3: Mean and standard deviation of pain ratings at the start, middle, and end each task. For the physical, mental, and passive observation tasks, participants played through the respective level in ChronicVR. For the non-VR task, participants engaged in an ordinary activity that they liked such as reading or listening to music $(\S 4.1$.

interquartile range) is 0 for all three time-point comparisons. The reasons for the increase in pain varies between participants. For some participants, it was due to sitting down and not moving for too long of a period. For one participant, it was due to the effects of medication, which was applied in an appointment before participating in the study, wearing off.

For physical tasks, mean pain ratings increased between the middle and end of the task. This result was also due to three outliers, as shown in Figure 5.3. One participant's pain ratings increased by 2.5, while two others increased by 2 . Seven participants saw no change in pain ratings 


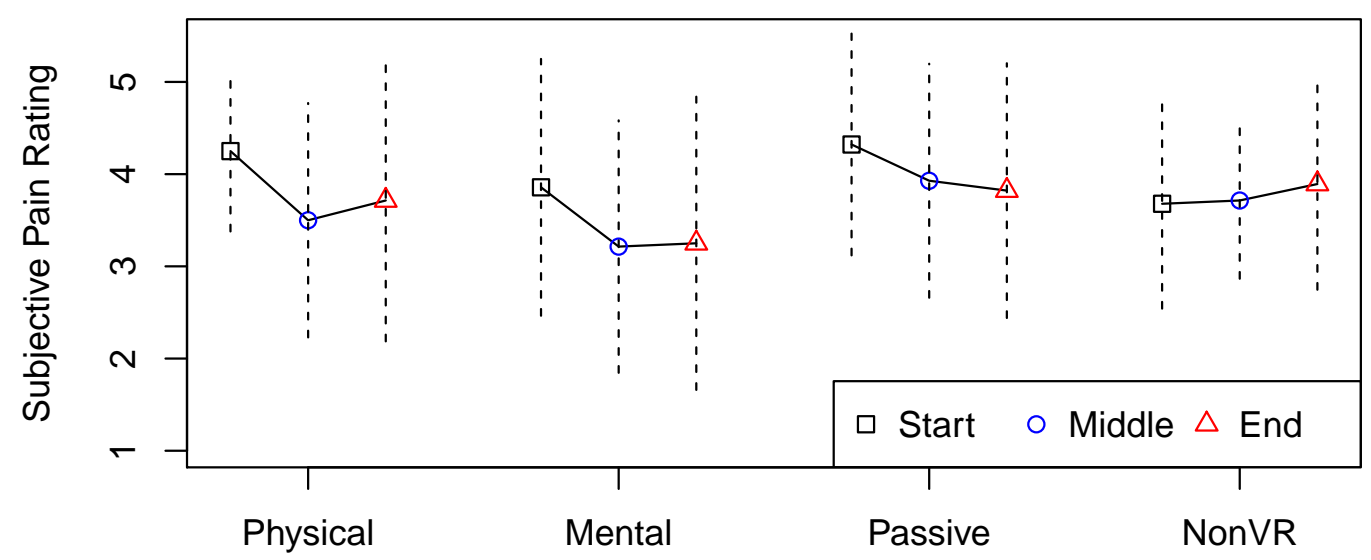

Figure 5.1: Mean \pm 1 standard deviation of pain ratings at the start, middle, and end each task.

between the middle and end of physical tasks, and four saw a decrease in pain. The pain increased due to participants having difficulty with later (and thus more difficult) levels in the game. Performing repeated motions for ten continuous minutes also caused pain for some participants. The pain was different for different participants. Some had tired arms from using the controllers, and some had tired legs from standing for $10 \mathrm{~min}$ utes.

In the physical and non-VR tasks, pain ratings increased between the middle and end of the task. Average pain increased by 0.214 in the physical task and 0.179 in the non-VR task. Pain also went up between the middle and end of the mental task, but not by as much as physical. The pain increased by 0.036 between the middle and end of the mental task. Only in the passive observation task did pain continue to decrease between the middle and end of the task, dropping by 0.107 on average.

Statistical analysis was conducted using $R$ version 3.5.2 [98]. A ShapiroWilk test was used to see if the decreases in pain were normally distributed. All three of Middle-Start $(p<0.001)$, End-Start $(p<0.01)$, and End-Middle $(p<0.001)$ were found to be significantly different from a normal distribution. 


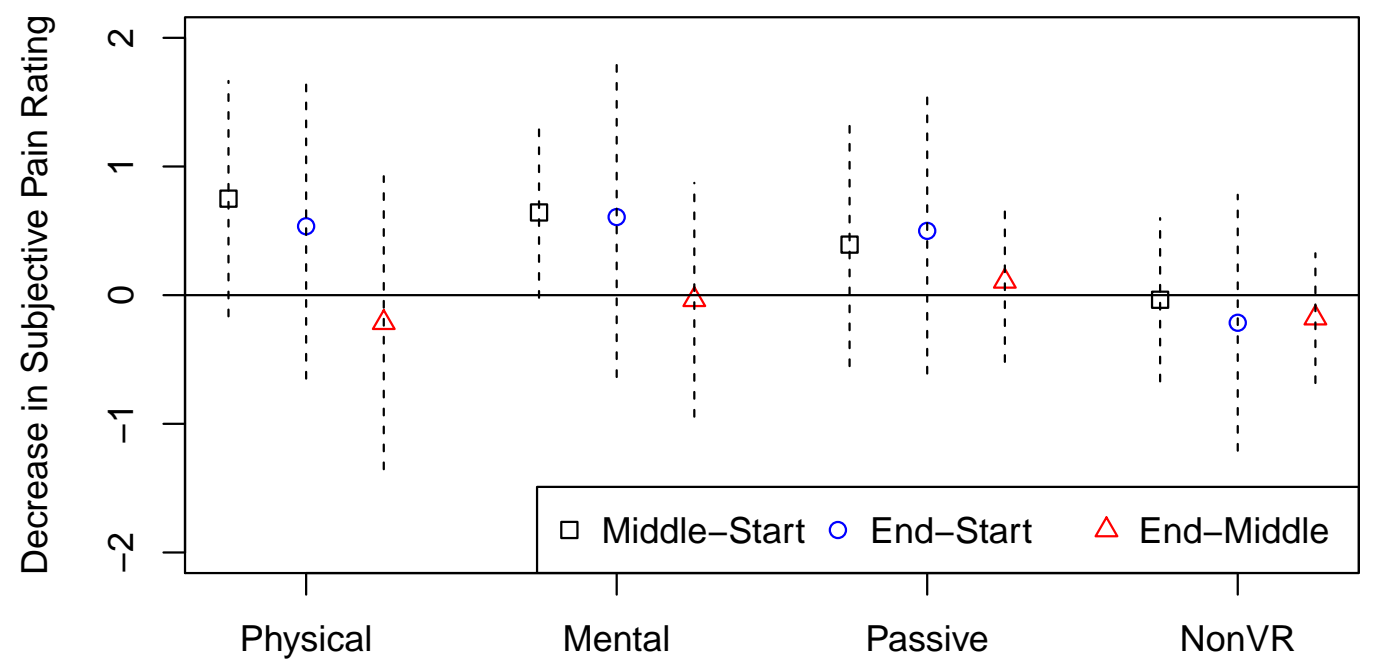

Figure 5.2: Mean \pm 1 standard deviation of the decreases in pain ratings between start and middle, start and end, and middle and end. A higher value indicates a higher decrease in pain ratings.

As the results are not normally distributed, a Friedman test was used to determine if decreases in pain between the four tasks were significantly different. All three of Middle-Start $(p=0.103)$, End-Start $(p=0.0838)$, and End-Middle ( $p=0.769$ ) were found to be not significantly different between tasks. These results were validated by a Wilcoxon signed-rank test with p-values adjusted using the Holm-Bonferroni method.

Although on average tasks in VR reduced more pain than non-VR, due to the spread and range of the results, there are no statistically significant differences between the four tasks.

A linear mixed-effects model was created using $\mathrm{R}$ version 3.5.2 [98] and the lme4_1.1-21 package [7]. Gender, age, the order of the task, participants' average daily pain, and their familiarity with VR were set as the fixed effects. Participants were set as a random effect. This model was used to examine if different aspects of participants had significant influences on pain ratings.

The car _3.0-7 package [38] was used to perform an analysis of deviance 


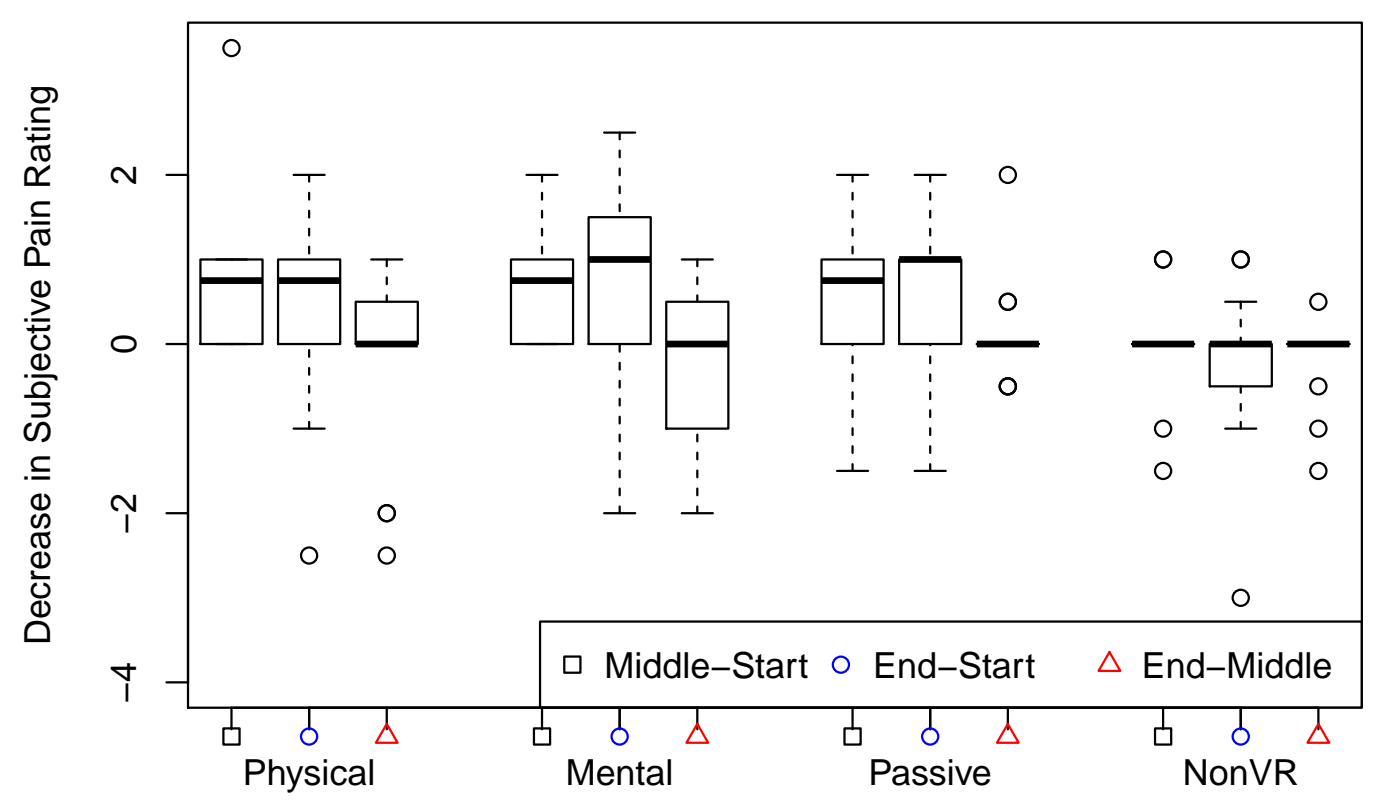

Figure 5.3: Boxplot of the decreases in pain ratings between start and middle, start and end, and middle and end, showing the median, quartiles, and outliers. A higher value indicates a higher decrease in pain ratings.

using Type II Wald chi-square tests to determine which fixed factors had a significant influence on pain ratings. None of the factors had significant influence on the pain ratings. Age $\left(\chi_{1}^{2}=0.663, p=0.415\right)$, gender $\left(\chi_{2}^{2}=\right.$ $1.464, p=0.481)$, session $\left(\chi_{1}^{2}=2.683, p=0.101\right)$, average daily pain $\left(\chi_{1}^{2}=\right.$ $0.071, p=0.789)$, familiarity with VR $\left(\chi_{1}^{2}=0.519, p=0.471\right)$, head pain $\left(\chi_{1}^{2}=0.647, p=0.421\right)$, neck pain $\left(\chi_{1}^{2}=0.572, p=0.449\right)$, upper limb pain $\left(\chi_{1}^{2}=2.616, p=0.106\right)$, lower limb pain $\left(\chi_{1}^{2}=2.068, p=0.150\right)$ were found to have no significant impact on pain ratings. Torso pain was not included in the model as every participant was reported to have torso pain, so there are no participants without torso pain to compare against. 


\subsection{Qualitative Results}

This section presents a summary of the post-questionnaire responses, observations made during the studies, as well as general feedback.

\section{Feedback on ChronicVR and Virtual Reality for Pain Management}

In the post-study questionnaire, all participants reported that they enjoyed the experience. Reoccurring concepts are novel, fun, and a good distraction. Some quotes include:

"It's lots of fun." —PID 01

"A great experience." - PID 04

"A good distraction from my pain." -PID 04

"A novel approach." -PID 05

"I hadn't tried it before and it was fun." -PID 09

"The games were really fun and my pain dropped from a 6/10 to a 0.75/10." -PID 11

Twelve of fourteen participants would use VR as part of their day to day pain management, and all reported that they would recommend others to use VR. However, many participants cited concerns regarding the cost and availability of the hardware.

"If I had regular access to [VR], I'd certainly incorporate it into my pain management routine." -PID 01

Two participants had pain in the arms that increased due to waving the controllers around.

No participant reported any motion sickness. 


\section{Feedback on Headset Weight}

Four participants reported that the headset was heavy, with two participants who had pain in the neck area experienced increased stress from the weight. Participants said in the feedback at the end:

"Should have neck brace to offset [the] weight of the VR goggles, spe-

cific to neck pain." -PID 07

"I found the headset was very heavy for my neck." -PID 09

The weight was manageable for other participants with one participant reporting that

"The headset is a lil heavy but the brain games made me forget about it." -PID 14

\section{Feedback on ChronicVR}

Two participants particularly enjoyed using the fireball magic to burn down logs in the physical level (\$3.2.4). One of them said that

"Setting things on fire is very therapeutic." -PID 01

Two participants commented on the features of ChronicVR that was designed for pain management. Teleporting for accessibility and reminding players to take deep breathes to aid relaxation.

"Being able to ... teleport instead of being required to move around was a great plus!" -PID 08

"I liked the reminders to breathe. Wish more games did that." -PID 14

Two participants suggested natural sounds or meditation audio during the passive observation tasks. The same music was played across every level of ChronicVR to maintain consistency (\$3.2.2). 
"Nature sounds in the video section could add to the immersion."

-PID 01

"I would [use it] if it had natural sounds ... or guided meditation for the audio." -PID 03

Participant preference for active distraction or passive observation was divided. One participant reported that

"I liked the scenery part the most." - PID 03

While other participants reported that having an activity to focus on was most effective at pain management

"I found that during the first 2 sessions when I had to engage in the activities that my pain was significantly less." -PID 06

"Ability to interact with the environment or otherwise have a purpose or task was crucial for effectiveness." -PID 08

\subsection{Discussion}

The results for physical and mental levels are consistent with previous chronic pain research $(\$ 2.5 .3)$ in that pain decreased during VR sessions, but after the session was over the pain revert up. However, for the passive observation level, the pain decreased between the start and middle and decreased even further between the middle and end. The decrease between the middle and end could be due to the relaxing nature of the task continuing after the task was completed. Both physical and mental are active distractions. Once the task was completed, the distraction finished. However, with a relaxing activity like the passive observation level, the relaxation continues after the VR session. The gap between the end of the task and when the pain is rated is minimal, merely the time it takes to take off the headset.

The research questions of this thesis are: 
RQ1: Is active attention-diversion VR content more effective at managing chronic pain than passive observation VR content?

RQ2: Within active attention-diversion VR content, is physically active or mentally active more effective at managing chronic pain?

To answer RQ1, active attention-diversion VR content is more effective while the patient is actively using VR and engaging with the content. Once the patient has taken off the headset, their pain reverts to previous values. Whereas with passive observation VR content, if the content is relaxing, the relaxation experience by the patient continues after the VR session has ended. Participant preference between active attention-diversion and passive observation is also divided, with some participants preferring to be actively engaged in the game while others prefer to relax and watch videos.

To answer RQ2, physically active and mentally active distraction yielded remarkably similar results in the 10-minute session. Should the session have gone on for, say, 20 minutes, some participants may experience increased pain and stress as they tire. Some participants did begin to tire towards the end of the 10-minute session. Over longer sessions of 20 to 30 minutes, mentally active might prove more effective than physically active as mentally active requires less stamina. However, it is hard to say what the effects of long-term use on pain would be. Should a patient play physically active distraction content for 10 minutes every day, they can potentially become more comfortable with their body as they explore their full range of motion, and result in lower pain ratings even outside of VR. This longitudinal exposure is an area worthy of further exploration as part of future work.

Although the results between the four tasks were not significantly different when analysed with a Friedman test, all participants reported a positive experience with VR. While it is a novel experience for some, pre- 
vious research has shown that repeated exposure does not diminish the results [42, 58, 59, 103, 113].

ChronicVR divided up physically engaging content, mentally engaging content, and passive observation content into their distinct level to answer the research questions. While this division may work for players who strongly prefer one type over the other two, the distinction introduces a lack of variety. The three types of content should be used together cohesively to increase the engagement of the game. If a well-designed game has a player performing a physical task one moment and solving a mental puzzle the next, and having a relaxing break with passive observation content from time to time, it will draw in players' focus and attention, making them continuously wonder what would be next. Although the VR tasks did not significantly decrease participants' pain ratings, a better designed, more engaging game would improve the effectiveness of VR for pain relief.

Music was played during the passive observation task, the same music as the physical and mental levels (\$3.2.2). Two participants reported that they would prefer to have the natural sound of the video or a guided meditation. Natural sound playing as part of the video environment would strengthen immersion and provide a stronger sense of presence. It was established that a stronger sense of presence led to stronger pain relief (§ 2.5.6). Playing guided meditation audio would lead to increased relaxation in the patient. Patients would also be able to use the opportunity to learn meditation techniques that they can apply outside of VR ( $\$ 2.5 .5)$. Teaching patients self-management techniques inside VR also ties back to the design principles established with advice from the Pain Management Services $(\$ 3.1)$.

The weight of the headset was a concern for four participants. Having such a weight sit on their head had increased pain for two participants, discomfort for one, while for one participant, the content was engaging enough that they forgot about the weight. The key to alleviating 
this problem lies in the choice of headsets. As the headset includes more and more features, the more weight there will be. There is a balance between high-tech headsets for more immersion and lightweight headsets to reduce pressure on the head and neck. However, this is a diminishing problem, as the hardware improves. VR headset makers are aware of the strain the headset puts on the head and neck and are actively working to reduce the weight of headsets [77].

No participant reported any motion sickness [112]. This is most likely due to participant sampling, as with a sample size of fourteen, instances of motion sickness can be expected. The short 10 minutes session times, combined with frequent 5-minute rest, is also a contributing factor.

While participants had fun playing the game, many were unaccustomed to the VR controller. This unfamiliarity with the controllers was a source of frustration for most participants at the beginning as they learned how to operate the controls. Although the controls were explained to them, and time was given for them to practise using the controller, those inexperienced with video games often pressed buttons different to their intentions.

For most participants, the struggle with controls would last until around the 5-minute mark, but for a small number of participants, they were unable to become fully accustomed to the controls. These participants struggled to complete levels in the game and did not get through many levels in the 10-minute session. On the opposite end, participants more familiar with video games were able to quickly pick-up the controls and complete levels as a much faster pace, completing up to the ending levels or even every level in the 10-minute session. Although ChronicVR was designed to introduce players to the game mechanics gradually, a more effective tutorial system could be utilised for players to learn and familiarise themselves with the controls. One participant responded to "Any other feedback/comments?" with

"An initial guide on what the magic does such as the fire burning 
down logs - perhaps a tutorial section where you practise each magic first with its intended purpose" -PID 03

A sampling bias arose from participant willingness. Ten out of fourteen participants were under the age of 40 , which is not reflective of the population observed during recruitment. The population observed at the hospital skewed towards older generations [67]. This bias arose from the younger generations more willingness to engage with novel technologies and elderly (aged 70+) generation's stigma that video games are

"A waste of time." -Elderly Person A

"Hinders the development of social skills." -Elderly Person A

The sample size of fourteen makes accurate statistical analysis difficult. Every participant has a noticeable impact on the numbers. Both quantitative and qualitative data were self-reported by the participant. Selfreported data opens up the possibility of bias. Introducing an objective measure would strengthen the validity of the data.

Participants only played one VR game in one sitting. The longitudinal effects of physically engaging content were not studied.

The study was not carried out in a lab under a controlled environment, but rather a borrowed room at Wellington Regional Hospital. Conducting the study in a controlled environment with more observers would yield more accurate results.

Participants activities before participating in the user study were not controlled. Their activities could lead to fluctuations in pain ratings. Many participants participated after their appointment with the Pain Management Services. One participant received pain medication during this appointment, and the medication began to wear off during the user study, leading to increases in pain ratings. Other participants may have been tired out either from their appointment or the effort they made to attend the study. 
In summary, the results were consistent with the existing literature. Pain ratings when using active attention-diversion content increased once the session was over, and the distraction had stopped. Pain ratings when using passive observation content decreased further after the session was over, possibly due to continued relaxation from the content. RQ1 asked which of active attention-diversion or passive observation was more effective at pain relief. Active attention-diversion was more effective while the patient was actively engaged with the content, whereas the effects of passive observation continued after the session. RQ2 asked which of physically active or mentally active distraction was more effective at pain relief. The results were similar for the 10-minute sessions in the user study. However, longer session times may see pain ratings in physically active content increase as patients become tired. Longitudinal exposure to physically active content should be explored in future work. 


\section{Chapter 6}

\section{Conclusion}

Chronic pain is persistent pain that lasts long after the original injury or disease has healed [114]. Medication is the most prevalent method of managing chronic pain, but it not an ideal solution as all medications can cause side effects [51]. Chronic pain patients are encouraged to utilise nonpharmacological tools to self-manage [49]. Distraction therapy is one such tool where the patient engages in an engaging stimulus or activity. By concentrating on this activity, the patient has a lower cognitive load to register the pain. Distraction therapy is categorised into active attention-diversion where patients actively perform some task to keep them distracted, and passive observation where patients simply observe something interest like watching a movie. This thesis further divided active attention-diversion into physically active and mentally active diversion, where the main task to be performed for distraction is of a physical or mental nature respectively. Virtual reality is one platform for distraction therapy [81]. VR engages multiple senses to give the illusion of being in a virtual world.

Current literature on VR for pain relief is lacking evaluation of what kind of content delivered through VR would be optimal for pain relief. Especially physically active content using VR tracking capabilities for head and hands. In order to understand what kind of content would be most effective for pain relief, this thesis addressed the following research ques- 
tions:

RQ1: Is active attention-diversion VR content more effective at managing chronic pain than passive observation VR content?

RQ2: Within active attention-diversion VR content, is physically active or mentally active more effective at managing chronic pain?

A VR game called ChronicVR was designed and developed to answer these two research questions. Staff from Wellington Regional Hospital's Pain Management Services were consulted on the design of ChronicVR. The staff there provided information on what activities would be suitable for chronic pain patients and what patients liked in general. The game encouraged patients to move about physically, to bring them joy and excitement, to help them understand that they can still enjoy activities, and help teach pain management techniques such as deep breathing to relax the body. The information provided by the staff at the Pain Management Services formed the foundational design principles of ChronicVR.

ChronicVR was developed in Unity for the HTC Vive VR headset. The game consisted of three distinct levels: physical interactions, mental puzzles, and passive observation. The distinction between the three levels was made to evaluate each level on their own in the user study to help answer the research questions. The physical level require players to move around virtual objects into specific positions physically. The mental level require players to solve puzzles using memory and logical thinking. The passive observation level had players watching relaxing natural videos.

To evaluate the effectiveness of VR for people with chronic pain ChronicVR was tested in a user study with fourteen chronic pain patients, the majority of whom were recruited from the Pain Management Services. The study had participants play all three levels of ChronicVR as well as a non-VR control task in a randomised order. Participants were asked to rate their pain on a 0-10 descriptive pain scale at the start, middle, and 
end of each level. Each level lasted for 10 minutes with a 5-minute rest in between.

While the VR tasks; physical interactions, mental puzzles, and passive observation; were more effective at decreasing subjective pain ratings than the non-VR control group, the results were not statistically significant once adjusted, and very little difference was observed between the three VR tasks. Although ChronicVR tasks were not a significant improvement over the non-VR control task, the results have shown that physically engaging content, mentally engaging content, and passive observation content were equally effective at reducing subjective pain ratings.

The results answered the two research questions:

RQ1 asked if active attention diversion content was more effective than passive observation content at managing chronic pain. The results found that, on average, the decreases in pain were higher in active attention diversion content, but the decreases were not significant. However, decreases in pain in passive observation content persisted after the VR session had ended, whereas with active attention diversion content the pain ratings reverted once the patient had taken off the headset and disengaged from the content. This is possibly due to the passive observation content aided relaxation, and the relaxation persisted past the VR session leading to the reduction in pain after the session had ended. Participant preference was divided between the two. Some participants enjoyed having a task to do while others enjoyed just relaxing and watching the passive observation videos.

RQ2 asked which of physically engaging content or mentally engaging content was more effective at managing chronic pain. The results showed that they were similarly effective in the 10-minute sessions. In longer sessions, patients may experience increased pain and fatigue with the physically engaging content as they are moving for an extended period. However, with repeated long-term use such as 10 minutes every day, patients may experience increased pain relief from the physically engaging con- 
tent, even outside of VR. Education is an important part of rehabilitation for chronic pain patients, and physically moving helps them gain a better understanding of their range of motion.

Qualitative feedback on VR as a pain management tool was positive, and all participants enjoyed the experience. Virtual reality is effective for pain management. Each of physically engaging content, mentally engaging content, and passive observation content appealed to different people. ChronicVR separated each of the three types of content into their distinct levels for the sake of performing the user study, which compared them against each other. For a more engaging game, the three aspects should be combined, with players rapidly swapping between them all. For example, physical interactions would be utilised to find objects necessary to solve a mental puzzle, which requires hints that are obtained by observing fascinating objects and events happening in the virtual world. Future designs of games and other content targeting pain should not discount any of physical, mental, or passive content, but instead, work to bring them all together into a cohesive and thoroughly engaging experience where pain patients can forget about their pain in the virtual world. 


\section{Appendix A}

\section{Ethics Approval Documents}

This appendix contains user study approval documentation from the Ministry of Health's Health and Disability Ethics Committees and Māori Parternship Board's Research Advisory Group Māori (RAG-M). 
27 August 2019

Mr Jiaheng Wang

Lower Hutt 5011

Dear Mr Wang

\section{Re: Ethics ref: $\quad 19 / C E N / 88$}

Study title:

Virtual Reality for Chronic Pain: the Effects of Content on Pain Relief

I am pleased to advise that this application has been approved by the Central Health and Disability Ethics Committee. This decision was made through the HDEC-Expedited

Review pathway.

\section{Conditions of HDEC approval}

HDEC approval for this study is subject to the following conditions being met prior to the commencement of the study in New Zealand. It is your responsibility, and that of the study's sponsor, to ensure that these conditions are met. No further review by the Central Health and Disability Ethics Committee is required.

Standard conditions:

1. Before the study commences at any locality in New Zealand, all relevant regulatory approvals must be obtained.

2. Before the study commences at any locality in New Zealand, it must be registered in a clinical trials registry. This should be a WHO-approved registry (such as the Australia New Zealand Clinical Trials Registry, www.anzctr.org.au) or https://clinicaltrials.gov/.

3. Before the study commences at each given locality in New Zealand, it must be authorised by that locality in Online Forms. Locality authorisation confirms that the locality is suitable for the safe and effective conduct of the study, and that local research governance issues have been addressed.

\section{After HDEC review}

Please refer to the Standard Operating Procedures for Health and Disability Ethics Committees (available on www.ethics. health.govt.nz) for HDEC requirements relating to amendments and other post-approval processes.

\section{Your next progress report is due by 27 August 2019.}




\section{Participant access to ACC}

The Central Health and Disability Ethics Committee is satisfied that your study is not a clinical trial that is to be conducted principally for the benefit of the manufacturer or distributor of the medicine or item being trialled. Participants injured as a result of treatment received as part of your study may therefore be eligible for publicly-funded compensation through the Accident Compensation Corporation (ACC).

Please don't hesitate to contact the HDEC secretariat for further information. We wish you all the best for your study.

Yours sincerely,

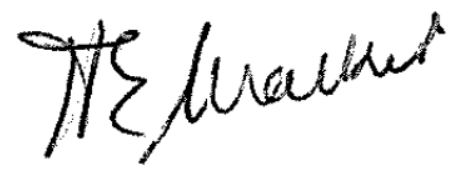

Mrs Helen Walker

Chairperson

Central Health and Disability Ethics Committee

Encl: appendix A: documents submitted

appendix B: statement of compliance and list of members 


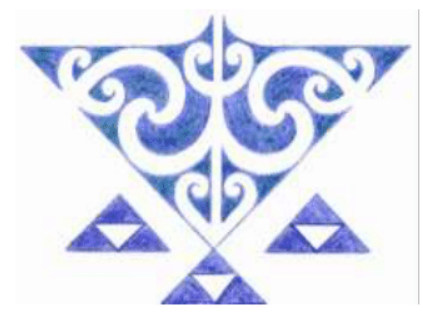

Māori Partnership Board, Capital \& Coast DHB

\section{RESEARCH ADVISORY GROUP MĀORI (RAG-M)}

12 November 2019

Jiaheng Wang

Lower Hutt 5011

Tēnā koe Jiaheng

Re: Virtual Reality for Chronic Pain Relief

$\square$ Your application has been endorsed

RAG-M wishes you all the very best with your study.

Ngā mihi

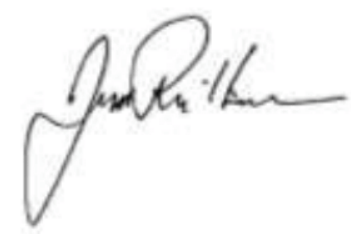

Jack Rikihana

Chairperson 


\section{Appendix B}

\section{User Study Documents}

This appendix contains documents used for the user study. The documents contained here are:

- Information Sheet

- Consent Form

- Pre-study Questionnaire

- Mid- and Post- Study Questionnaire 


\section{Virtual Reality for Chronic Pain: the Effects of Content on Pain Relief}

\section{INFORMATION SHEET FOR PARTICIPANTS}

You are invited to take part in this research. Please read this information before deciding whether or not to take part. If you decide to participate, thank you. If you decide not to participate, thank you for considering this request.

\section{Who am I?}

My name is Jiaheng Wang and I am a Masters student in Computer Science at Victoria University of Wellington. This research project is work towards my thesis.

\section{What is the aim of the project?}

This product is for testing how effective various virtual reality game mechanics are for relieving chronic pain. It has been developed by me. Your participation will support this research by providing the data needed to understand the effects the various game elements have on pain. The results of this study can help us better understand what is effective for relieving pain and aid future design and development of virtual reality content for pain relief.

This research has been approved by the Ministry of Health Health and Disability Ethics Committee reference 19/CEN/88.

\section{How can you help?}

You have been invited to participate because you are a chronic pain patient. If you agree to take part you will be asked to use the virtual reality headset which we will provide at the Victoria University of Wellington campus. We will make notes of your use of the headset. You will be asked to rate your current pain before and after you use the headset. At the conclusion of the session you will be asked to complete a questionnaire asking you about your experience using the headset.

The research will take around one hour. You can stop the user testing at any time by letting us know, without giving a reason. You can withdraw from the study by contacting me at any time within two weeks of completing the study. If you withdraw, the information you provided will be destroyed or returned to you. 


\section{Motion Sickness}

Some people may experience motion sickness while participating in VR. If this occurs, removing the headset is often enough to manage this symptom. If you have a history of intense motion sickness when using virtual reality, simulators, computer games, and/or 3D movies, it is advised that you do not take part in this research.

If you do choose to take part in this research and at any point feel motion sick, you are encouraged to stop immediately and rest.

\section{What will happen to the information you give?}

This research is confidential. This means that the researchers named below will be aware of your identity but the research data will be combined and your identity will not be revealed in any reports, presentations, or public documentation.

Only my supervisors and I will access the notes, recording and/or transcript of the interview and user test. The material I collect will be kept securely and destroyed on 4 Mar 2020 if it can be used to identify you, otherwise it will be destroyed on 1 Jan 2030 (10 years).

\section{What will the project produce?}

The information from my research will be used in my Masters thesis or academic publications and conferences.

\section{If you accept this invitation, what are your rights as a research participant?}

You do not have to accept this invitation if you don't want to. If you do decide to participate, you have the right to:

- choose not to answer any question;

- stop the interview or test at any time;

- withdraw from the study within two weeks of completing it;

- ask any questions about the study at any time;

- receive a copy of your questionnaire;

- be able to read the final report of this research by providing your contact details/emailing the researcher to request a copy. 
If you have any questions or problems, who can you contact?

If you have any questions, either now or in the future, please feel free to contact me:

Name: Jiaheng Wang

Email: Jiaheng.Wang@ecs.vuw.ac.nz

\section{Ministry of Health Health and Disability Ethics Committee}

You can also contact the health and disability ethics committee (HDEC) that approved this study on:

Email: hdecs@moh.govt.nz

Telephone: 08004 ETHICS

Independent health and disability advocate

If you want to talk to someone who isn't involved with the study, you can contact an independent health and disability advocate on:

Email: advocacy@advocacy.org.nz

Telephone: 0800555050

Fax: 08002 SUPPORT (0800 2787 7678) 


\section{Virtual Reality for Chronic Pain: the Effects of Content on Pain Relief CONSENT TO PARTICIPATE IN USER TESTING}

This consent form will be held for ten years.

Researcher: Jiaheng Wang, School of Engineering and Computer Science, Victoria University of Wellington.

- I have read the Information Sheet and the project has been explained to me. My questions have been answered to my satisfaction. I understand that I can ask further questions at any time.

- I agree to take part in this user test.

I understand that:

- I may withdraw from this study at any point within two weeks of completing the study, and any information that I have provided will be returned to me or destroyed.

- The identifiable information I have provided will be destroyed on 4 Mar 2020.

- Any information I provide will be included in a final report but the observation notes kept confidential to the researcher and the supervisor.

- I understand that the results will be used for a Masters dissertation, or academic publications, or presented to conferences.

- My name will not be used in reports and utmost care will be taken not to disclose any information that would identify me.

- I would like to receive a copy of the final report and have added my email address below. Yes $\square \quad$ No $\square$

Signature of participant:

Name of participant:

Date:

Email address: 


\section{Virtual Reality for Chronic Pain: the Effects of Content on Pain Relief}

Pre-study Questionnaire

- What is your gender?

- What is your age group?:

$\square<20 \quad \square$ 20-24 $\square$ 25-29 $\square$ 30-34 $\square$ 35-39 $\square$ 40-44 $\square$ 45-49

$\square$ 50-54 $\square$ 55-59 $\square$ 60-64 $\square$ 65-69 $\square$ 70-74 $\square$ 75-79 $\square$ 80+

- Which ethnic group do you belong to? Mark the space or spaces which apply to you.

$\square$ New Zealand European

$\square$ Māori

$\square$ Samoan

$\square$ Cook Islands Māori

$\square$ Tongan

$\square$ Niuean

$\square$ Chinese

$\square$ Indian

$\square$ Other (Please state: eg, Dutch, Japanese, Tokelauan):

$\square$ I don't know my ethnicity

$\square$ I do not want to state my ethnicity

- What is your average daily pain over the past 3 months? Please refer to the pain rating chart (0-10): 
- Where is your pain located?

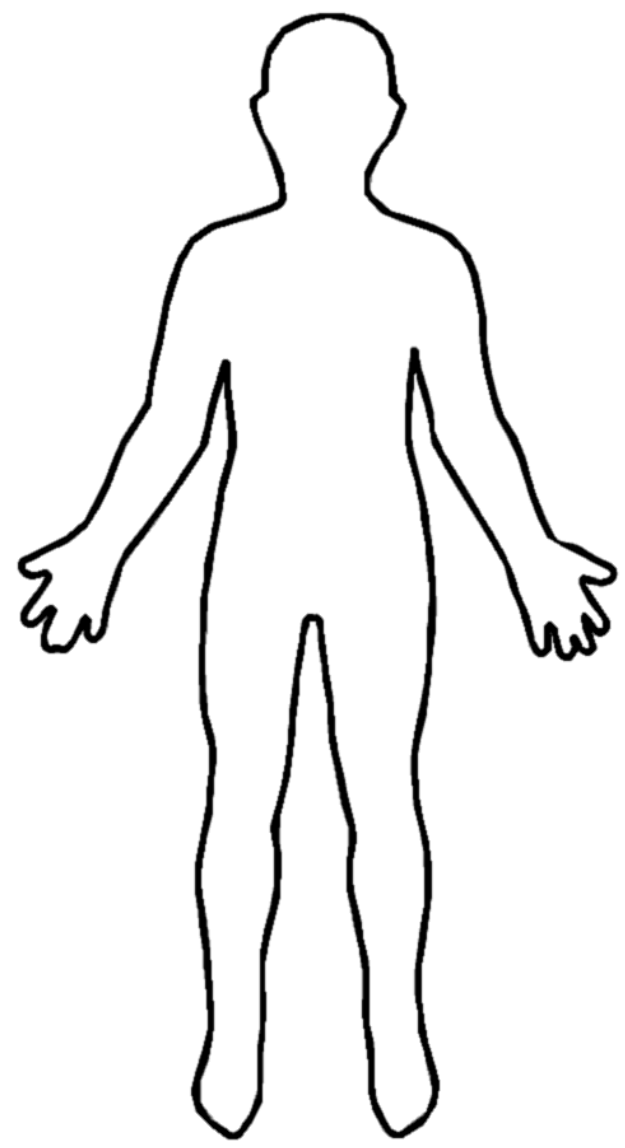

- On a normal day, what do you do to self manage the pain? (eg. meditation, reading, listening to music)

- How familiar are you with virtual reality?

Not at all familiar

$\square$ A little familiar

$\square$ Somewhat familiar

Very familiar

$\square$ Extremely familiar 


\section{Virtual Reality for Chronic Pain: the Effects of Content on Pain Relief}

Mid- and Post-study Questionnaire

Session A

Activity:

Pre-session pain:

Mid-session pain:

Post-session pain:

Session B

Activity:

Pre-session pain:

Mid-session pain:

Post-session pain:

\section{Session C}

Activity:

Pre-session pain:

Mid-session pain:

Post-session pain:

Session D

Activity:

Pre-session pain: Mid-session pain: Post-session pain: 


\section{Virtual Reality for Chronic Pain: the Effects of Content on Pain Relief}

Mid- and Post-study Questionnaire

Did you enjoy the VR experience?

Would you use it for pain relief in your daily life?

Would you recommend others to use it?

Any other feedback/comments? 


\section{Glossary}

Definitions taken from the Oxford Dictionary of English, accessed via [93].

acute (of a disease or its symptoms) severe but of short duration.

Often contrasted with chronic.

analgesia Medication that acts to relieve pain.

chronic (of an illness) persisting for a long time or constantly recurring. Often contrasted with acute.

opioid A compound resembling opium in addictive properties or physiological effects.

pharmacological Relating to the branch of medicine concerned with the uses, effects, and modes of action of drugs.

psychosocial Relating to the interrelation of social factors and individual thought and behaviour. 


\section{Bibliography}

[1] Allison, D., Wills, B., Bowman, D., Wineman, J., AND HODGES, L. F. The virtual reality gorilla exhibit. IEEE Computer Graphics and Applications 17, 6 (1997), 30-38.

[2] Ambrose, K. R., AND Golightly, Y. M. Physical exercise as nonpharmacological treatment of chronic pain: why and when. Best practice \& research Clinical rheumatology 29, 1 (2015), 120-130.

[3] BAni Mohammad, E., AND Ahmad, M. Virtual reality as a distraction technique for pain and anxiety among patients with breast cancer: A randomized control trial. Palliative and Supportive Care 17, 1 (2019), 29-34.

[4] Bannister, H., Selwyn-Smith, B., Anslow, C., Robinson, B., PhD, R. K. D. A., Pires, D., KANE, P., AND LeONG, A. Linacvr: Vr simulation for radiation therapy education. In 25th ACM Symposium on Virtual Reality Software and Technology (2019), ACM, pp. 1-10.

[5] BARbeR, T. X., AND COOPER, B. J. Effects on pain of experimentally induced and spontaneous distraction. Psychological Reports 31, 2 (1972), 647-651.

[6] BARNARD, D. History of $\mathrm{vr}$ - timeline of events and tech development. https://virtualspeech.com/blog/history-of-vr, August 2019. Accessed May 2020. 
[7] Bates, D., MÄChler, M., BOlker, B., AND WAlker, S. Fitting linear mixed-effects models using lme4. Journal of Statistical Software 67,1 (2015), 1-48.

[8] BeERs, T. M., AND KAROLY, P. Cognitive strategies, expectancy, and coping style in the control of pain. Journal of Consulting and Clinical Psychology 47, 1 (1979), 179.

[9] BHATTACHARJEE, Y. Scientists are unraveling the mysteries of pain. National Geographic (January 2020).

[10] Bijur, P. E., LATimer, C. T., AND Gallagher, E. J. Validation of a verbally administered numerical rating scale of acute pain for use in the emergency department. Academic Emergency Medicine 10, 4 (2003), 390-392.

[11] Botella, C., Garcia-Palacios, A., Vizcaíno, Y., Herrero, R., BAÑOS, R. M., AND BELMONTE, M. A. Virtual reality in the treatment of fibromyalgia: a pilot study. Cyberpsychology, Behavior, and Social Networking 16, 3 (2013), 215-223.

[12] BreiviK, H., Collett, B., Ventafridda, V., Cohen, R., AND GALLACHER, D. Survey of chronic pain in europe: prevalence, impact on daily life, and treatment. European journal of pain 10, 4 (2006), 287-287.

[13] BRUCATO, D. B. The psychological control of pain: The role of attentional focusing and capacity on the experience of pain. $\mathrm{PhD}$ thesis, ProQuest Information \& Learning, 1978.

[14] Budiu, R. Between-subjects vs. within-subjects study design. https://www.nngroup.com/articles/between-withinsubjects/, May 2018. Accessed May 2020. 
[15] Caine, K. Local standards for sample size at chi. In Proceedings of the 2016 CHI conference on human factors in computing systems (2016), pp. 981-992.

[16] Campbell, P., Tang, N., McBeth, J., Lewis, M., Main, C. J., CROFT, P. R., Morphy, H., AND DUnN, K. M. The role of sleep problems in the development of depression in those with persistent pain: a prospective cohort study. Sleep 36, 11 (2013), 1693-1698.

[17] Carlin, A. S., Hoffman, H. G., And Weghorst, S. Virtual reality and tactile augmentation in the treatment of spider phobia: a case report. Behaviour research and therapy 35, 2 (1997), 153-158.

[18] Carlsson, A. M. Assessment of chronic pain. i. aspects of the reliability and validity of the visual analogue scale. Pain 16, 1 (1983), 87-101.

[19] CARSON, E. Nasa shows the world its 20-year virtual reality experiment to train astronauts: The inside story. https:// www.techrepublic.com/article/nasa-shows-the-worldits-20-year-vr-experiment-to-train-astronauts/.

September 2015. Accessed May 2020.

[20] Chan, E. A., Chung, J. W., Wong, T. K., Lien, A. S., AND YANG, J. Y. Application of a virtual reality prototype for pain relief of pediatric burn in taiwan. Journal of clinical nursing 16, 4 (2007), 786-793.

[21] ChAN, P. Y., AND SCHARF, S. Virtual reality as an adjunctive nonpharmacological sedative during orthopedic surgery under regional anesthesia: A pilot and feasibility study. Anesthesia \& Analgesia 125, 4 (2017), 1200-1202.

[22] Chang, K., Fillingim, R., Hurley, R., And Schmidt, S. Chronic pain management: nonpharmacological therapies for chronic pain. FP essentials 432 (2015), 21-26. 
[23] Cox, J. J., Reimann, F., Nicholas, A. K., Thornton, G., Roberts, E., Springell, K., Karbani, G., JAFri, H., MANnAN, J., RAASHID, Y., ET AL. An scn9a channelopathy causes congenital inability to experience pain. Nature 444, 7121 (2006), 894-898.

[24] CRECEnTE, B. Magic leap: Founder of secretive start-up unveils mixed-reality goggles. https://variety.com/2017/gaming/ news/magic-leap-impressions-interview-1202870280/, December 2017. Accessed May 2020.

[25] Cruz-Neira, C., SAndin, D. J., DeFanti, T. A., Kenyon, R. V., AND HART, J. C. The cave: audio visual experience automatic virtual environment. Communications of the ACM 35, 6 (1992), 64-73.

[26] Dahlquist, L. M., McKenna, K. D., Jones, K. K., Dillinger, L., WEISS, K. E., AND ACKERMAN, C. S. Active and passive distraction using a head-mounted display helmet: effects on cold pressor pain in children. Health Psychology 26, 6 (2007), 794.

[27] Dahlquist, L. M., Weiss, K. E., Dillinger Clendaniel, L., LAW, E. F., ACKERMAN, C. S., AND MCKENNA, K. D. Effects of Videogame Distraction using a Virtual Reality Type Head-Mounted Display Helmet on Cold Pressor Pain in Children. Journal of Pediatric Psychology 34, 5 (03 2008), 574-584.

[28] Dahlquist, L. M., Weiss, K. E., LaW, E. F., Sil, S., Herbert, L. J., Horn, S. B., Wohlheiter, K., AND AcKerman, C. S. Effects of Videogame Distraction and a Virtual Reality Type HeadMounted Display Helmet on Cold Pressor Pain in Young Elementary School-Aged Children. Journal of Pediatric Psychology 35, 6 (09 2009), 617-625.

[29] Das, D. A., Grimmer, K. A., Sparnon, A. L., McRae, S. E., AND THOMAS, B. H. The efficacy of playing a virtual reality game in 
modulating pain for children with acute burn injuries: a randomized controlled trial [isrctn87413556]. BMC pediatrics 5, 1 (2005), 1.

[30] Diette, G. B., Lechtzin, N., Haponik, E., Devrotes, A., AND Rubin, H. R. Distraction therapy with nature sights and sounds reduces pain during flexible bronchoscopy: A complementary approach to routine analgesia. Chest 123, 3 (2003), 941-948.

[31] Donalek, C., Djorgovski, S. G., Cioc, A., Wang, A., Zhang, J., LaWler, E., YeH, S., Mahabal, A., Graham, M., Drake, A., ET AL. Immersive and collaborative data visualization using virtual reality platforms. In 2014 IEEE International Conference on Big Data (Big Data) (2014), IEEE, pp. 609-614.

[32] D'Orazio, D., AND SAVOV, V. Valve's vr headset is called the vive and it's made by htc. https: / www.theverge.com/2015/3/ 1/8127445/htc-vive-valve-vr-headset, March 2015. Accessed May 2020.

[33] Dunn, J., Yeo, E., Moghaddampour, P., Chau, B., And HumBERT, $\mathrm{S}$. Virtual and augmented reality in the treatment of phantom limb pain: A literature review. NeuroRehabilitation 40, 4 (2017), 595601.

[34] EDWARDS, B. The story of sega vr: Sega's failed virtual reality headset. https://www.fastcompany.com/3050016/unravelingthe-enigma-of-nintendos-virtual-boy-20-yearslater, March 2019. Accessed May 2020.

[35] Farrar, J. T., Portenoy, R. K., Berlin, J. A., Kinman, J. L., AND STROM, B. L. Defining the clinically important difference in pain outcome measures. Pain 88, 3 (2000), 287-294.

[36] Fernandez, E. A classification system of cognitive coping strategies for pain. Pain 26, 2 (1986), $141-151$. 
[37] Foertsch, C., O’Hara, M., Stoddard, F., and Kealey, G. Parent participation during burn debridement in relation to behavioral distress. The Journal of burn care E rehabilitation 17, 4 (1996), 372-377.

[38] Fox, J., And Weisberg, S. An R Companion to Applied Regression, third ed. Sage, Thousand Oaks CA, 2019.

[39] Frey, D. P., Bauer, M. E., Bell, C. L., Low, L. K., Hassett, A. L., Cassidy, R. B., Boyer, K. D., And Sharar, S. R. Virtual reality analgesia in labor: The vrail pilot study-a preliminary randomized controlled trial suggesting benefit of immersive virtual reality analgesia in unmedicated laboring women. Anesthesia and analgesia (2018).

[40] FRIEDMAN, M. The use of ranks to avoid the assumption of normality implicit in the analysis of variance. Journal of the american statistical association 32, 200 (1937), 675-701.

[41] Garra, G., Singer, A. J., TAira, B. R., Chohan, J., Cardoz, H., ChISENA, E., AND THODE JR, H. C. Validation of the wong-baker faces pain rating scale in pediatric emergency department patients. Academic Emergency Medicine 17, 1 (2010), 50-54.

[42] Garrett, B., TAVERner, T., AND MCDAde, P. Virtual reality as an adjunct home therapy in chronic pain management: an exploratory study. JMIR medical informatics 5, 2 (2017), e11.

[43] Gershon, J., Zimand, E., Pickering, M., Rothbaum, B. O., AND HODGES, L. A pilot and feasibility study of virtual reality as a distraction for children with cancer. Journal of the American Academy of Child E Adolescent Psychiatry 43, 10 (2004), 1243-1249.

[44] GrafF, V., CAi, L., Badiola, I., And Elkassabany, N. M. Music versus midazolam during preoperative nerve block placements: a 
prospective randomized controlled study. Regional Anesthesia \& Pain Medicine 44, 8 (2019), 796-799.

[45] Grichnik, K., And Ferrante, F. The difference between acute and chronic pain. The Mount Sinai journal of medicine, New York 58, 3 (May 1991), 217-220.

[46] Grisart, J. M., And PlaghKI, L. H. Impaired selective attention in chronic pain patients. European journal of pain 3, 4 (1999), 325-333.

[47] Gromala, D., Tong, X., Choo, A., Karamnejad, M., and SHAW, C. D. The virtual meditative walk: virtual reality therapy for chronic pain management. In Proceedings of the 33rd Annual ACM Conference on Human Factors in Computing Systems (2015), ACM, pp. 521-524.

[48] HART, S. G. Nasa-task load index (nasa-tlx); 20 years later. In Proceedings of the human factors and ergonomics society annual meeting (2006), vol. 50, Sage publications Sage CA: Los Angeles, CA, pp. 904-908.

[49] Health Navigator. Chronic pain. https:// www.healthnavigator.org.nz/health-a-z/c/chronicpain/. Accessed March 2020.

[50] Health Navigator. How mindfulness supports wellbeing. https://www.healthnavigator.org.nz/healthy-living/ m/mindfulness/. Accessed March 2020.

[51] Health Navigator. Medicines for chronic pain. https: //www.healthnavigator.org.nz/medicines/p/painrelief-medications-chronic-pain/. Accessed March 2020. 
[52] Health Navigator. Non-medicine treatments for pain. https://www.healthnavigator.org.nz/health-a-z/p/ pain-non-medication-treatments/. Accessed March 2020.

[53] Health Navigator. Side effects of medicines. https: //www.healthnavigator.org.nz/medicines/s/sideeffects-medicines/. Accessed March 2020.

[54] Hempel, J. Project hololens: Our exclusive hands-on with microsoft's holographic goggles. https://www.wired.com/2015/ 01/microsoft-hands-on/, January 2015. Accessed May 2020.

[55] Hoffman, H. G., Doctor, J. N., Patterson, D. R., CarROUGHER, G. J., AND FURNESS III, T. A. Virtual reality as an adjunctive pain control during burn wound care in adolescent patients. Pain 85, 1-2 (2000), 305-309.

[56] Hoffman, H. G., Garcia-Palacios, A., Patterson, D. R., JEnsen, M., Furness III, T., AND Ammons JR, W. F. The effectiveness of virtual reality for dental pain control: a case study. $\mathrm{Cy}$ berPsychology E Behavior 4, 4 (2001), 527-535.

[57] Hoffman, H. G., Patterson, D. R., and Carrougher, G. J. Use of virtual reality for adjunctive treatment of adult burn pain during physical therapy: a controlled study. The Clinical journal of pain 16, 3 (2000), 244-250.

[58] Hoffman, H. G., Patterson, D. R., Carrougher, G. J., NakaMurA, D., MoOre, M., Garcia-Palacios, A., And Furness III, T. A. The effectiveness of virtual reality pain control with multiple treatments of longer durations: A case study. International Journal of Human-Computer Interaction 13, 1 (2001), 1-12.

[59] Hoffman, H. G., Patterson, D. R., Carrougher, G. J., And SHARAR, S. R. Effectiveness of virtual reality-based pain control 
with multiple treatments. The Clinical journal of pain 17, 3 (2001), 229-235.

[60] Hoffman, H. G., Patterson, D. R., Magula, J., CARrougher, G. J., ZeltZER, K., DAGADAKIS, S., AND ShARAR, S. R. Waterfriendly virtual reality pain control during wound care. Journal of clinical psychology 60, 2 (2004), 189-195.

[61] Hoffman, H. G., Richards, T., CODA, B., Richards, A., AND SHARAR, S. R. The illusion of presence in immersive virtual reality during an fmri brain scan. CyberPsychology \& Behavior 6, 2 (2003), 127-131. PMID: 12804024.

[62] Hoffman, H. G., Richards, T. L., Magula, J., Seibel, E. J., Hayes, C., Mathis, M., Sharar, S. R., AND Maravilla, K. A magnet-friendly virtual reality fiberoptic image delivery system. $\mathrm{Cy}$ berPsychology \& Behavior 6, 6 (2003), 645-648. PMID: 14756930.

[63] Hoffman, H. G., Richards, T. L., Van Oostrom, T., Coda, B. A., Jensen, M. P., Blough, D. K., And Sharar, S. R. The analgesic effects of opioids and immersive virtual reality distraction: evidence from subjective and functional brain imaging assessments. Anesthesia \& analgesia 105, 6 (2007), 1776-1783.

[64] Hoffman, H. G., Seibel, E. J., Richards, T. L., Furness, T. A., PATTERSON, D. R., AND SHARAR, S. R. Virtual reality helmet display quality influences the magnitude of virtual reality analgesia. The Journal of Pain 7, 11 (2006), 843 - 850.

[65] Hoffman, H. G., Sharar, S. R., Coda, B., Everett, J. J., Ciol, M., Richards, T., AND PATterson, D. R. Manipulating presence influences the magnitude of virtual reality analgesia. Pain 111, 1-2 (2004), 162-168. 
[66] Holm, S. A simple sequentially rejective multiple test procedure. Scandinavian journal of statistics (1979), 65-70.

[67] Hunter, J. Demographic variables and chronic pain. The Clinical journal of pain 17,4 (2001), S14-S19.

[68] Jin, W., Choo, A., Gromala, D., Shaw, C., And Squire, P. A virtual reality game for chronic pain management: A randomized, controlled clinical study. In MMVR (2016), pp. 154-160.

[69] Jones, T., MoOre, T., AND CHOO, J. The impact of virtual reality on chronic pain. PLOS ONE 11, 12 (12 2016), 1-10.

[70] Kennedy, R. S., LANE, N. E., Berbaum, K. S., AND Lilienthal, M. G. Simulator sickness questionnaire: An enhanced method for quantifying simulator sickness. The international journal of aviation psychology 3, 3 (1993), 203-220.

[71] Kharoub, H., Lataifeh, M., And Ahmed, N. 3d user interface design and usability for immersive vr. Applied Sciences 9, 22 (2019), 4861.

[72] KimurA, M. A basic study for human stress reduction by virtual reality system. Proceeding of VSMM'96 (1996).

[73] KNudson-CoOper, M. S. Relaxation and biofeedback training in the treatment of severely burned children. The Journal of Burn Care $\mathcal{E}$ Rehabilitation 2, 2 (1981), 102-110.

[74] KozareK, R., Raltz, S., Brandabur, J., Bredfeldt, J., PatterSON, D., AND WOLFSEN, H. Prospective study using virtual vision for diagnostic and therapeutic endoscopy and colonoscopy. Gastrointestinal Endoscopy 41, 4 (1995), 307.

[75] KozareK, R. A., Raltz, S. L., Neal, L., Wilbur, P., Stewart, S., AND RAGSDALE, J. Prospective trial using virtual vision ${ }^{\circledR}$ as 
distraction technique in patients undergoing gastric laboratory procedures. Gastroenterology Nursing 20, 1 (1997), 12-14.

[76] Kulshreshth, A. K., AND LaViola JR, J. J. Designing Immersive Video Games Using 3DUI Technologies: Improving the Gamer's User Experience. Springer, 2018.

[77] LANG, B. New htc vives weigh $15 \%$ less than they did at launch. https://www.roadtovr.com/htc-vive-weight-15percent-lighter-than-original-headset-vs-oculusrift-comparison/, April 2017. Accessed July 2020.

[78] LANTZ, B. Equidistance of likert-type scales and validation of inferential methods using experiments and simulations. The Electronic Journal of Business Research Methods 11, 1 (2013), 16-28.

[79] LeE, J., AhN, S. C., AND HWANG, J.-I. A walking-in-place method for virtual reality using position and orientation tracking. Sensors 18, 9 (2018).

[80] Loftin, R. B., AND KenNeY, P. Training the hubble space telescope flight team. IEEE Computer Graphics and Applications 15, 5 (1995), 3137.

[81] Malloy, K. M., And Milling, L. S. The effectiveness of virtual reality distraction for pain reduction: A systematic review. Clinical Psychology Review 30, 8 (2010), 1011 - 1018.

[82] Marsh, J., PetTifer, S., Richardson, C., AND Kulkarni, J. Experiences of treating phantom limb pain using immersive virtual reality. In ACM SIGGRAPH 2019 Talks. 2019, pp. 1-2.

[83] McCaul, K. D., And Malott, J. M. Distraction and coping with pain. Psychological bulletin 95, 3 (1984), 516. 
[84] McDonnell, A., Schulman, B., Ali, Z., Dib-HajJ, S. D., Brock, F., Cobain, S., Mainka, T., Vollert, J., TARAbar, S., AND WAXMAN, S. G. Inherited erythromelalgia due to mutations in scn9a: natural history, clinical phenotype and somatosensory profile. Brain 139, 4 (2016), 1052-1065.

[85] Merskey, H. Pain terms : a list with definitions and notes on usage. recommended by the iasp subcommittee on taxonomy. Pain 6 (1979), 249-252.

[86] Mihajlovic, Z., Popovic, S., BrKic, K., And Cosic, K. A system for head-neck rehabilitation exercises based on serious gaming and virtual reality. Multimedia Tools and Applications 77, 15 (2018), 1911319137.

[87] Milgram, P., Takemura, H., Utsumi, A., and Kishino, F. Augmented reality: A class of displays on the reality-virtuality continuum. In Telemanipulator and telepresence technologies (1995), vol. 2351, International Society for Optics and Photonics, pp. 282-292.

[88] Miron, D., Duncan, G. H., And Bushnell, M. C. Effects of attention on the intensity and unpleasantness of thermal pain. Pain 39,3 (1989), 345-352.

[89] Moriarty, O., AND FinN, D. P. Cognition and pain. Current opinion in supportive and palliative care 8, 2 (2014), 130-136.

[90] Moriarty, O., MCGuire, B. E., And Finn, D. P. The effect of pain on cognitive function: a review of clinical and preclinical research. Progress in neurobiology 93, 3 (2011), 385-404.

[91] Naughton, F., Ashworth, P., And Skevington, S. M. Does sleep quality predict pain-related disability in chronic pain patients? the mediating roles of depression and pain severity. Pain 127, 3 (2007), 243-252. 
[92] Niehorster, D. C., Li, L., And Lappe, M. The accuracy and precision of position and orientation tracking in the htc vive virtual reality system for scientific research. i-Perception 8, 3 (2017), 2041669517708205.

[93] OXFord UNIVERsity PRESS. Lexico.com. https: //www.lexico.com/, 2019. Accessed Feburary 2020.

[94] OYAmA, H. Virtual reality for the palliative care of. Virtual Reality in Neuro-psycho-physiology: Cognitive, Clinical and Methodological Issues in Assessment and Rehabilitation 44 (1997), 87.

[95] Passman, J. The world's most relaxing song. Forbes (November 2016).

[96] Patterson, D. R., Everett, J. J., Burns, G. L., and Marvin, J. A. Hypnosis for the treatment of burn pain. Journal of consulting and clinical psychology 60, 5 (1992), 713.

[97] Philips, H. Avoidance behaviour and its role in sustaining chronic pain. Behaviour research and therapy 25, 4 (1987), 273-279.

[98] R CORE TeAm. R: A Language and Environment for Statistical Computing. R Foundation for Statistical Computing, Vienna, Austria, 2018.

[99] RaZALI, N. M., WAH, Y. B., ET AL. Power comparisons of shapirowilk, kolmogorov-smirnov, lilliefors and anderson-darling tests. Journal of statistical modeling and analytics 2, 1 (2011), 21-33.

[100] Reibel, D. K., Greeson, J. M., Brainard, G. C., And RosenZWEIG, S. Mindfulness-based stress reduction and health-related quality of life in a heterogeneous patient population. General hospital psychiatry 23, 4 (2001), 183-192. 
[101] RIzzo, A. S., AND KIM, G. J. A swot analysis of the field of virtual reality rehabilitation and therapy. Presence: Teleoperators $\mathcal{E}$ Virtual Environments 14, 2 (2005), 119-146.

[102] Russo, C. M., AND Brose, W. G. Chronic pain. Annual Review of Medicine 49, 1 (1998), 123-133. PMID: 9509254.

[103] Rutter, C. E., Dahlquist, L. M., And Weiss, K. E. Sustained efficacy of virtual reality distraction. The Journal of Pain 10, 4 (2009), 391-397.

[104] SancheZ-Vives, M. V., AND Slater, M. From presence to consciousness through virtual reality. Nature Reviews Neuroscience 6, 4 (2005), 332-339.

[105] Satava, R. M. Medical applications of virtual reality. Journal of Medical Systems 19, 3 (1995), 275-280.

[106] Schubert, T., Friedmann, F., And Regenbrecht, H. The experience of presence: Factor analytic insights. Presence: Teleoperators $\mathcal{E}$ Virtual Environments 10, 3 (2001), 266-281.

[107] Singh, A., Klapper, A., Jia, J., Fidalgo, A., TajaduraJiMÉNEZ, A., KANAKAM, N., BIANCHI-BERTHOUZE, N., AND WiLliams, A. Motivating people with chronic pain to do physical activity: opportunities for technology design. In Proceedings of the SIGCHI Conference on Human Factors in Computing Systems (2014), pp. 2803-2812.

[108] Sмiтh, F. How science is unlocking the secrets of addiction. National Geographic (September 2017).

[109] Smith, L. B., KemLeR, D. G., AND Aronfreed, J. Developmental trends in voluntary selective attention: Differential effects of source 
distinctness. Journal of Experimental Child Psychology 20, 2 (1975), 352 -362 .

[110] Smith, M. T., And Haythornthwaite, J. A. How do sleep disturbance and chronic pain inter-relate? insights from the longitudinal and cognitive-behavioral clinical trials literature. Sleep medicine reviews 8,2 (2004), 119-132.

[111] Spanos, N. P., STAM, H. J., AND BRAZIL, K. The effects of suggestion and distraction on coping ideation and reported pain. Journal of Mental Imagery (1981).

[112] Stanney, K. M., Hale, K. S., Nahmens, I., And Kennedy, R. S. What to expect from immersive virtual environment exposure: Influences of gender, body mass index, and past experience. Human factors 45,3 (2003), 504-520.

[113] Steele, E., Grimmer, K., Thomas, B., Mulley, B., Fulton, I., AND HoffMAN, H. Virtual reality as a pediatric pain modulation technique: a case study. Cyberpsychology \& Behavior 6, 6 (2003), 633638.

[114] Taub, N. S., Worsowicz, G. M., Gnatz, S. M., AND CifU, D. X. 1. definitions and diagnosis of pain. Archives of Physical Medicine and Rehabilitation 79, 3, Supplement 1 (1998), S49 - S53.

[115] Teague, E. More vr in more places. https:// youtube.googleblog.com/2018/07/more-vr-in-moreplaces.html, July 2018. Accessed May 2020.

[116] Tong, X., Jin, W., Cruz, K., Gromala, D., Garret, B., AND TAVERNER, T. A case study: Chronic pain patients' preferences for virtual reality games for pain distraction. In International Conference on Virtual, Augmented and Mixed Reality (2018), Springer, pp. 3-11. 
[117] TURK, D. C., RudY, T. E., AND Sorkin, B. A. Neglected topics in chronic pain treatment outcome studies: determination of success. Pain 53, 1 (1993), 3-16.

[118] Villemure, C., ANd Bushnell, C. M. Cognitive modulation of pain: how do attention and emotion influence pain processing? Pain 95, 3 (2002), 195-199.

[119] Whyte, J., Bouchlaghem, N., Thorpe, A., And McCaffer, R. From cad to virtual reality: modelling approaches, data exchange and interactive $3 \mathrm{~d}$ building design tools. Automation in construction $10,1(2000), 43-55$.

[120] Wiederhold, B. K., GaO, K., Sulea, C., AND Wiederhold, M. D. Virtual reality as a distraction technique in chronic pain patients. Cyberpsychology, Behavior, and Social Networking 17, 6 (2014), 346-352.

[121] Wiederhold, M. D., GaO, K., AND Wiederhold, B. K. Clinical use of virtual reality distraction system to reduce anxiety and pain in dental procedures. Cyberpsychology, Behavior, and Social Networking 17, 6 (2014), 359-365.

[122] WiLCOXON, F. Individual comparisons by ranking methods. In Breakthroughs in statistics. Springer, 1992, pp. 196-202. 